Army Regulation 360-1

Army Public Affairs

\title{
The Army Public Affairs Program
}




\section{SUMMARY of CHANGE}

AR 360-1

The Army Public Affairs Program

This major revision, dated 8 October 2020-

o Updates Title 10, United States Code authorizations of public affairs (para 1-7).

o Adds communication synchronization (para 1-12).

o Updates category of fundraising authorized by AR 600-29 (para 3-1t).

o Clarifies exhibits, loans, and explosives as Army informational exhibits with a clear distinction between museum exhibitory (para 3-6).

o $\quad$ Revises orientation flights guidance to ensure consistency with DoDI 4515.13 (para 5-13d).

o Updates procedures to avoid the release of critical information during ongoing criminal investigations and crisis communication (para 7-3).

o Incorporates Army Directive 2018-05 (Army Flyovers for Public Affairs Missions) (para 7-34).

o Introduces and defines social media and digital media roles functions (chap 8).

o $\quad$ Adds definitions for propriety and public affairs products (glossary). 
Headquarters

Department of the Army

Washington, DC

8 October 2020
*Army Regulation 360-1

Effective 8 November 2020

\section{Army Public Affairs \\ The Army Public Affairs Program}

By Order of the Secretary of the Army:

\section{JAMES C. MCCONVILLE General, United States Army Chief of Staff}

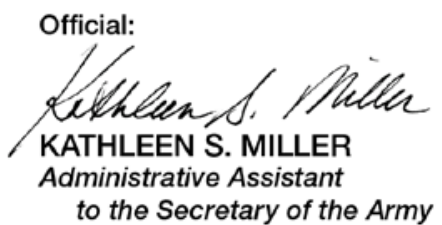

History. This publication is a major revision.

Summary. This regulation provides guidelines for release of command and public information, including information released to the media, and community engagement programs intended for internal and external publics with interest in the U.S. Army. This revision also defines the staff relationship of the public affairs officer; identifies public affairs as an inherently governmental function; requires commanders to appoint a unit public affairs representative to any unit that is not supported by a designated public affairs officer; updates policies for Army musical support; and adds official and unofficial website publishing guidance.
Applicability. This regulation applies to the Regular Army, the Army National Guard/Army National Guard of the United States, and the U.S. Army Reserve, unless otherwise stated. It also applies to civilian employees of the Department of the Army. Overseas commanders are responsible for the conduct of public affairs activities within their commands and will be guided by the policies of the Department of the Army and the commanders of unified commands. In the event of a conflict, the policies of the unified command will govern.

Proponent and exception authority. The proponent of this regulation is the Chief of Public Affairs. The proponent has the authority to approve exceptions or waivers to this regulation that are consistent with controlling law and regulations. The proponent may delegate this approval authority, in writing, to a division chief within the proponent agency or its direct reporting unit or field operating agency, in the grade of colonel or the civilian equivalent. Activities may request a waiver to this regulation by providing justification that includes a full analysis of the expected benefits and must include formal review by the activity's senior legal officer. All waiver requests will be endorsed by the commander or senior leader of the requesting activity and forwarded through their higher headquarters to the policy proponent. Refer to AR 25-30 for specific guidance.

Army internal control process. This regulation contains internal control provisions in accordance with AR 11-2 and identifies key internal controls that must be evaluated (see app).

Supplementation. Supplementation of this regulation and establishment of agency, command, and installation forms are prohibited without prior approval from the Chief of Public Affairs (SAPA-ZA), 1500 Army Pentagon, Washington, DC 20310-1500.

Suggested improvements. Users are invited to send comments or suggested improvements on DA Form 2028 (Recommended Changes to Publications and Blank Forms) directly to the Chief of Public Affairs (SAPA-ZA), 1500 Army Pentagon, Washington, DC 20310-1500.

Distribution. This regulation is available in electronic media only and is intended for the Regular Army, the Army National Guard/Army National Guard of the United States, and the U.S. Army Reserve.

Contents (Listed by paragraph and page number)

\section{Chapter 1}

Introduction, page 1

Purpose $\cdot 1-1$, page 1

References and forms $\bullet 1-2$, page 1

Explanation of abbreviations and terms $\bullet$ 1-3, page 1

Responsibilities $\bullet 1-4$, page 1

Records management (recordkeeping) requirements $\bullet 1-5$, page 1

Overview $\bullet$ 1-6, page 1

Principles of Information $\bullet 1-7$, page 2

Establishment of Chief of Public Affairs $\bullet 1-8$, page 2

Organization of the Office of the Chief of Public Affairs $\bullet$ 1-9, page 2

Public affairs staff relationships $\bullet 1-10$, page 2

*This regulation supersedes AR 360-1, dated 25 May 2011. AD 2018-05 is rescinded upon publication of this revision. 
Authorization for direct communication 1 1-11, page 3

Commander's communication synchronization $\bullet 1-12$, page 3

Countering misinformation and disinformation $\bullet 1-13$, page 3

\section{Chapter 2}

Responsibilities, page 4

Headquarters, Department of the Army principal officials $\bullet 2-1$, page 4

Chief of Public Affairs $\cdot 2-2$, page 4

Deputy Chief of Staff, G-3/5/7 $\bullet 2-3$, page 5

Commanders of all echelons $\bullet 2-4$, page 5

Public affairs officers $\bullet 2-5$, page 7

Army personnel $\bullet 2-6$, page 8

\section{Chapter 3}

Policies, page 8

Public affairs restrictions, limitations, and other considerations $\bullet 3-1$, page 8

Use of unmanned aerial systems for public affairs activities $\bullet$ 3-2, page 10

Visual information $\cdot 3-3$, page 10

Archiving visual information $\bullet$ 3-4, page 11

Visual information products by Army agencies and commands $\bullet 3-5$, page 11

Exhibits, loans, explosives, and donations $\bullet 3-6$, page 12

Donation of obsolete or condemned combat equipment $\cdot 3-7$, page 13

Other policies with public affairs impact $\bullet 3-8$, page 14

\section{Chapter 4}

Organizations and Associations, page 14

General $\bullet 4-1$, page 14

Membership in organizations and associations $\bullet 4-2$, page 15

Liaison with organizations and associations $\bullet 4-3$, page 15

Support to national military association annual conferences $\bullet 4-4$, page 15

Activities involving contractors and military related organizations and associations $\bullet 4-5$, page 16

Business and industry organizations and associations $\bullet 4-6$, page 16

\section{Chapter 5}

Public Affairs Resourcing, page 17

Public affairs funding authority $\bullet$ 5-1, page 17

Use of Army funds and other resources $\bullet 5-2$, page 17

Events or engagements qualifying for Army funding $\bullet 5-3$, page 18

Events or engagements qualifying for outside funding $\bullet$ 5-4, page 18

Finance guidelines $\bullet 5-5$, page 18

Advertising for environmental hearing notices $\bullet$ 5-6, page 19

Contracted services $\bullet 5-7$, page 19

Contracting for Army-Funded video and television production $\bullet$ 5-8, page 19

Use of military transportation assets $\bullet$ 5-9, page 19

Local media travel procedures and approvals $\bullet 5-10$, page 19

Nonlocal travel procedures and approvals for media $\bullet$ 5-11, page 20

Special travel categories $\bullet$ 5-12, page 20

Use of Army aircraft for nonmedia public affairs travel $\bullet$ 5-13, page 20

\section{Chapter 6}

Media Coverage, page 21

Facilitating media visits $\bullet 6-1$, page 21

News media accreditation $\bullet 6-2$, page 21

Official discussions with the media $\bullet 6-3$, page 21

Unofficial discussions $\bullet 6-4$, page 21

Photographing and recording personnel in a hostile area $\bullet 6-5$, page 22 
Media coverage of equipment testing and evaluation $\bullet 6-6$, page 22

Media coverage of battle labs and advanced warfighting experiments $\bullet 6-7$, page 22

\section{Chapter 7 \\ Public Communication, page 22}

Release of official information $\bullet 7-1$, page 22

Impartial and objective dissemination $\cdot 7-2$, page 22

Crisis communication $\bullet 7-3$, page 22

Personal privacy $\bullet-7$, page 22

Health information security $\bullet 7-5$, page 23

Authority to release information $\bullet 7-6$, page 23

Safeguarding information $\bullet 7-7$, page 24

Release of Army records $\bullet 7-8$, page 24

Missing in action or duty status whereabouts unknown $\bullet 7-9$, page 24

Military accidents $\bullet 7-10$, page 24

Release of accidents involving military personnel or equipment $\bullet 7-11$, page 25

Personnel under treatment in Army medical facilities $\bullet 7-12$, page 26

Personnel participating in alcohol and drug abuse control programs $\bullet 7-13$, page 26

U.S. Army Criminal Investigation Command personnel or activities $\bullet$ 7-14, page 26

Release of criminal investigations $\bullet 7-15$, page 26

Coverage of courts-martial $\bullet 7-16$, page 26

Litigation and debarment cases $\bullet 7-17$, page 27

Inspector general activities $\bullet 7-18$, page 27

Release of information on units $\bullet-19$, page 27

Photographing military installations or equipment $\bullet 7-20$, page 29

Releases about foreign military personnel attending U.S. Army schools $\bullet 7-21$, page 29

Release of Army studies • 7-22, page 30

Release of information by manufacturers, research organizations, educational institutions, and other commercial entities holding Army contracts $\bullet$ 7-23, page 30

Community outreach $\bullet 7-24$, page 30

Activities to support community outreach $\bullet 7-25$, page 30

Department of Defense-coordinated activities $\bullet 7-26$, page 30

Use of military assets for public affairs $\bullet 7-27$, page 31

Authorized Army musical, ceremonial, and troop asset support participation $\bullet 7-28$, page 31

Prohibited participation $\bullet 7-29$, page 32

Bands and other musical units $\bullet$ 7-30, page 32

Ceremonial units $\bullet 7-31$, page 33

Color guards $\bullet 7-32$, page 33

Aerial activities $\bullet$ 7-33, page 34

Criteria for Army aerial demonstrations $\bullet 7-34$, page 34

Qualifying air shows and other outdoor events $\bullet 7-35$, page 34

Public engagement programs and activities $\bullet 7-36$, page 36

Consultation with state and local officials $\bullet 7-37$, page 37

Significant days and observances for the Army $\bullet-7-38$, page 37

Open house $\cdot 7-39$, page 38

Support to state governor's inaugural activities $\bullet 7-40$, page 38

Joint Civilian Orientation Conference $\bullet$ 7-41, page 38

Army support to non-U.S. Government authors and producers of documentaries and entertainment-oriented publications and audio and audiovisual products $\bullet 7-42$, page 38

Army support to disaster relief and civil disturbances $\bullet 7-43$, page 39

Clearance of speakers, speeches, and manuscripts $\bullet 7-44$, page 39

Writing style $\bullet 7-45$, page 42

\section{Chapter 8}

Digital Media Management and Publications, page 42

General social media guidance $\bullet$ 8-1, page 42 
Contents-Continued

Functions $\bullet$ 8-2, page 42

Social media and blogs $\bullet$ 8-3, page 43

Nonaccredited social media accounts $\bullet 8-4$, page 45

Social media in crisis communication $\bullet$ 8-5, page 45

Personal use of social media and appropriate online conduct $\bullet$ 8-6, page 45

Official U.S. Army webpage and content management platform • 8-7, page 46

Organizational website publishing guidance $\bullet$ 8-8, page 46

Publication guidelines $\bullet$ 8-9, page 46

Civilian enterprise operations $\bullet 8-10$, page 49

Appropriated funded operations $\bullet 8-11$, page 51

Contracting for appropriated funded publications $\bullet$ 8-12, page 51

Editorial contributions • 8-13, page 51

\section{Appendixes}

A. References, page 53

B. Awards, page 61

C. Feasibility Study for Civilian Enterprise Newspapers, page 64

D. Guidance on Release of Information under the Privacy Act, page 66

E. Clearance and Release of Contractor Materials and Scientific and Technical Information, page 68

F. Internal Control Evaluation, page 70

\section{Figure List}

Figure 7-1: Current Deployment Announcement Process, page 29

Figure 8-1: Sample masthead, page 49

\section{Glossary}




\section{Chapter 1 Introduction}

\section{1-1. Purpose}

This regulation establishes policies for conducting Army public affairs (PA) programs.

\section{1-2. References and forms}

See appendix A.

1-3. Explanation of abbreviations and terms

See glossary.

\section{1-4. Responsibilities}

Responsibilities are listed in chapter 2.

\section{1-5. Records management (recordkeeping) requirements}

The records management requirement for all record numbers, associated forms, and reports required by this regulation are addressed in the Records Retention Schedule-Army (RRS-A). Detailed information for all related record numbers, forms, and reports are located in ARIMS/RRS-A at https://www.arims.army.mil. If any record numbers, forms, and reports are not current, addressed, and/or published correctly in ARIMS/RRS-A, see DA Pam 25-403 for guidance.

\section{1-6. Overview}

The Army defines the PA Program as the guide to conducting public communication strategy for information, command information, leader engagements, and community outreach activities directed toward both the external and internal publics with interest in the Department of Defense (DoD). PA policies and principles apply across the range of military and peacetime operations. PA is a command responsibility and will not be delegated or subordinated to any other staff function. PA follows the DoD Principles of Information (see DoDD 5122.05). PA exists to maintain the trust and confidence of the American public and deter adversaries. It is the commander's responsibility to disseminate accurate and timely information (see DoDD 5122.05).

$a$. The U.S. Army is required, according to DoDI 5400.13, to communicate with its members, the U.S. public, and international publics. The proactive release of accurate information puts U.S. military operations in context, facilitates informed perceptions about military operations, counters misinformation and disinformation, reinforces public support to Army Title 10, United States Code (10 USC) responsibilities, and helps achieve national, strategic, operational, and tactical objectives.

$b$. The First Amendment guarantees freedom of the press. Within DoD, this right must be balanced against operations security (OPSEC) to protect the lives of U.S. or multinational forces and the security of ongoing or future operations. These competing interests sometimes cause friction between the members of the press and the military. The Privacy Act of 1974 prevents the release of certain personal information to the public, but does not forbid individuals from releasing their own personal information on social media channels. Stringent restrictions exist for protecting personally identifiable information (PII). There are strict reporting requirements if PII is released, even inadvertently.

$c$. The proliferation of information sources, coupled with improved mobile technology, allows information to travel instantaneously around the globe. The tempo of military operations, OPSEC concerns, network constrictions, and competing information sources are among the factors that complicate the commander's ability to provide information at the same pace as external sources. All military activities produce information. Informational aspects are the features and details of military activities observers interpret and use to assign meaning and gain understanding. Those aspects affect the perceptions and attitudes that drive the behavior and decision making of relevant actors. Ultimately, the combatant commander leverages information aspects of military activities to gain an advantage; failing to leverage those aspects may cede this advantage to others. Leveraging the informational aspects of military activities ultimately affects strategic outcomes.

$d$. Commanders must, therefore, task organize and include communication planning in all phases of the mission in order to reduce the time lag between an event and the release of information in order to meet the Army requirement to communicate. 
e. The public affairs officer (PAO) is a personal staff member and provides the communication expertise required to advise commanders in all aspects of information and communication. PA is responsible for coordinating and synchronizing themes and messages through effective planning, ensuring unity of effort throughout the information environment.

$f$. PA supports U.S. military operations with communication tailored to friendly, neutral, and adversarial audiences. These diverse audiences increasingly expect two-way communication with institutions, as two-way conversation permits greater transparency and clarity.

g. The public can get information about the Army and its operations from official and unofficial sources (for example, information disseminated by Service members, their Families, the public, the media, or groups hostile to U.S. interests). Regardless of the source, intention, or method of distribution, information in the public domain has the potential to contribute to or undermine the operational objectives. Official information helps create, strengthen, and preserve conditions favorable to the advancement of national interests and policies, simultaneously mitigating adverse effects from unofficial, misinformed, or hostile sources.

h. Public support for the U.S. Army's presence or operations is likely to vary. The PAO must be able to quickly and accurately assess the information environment to provide valuable guidance and PA courses of action directly to the commander. Such assessments enable the commander to better inform the public about ongoing operations and engender their support.

\section{1-7. Principles of Information}

The DoD, and thus the U.S. Army, is responsible for making timely and accurate information available so that the American public may assess and understand facts about national security and defense strategy. Requests for information from organizations and private citizens should be answered quickly (see DoDD 5122.05).

\section{1-8. Establishment of Chief of Public Affairs}

The Chief of Public Affairs (CPA) was established under the authority of 10 USC 3014. The CPA works directly for the Secretary of the Army (SECARMY), who has assigned the CPA with the responsibility for keeping the American people and the Army informed about the Army and for providing PA support to principal officials of Headquarters, Department of the Army (HQDA). The Office of the Chief of Public Affairs (OCPA) is designated as the single office in HQDA responsible for PA. The CPA is the proponent for Army PA (see AGO 2020-01).

\section{1-9. Organization of the Office of the Chief of Public Affairs}

OCPA is an HQDA staff element at the Pentagon, organized into divisions to conduct outreach, strategy and plans, operations, resource management, digital media, assessments, media relations, and serve as the functional proponent. OCPA has several field operating agencies: OCPA-West; OCPA-Northeast; OCPA-Midwest; and the Army Public Affairs Center (APAC).

\section{1-10. Public affairs staff relationships}

a. PAOs at echelon serve on the commander's personal staff and require direct access as PA is a commander's responsibility that often requires quick decisions to implement effectively. PAOs operate as the commander's senior advisors when communicating and are responsible for public information and leader engagement in the information domain. The PAO may not be delegated or subordinate to any other staff section. The commander will rate or seniorrate the PAO. Commanders and agency heads may assign PAOs coordinating staff authority actions or missions as deemed appropriate.

$b$. Officers, enlisted Soldiers, and civilians working and supervising PA offices will qualify through the appropriate level of the Defense Information School training. Non-PA staff sections or officials will not be assigned primary responsibility for planning, directing, or executing PA missions.

c. All career program 22 (CP22) civilian PA managing and supervising PA offices will meet Office of Personnel Management qualification standards, demonstrate identified CP22 competencies, and complete CP22 training and development requirements for the position.

d. PA and the release of information is an inherently governmental function. Formulation and promulgation of Army PA policy is an official responsibility and may be performed only by military or civilian PA officials of the Army, commanders, or their designated official spokespersons.

e. Unit public affairs representatives (UPARs) are non-PA Soldiers identified to increase PA capability across a command. Commanders at the battalion level and below will appoint and resource UPARs to assist higher PA elements achieve the commander's requirement to communicate. PAOs are responsible for cultivating, coordinating, and train- 
ing UPARs within their subordinate units. UPARs are assigned through additional duty appointment orders to represent their units for PA functions. UPAR products are subject to normal PA editing and release procedures. UPAR training materials are available at the Army Learning Management System (ALMS).

\section{1-11. Authorization for direct communication}

The immediacy and speed at which information flows via media organization news reports, social media, and other channels requires Army communications be coordinated. OCPA must establish communication with Army units, agencies, direct reporting units (DRUs), and subordinate elements immediately to facilitate the communication synchronization process to address internal and external audiences. Guidance on audiences, stakeholders, and publics is specified in JP 3-61. Army PA assigned to joint, interagency, and multinational environments operate according to the policies and procedures of that organization unless following a policy or procedure would break U.S. law.

$a$. OCPA is authorized to execute direct communication with DoD and HQDA agencies, Army commands (ACOMs), Army service component commands (ASCCs), installations, DRUs, and subordinate Army elements when those elements' higher headquarters are unavailable to establish timely communication.

$b$. Commands and installations are authorized to communicate directly with OCPA if their higher headquarters are unavailable to facilitate timely communication. Any headquarters bypassed as a result of direct communication with OCPA must be informed of the communication by the office initiating the direct communication.

$c$. The commander is most effective and has the greatest freedom of movement when perceived as credible. PA plays a central role in building and maintaining that credibility. Trust takes time to build, but can be destroyed instantly.

d. All PA Soldiers and civilians must follow a code of professional ethics to ensure the Army retains the trust and confidence of the American people and host nation audiences.

$e$. PA Soldiers and civilians should be familiar with industry best practices and codes of ethics as published by the International Association of Business Communicators, the Public Relations Society of America, and the Arthur W. Page Society.

f. PA professionals will-

(1) Be truthful at all times. PA Soldiers and civilians will hold themselves to be key experts in their craft, ensuring all information for release is accurate, truthful, timely, and presented in its proper context.

(2) Be loyal to and act in the best interest of the American public, HQDA, the mission, and their command.

(3) Receive all requests for information and support with respect. Treat each request with integrity and expeditiously while preserving the free flow of information among commanders, requesting organizations, and audiences.

(4) Disclose the most information available for release in the shortest time allowable.

(5) Serve to enhance the value of public communication between the Army, the American people, and key audiences.

(6) Always be ready and willing, even in the face of opposition, to provide candid advice and counsel that must be asserted to aid commanders and other leaders in making PA decisions.

\section{1-12. Commander's communication synchronization}

a. Commander's communication synchronization (CCS) (formally known as strategic communication) is the process for coordinating and synchronizing themes, messages, images, operations, and actions to support U.S. Government strategic communication-related objectives and ensure the integrity and consistency of themes and messages to the lowest tactical level. This is done through the integration and synchronization of all relevant communication activities (see JP 3-61).

$b$. Army commanders will use the CCS process to plan, develop, and execute goal-based communication plans. The CCS process aligns communication across echelons with the broader national strategic narrative. The command's PAO will lead the CCS process to maximize alignment across all command echelons.

c. PA counsels leadership on how audiences may perceive military actions, as well as how the information environment may affect operations. PA may create, strengthen, or preserve conditions favorable to accomplishing desired objectives by providing the public timely, factual, and accurate information. PA also analyzes and assesses communication effects and their progress toward mission accomplishment. This assists commanders with decision making and adjusting their communication strategy when necessary.

\section{1-13. Countering misinformation and disinformation}

A commander cannot counter false information without being credible. In accordance with JP 3-61, PA can mitigate and counter adversary disinformation and misinformation with accurate and timely public information and imagery. This will be consistent with current DoD PA guidance, in accordance with PA ethics, and within the constraints of 
OPSEC, information security, safety, and privacy of DoD personnel and their Families. PA programs must remain proactive, maintaining positive professional relationships with news and other media representatives in the operational environment (OE).

\section{Chapter 2 Responsibilities}

\section{2-1. Headquarters, Department of the Army principal officials}

$a$. The SECARMY will have sole responsibility within the Office of the SECARMY and the Army staff (ARSTAF) for the function of PA, pursuant to 10 USC 3083. SECARMY has designated the CPA as the principal official in HQDA responsible for the PA function. Other elements of HQDA participate in PA functions under the direction of the CPA.

$b$. In accordance with this regulation, HQDA principal officials will prepare or coordinate information, records, and materials with the CPA for dissemination to the public. The CPA will ensure all necessary staff coordination and clearance have been completed prior to releasing information outside the Department of the Army (DA).

\section{2-2. Chief of Public Affairs}

The CPA reports to the SECARMY. The CPA directs Army PA as an enterprise communication hub that keeps the American people and international publics informed. The CPA also provides PA support to HQDA principal officials. The CPA, subject to the authority, direction, and control of the SECARMY, provides the Chief of Staff of the Army (CSA) staff support as the CSA considers necessary to perform his or her duties and responsibilities.

$a$. The CPA is assigned responsibility for:

(1) Developing and directing Army PA policy, regulating PA programs and processes, and directing the execution of PA policy, financial programs, and budgets.

(2) Advising, assisting, and providing direction to DA in developing and endorsing communication strategies, themes, and messages for internal and external audiences.

(3) Directing, coordinating, synchronizing, and assessing Army communication strategy, plans, campaigns, and engagements; supervising the Army communication synchronization process through the use of coordinated programs, plans, themes, messages, and products; and developing and integrating Army themes and messages into communication initiatives.

(4) Executing Army PA proponency, including developing a trained, equipped, professional PA capability for commanders.

(5) Providing public communication and media training for Army senior leaders.

(6) Recommending venues for delivery of communication strategies using best practices and emerging communication technology.

(7) Approving participation of the Army's official public demonstration teams and the U.S. Army Field Band, as required.

(8) Managing the Army’s Public Information Security Review Program.

b. The CPA will-

(1) Coordinate with the Army Chief Information Officer/G-6 (CIO/G-6) for visual information (VI) activity policy and authorizations, including internet policies. Work with knowledge management and application developers for review and clearance of public information.

(2) Collaborate with the CIO/G-6 to provide oversight and control of the content on Army public websites as the official primary point of access to Army information on the internet.

(3) Manage the Army's participant selection process for DoD-sponsored community outreach programs.

(4) Serve or designate a representative to serve on the Defense Media Oversight Board, pursuant to DoDD 5105.74.

(5) Coordinate timely news, information, and programing with the Defense Media Activity Joint Operations Center for distribution through the Army News Service.

(6) Process requests for Army aerial activities in public events, except the Army Parachute Team (Golden Knights) demonstrations. Requests for the Golden Knights will be processed through the U.S. Army Marketing and Engagement Brigade (see AD 2018-05).

(7) Execute the DA level communication competition and approve DA level communication awards (see app B for communication awards).

c. The CPA has authority to approve and process exceptions to Army PA policy in this regulation that are consistent with controlling law and regulations. The CPA may delegate approval authority in writing to the principal deputy CPA, chief of staff, or division chiefs within the proponent agency in the grade of colonel or the civilian equivalent. 
d. The Director, APAC develops and coordinates doctrine, organization, training, materiel, leadership and education, personnel, and facilities (DOTMLPF) requirements related to the PA function with U.S. Army Training and Doctrine Command (TRADOC) on behalf of the CPA. The Director, APAC, with CPA approval, approves doctrinal and training literature, training, and policies pertaining to PA professional qualifications, specific equipment requirements, and operations policy. The Director, APAC provides supervision for all organizational changes within the force development, force management, and force integration processes within the CPA's purview. The Director, APAC forwards PA tables of organization and equipment and force structure to the Deputy Chief of Staff (DCS), G-3/5/7 for inclusion in the force management process as established in AR 5-22 and AR 600-3.

(1) The Director, APAC will-

(a) Develop and document concepts, doctrine, tactics, techniques, procedures, organization designs, materiel requirements, training programs, training support requirements, and manpower requirements (except as provided in AR 600-3).

(b) Coordinate, assess, and provide feedback on new proponent initiatives with user units.

(c) Establish policy and procedures to affect functional proponent activities.

(d) Establish materiel requirements and comparable industry standards.

(2) Per AR 600-3, the Director, APAC is authorized to:

(a) Gather and evaluate manpower and personnel data.

(b) Identify issues and initiatives.

(c) Formulate alternatives.

(d) Coordinate actions.

(e) Recommend policy changes to the DCS, G-1.

(f) Advise and assist the U.S. Army Military Personnel Center and Reserve Component (RC) personnel.

$e$. The CPA, members of the Army assigned to PA positions by the SECARMY, and commissioned officers of the Army in the grade of major or above who are selected and specifically trained to perform as PAOs for the remainder of their careers are all members of the PA specialty career field, pursuant to 10 USC 3083. Members of the PA specialty (military and civilian) at all levels are responsible for executing PA functions. PAOs and PA noncommissioned officers (NCOs) assigned as primary PA staff members at all echelons will report directly to the organization's commanding officer.

(1) PA is defined as any communication activity with external and internal audiences. Core PA professionals' responsibilities include:

(a) Provide advice and counsel to commanders and appropriate staffs on PA matters.

(b) Conduct PA planning and develop and assess unit communications strategy, plans, campaigns, and engagements in coordination with the commander, staff, and next higher echelon PA staff, as appropriate.

(c) Facilitate all media interactions between news representatives and their organizations.

(d) Conduct PA training for commanders and members of their organizations.

(e) Conduct public communication.

(f) Assess effectiveness of commander's PA communication strategy.

(g) Mitigate misinformation and disinformation.

(h) VI planning.

(2) DoDD 5122.05 addresses the DoD Principles of Information.

\section{2-3. Deputy Chief of Staff, G-3/5/7}

The DCS, G-3/5/7 is the exception and waiver authority for requests for Army aerial demonstrations for public affairs missions. The DCS, G-3/5/7 may waive the 40-day and 60-day submission requirements prescribed in paragraph 7$34 c$ for good cause and may further delegate this exception and waiver authority in writing to an officer in the grade of O-7. Further delegation is not authorized.

\section{2-4. Commanders of all echelons}

a. Commanders at every echelon will-

(1) Provide PAOs and PA sections with the resources required to fulfill the Army's PA mission to include personnel, professional development training, facilities, transportation, equipment, supplies, and financial resources. Communication resources, including access to bandwidth, will be based on commander's communication requirements, concept of operations, the OE, and comparable industry standards as determined by the APAC.

(2) Ensure PAOs are OPSEC level II qualified. The PAO conducts an OPSEC review of all official information before it is released to the public. Examples of products requiring automatic review include: news releases; web content; teaching, speaking, and writing done by military personnel pertaining to military and national security matters in 
an unofficial capacity; subjects of significant concern to DoD; and responses to Freedom of Information Act (FOIA) and Privacy Act requests.

(3) Coordinate, synchronize, and assess their CCS, plans, campaigns, and engagements. Develop their command's communication synchronization process through the use of coordinated PA programs, plans, themes, messages, and products specific to their command, ensuring that command level communication initiatives are aligned with DA themes and messages. Commanders will ensure that they are knowledgeable of any differences between inform and influence actions pertaining to their communication strategies as they apply to both their mission and audience.

(4) Provide unclassified information about the Army and its activities to the public with maximum disclosure and minimum delay. Do not release information that would adversely affect national security, threaten the personal safety, or invade the privacy of members of the military, civilian employees, and their Families.

(5) Protect classified information and controlled unclassified information in the interest of national security under AR 380-5.

(6) Release unfavorable news with the same care and speed as favorable news.

(7) Take appropriate action to correct erroneous information about the Army that appears in any medium.

(8) Not engage in releases, events, or activities staged solely for self-serving or promotional publicity purposes.

(9) Support the PA mission of the senior commander.

(10) Process and approve requests for Army support at the lowest practical command level and forward all requests requiring DA or DoD approval through command channels to the CPA.

(11) Inform the CPA of any events that may have national or international interest as soon as details are known prior to the event.

(12) Request assistance for PA augmentation by Army National Guard (ARNG) and U.S. Army Reserve (USAR), if required. Requests must be submitted through proper ACOM, ASCC, or DRU; Chief, National Guard Bureau (CNGB); and Army Reserve Headquarters-Fort Bragg (ARHQ-FB) channels, when necessary.

$b$. All corps, division, brigade, or equivalent commanders will-

(1) Develop proposed PA guidance, strategies, plans, and operations (see DoDI 5405.03).

(2) Evaluate the effectiveness of PA projects, strategies, plans, and operations.

(3) Designate spokespersons to release information pertaining to their command. PA is an inherently governmental function requiring that official spokespersons are military, DoD, or Army civilian employees.

(4) Coordinate PA matters related to all U.S. Army Special Operations Forces (ARSOF) with the U.S. Army Special Operations Command (USASOC).

(5) Resource and maintain a PA capability to operate on the internet and to monitor the global information environment.

c. All garrison or equivalent commanders will-

(1) Give adequate publicity throughout the year to the global missions of the Army and the Army Campaign Plan, as directed by the CSA.

(2) Forward requests for support from foreign countries through the proper U.S. Defense Attaché Office to the Assistant to the Secretary of Defense for Public Affairs (ATSD (PA)).

(3) Develop inter-Service support agreements or memoranda of understanding that provide appropriate PA support to tenant units and activities, Army recruiters, ARNG, USAR, and Reserve Officers' Training Corps (ROTC) units.

(4) Ensure that all actions related to PA areas of responsibility are coordinated with the applicable tenant and neighboring activities and up and down the chain of command. Conflicts that cannot be resolved at the local level will be referred to higher headquarters for resolution.

(5) Will be familiar with and adhere to Army PA policies pertaining to partisan political activities on a military installation and DoD guidance concerning election year activities.

$d$. Battalion and equivalent commanders not assigned a PAO will-

(1) Appoint a UPAR and ensure certification through the ALMS UPAR and Army OPSEC Training External Official Presence Training certification courses.

(2) Ensure UPARs operate under the oversight of the higher echelon PAO.

(3) Ensure any subordinate unit with an external official digital presence complies with the guidance outlined in this regulation.

$e$. State adjutants general are responsible for PA activities, including public information, of ARNG units. The chain of communication for ARNG PA matters is through the National Guard Bureau Public Affairs (NGB-PA) office. The state adjutants general should keep ACOMs, ASCCs, and Regular Army installation PAOs informed of training activities on Regular Army installations that will involve media and visits by elected officials and other very important persons. The CNGB will establish publishing authority for ARNG unit publications.

f. ARHQ-FB will establish publishing authority for USAR publications. 
g. TRADOC will establish publishing authority for ROTC publications.

h. U.S. Army Intelligence and Security Command (INSCOM) will establish publishing authority for all INSCOM military intelligence units and provide security clearance procedures before publication.

i. USASOC will establish publishing authority for all special operations forces RC unit publications.

j. ACOM PAOs will-

(1) Serve as the principal public communication advisor to the commander. Advise commanders regarding functional needs throughout the command as well as direct engagements.

(2) Develop command-wide communication strategies and plans to include VI planning, functional issuances, and programs in coordination with the commander, subordinate units, and the CPA as appropriate.

(3) Serve as ACOM review and release authority for all information and products intended for public communication on behalf of the commander and command.

(4) Serve as a functional liaison between the commander and the CPA. Provide coordination and representation to the CPA planning teams, councils of colonels, and general officer steering committee in support of the CPA, as appropriate.

(5) Ensure PA products developed across the command for release through ACOM channels or forwarded to the CPA for Armywide distribution are aligned with ACOM and Army priorities. Develop ACOM priorities and messages in coordination with the CPA, as needed.

(6) Develop and coordinate functional assessment of PA operations at the headquarters across subordinate units, laterally with the other ACOMs and the CPA, as needed or directed by the CPA.

(7) Conduct regular assistance visits to subordinate units to assess the PA programs and determine unit commanders' needs for support.

(8) Serve as the command web content manager, ensuring command-wide compliance with functional social media and website policies and procedures. Responsible for approval of all command content releasable to publics.

(9) Serve as the command's functional liaison to Installation Management Command, the APAC, CP22 program manager, U.S. Army Human Resources Command and equivalent echelon joint service commands regarding functional communication issues and DOTMLPF, as appropriate.

(10) Execute the ACOM-level Keith L. Ware competition in accordance with appendix B.

\section{2-5. Public affairs officers}

PAOs at all levels will-

$a$. Serve as the principal communication advisor to the commander, advising commanders on all communication, VI planning, and PA requirements across all mission phases and domains.

$b$. Provide advice and counsel to commanders and appropriate staffs regarding the use and employment of the CCS process; plan, develop, and implement all communication strategies for their commander and command.

$c$. Serve as the commander's designated review and approval authority for the release of information to the public.

$d$. Direct, coordinate, synchronize, and assess their commander's communication strategy, plans, campaigns, and engagements. Develop their CCS process through the use of coordinated programs, plans, themes, messages, VI, and products specific to their command, ensuring that command level communication initiatives are aligned with DA themes and messages.

e. Develop PA plans and programs that support HQDA level communication strategies.

$f$. Formulate and release command messages in support of commander's communication requirements.

g. Serve as a liaison between the commander and the next higher headquarters PAO. Provide coordination and representation to planning, coordinating, and operations cells, as appropriate.

$h$. Supervise the preparation, production, and distribution of PA communication products.

$i$. Advise the commander on internal and external audience attitudes and perceptions of policies, programs, and information needs.

$j$. Conduct regular staff assistance visits to assess subordinate unit PA programs and determine additional support or training requirements.

$k$. Provide training and support to command-designated UPARs.

l. Coordinate with the installation network enterprise center to maintain a content production capability dedicated to the PA office.

$m$. Serve as the command web and social media content manager, reviewing and releasing official information intended for the internet and command external official presences.

$n$. Conduct routine reviews of subordinate unit publicly accessible websites and external official presences to ensure compliance with AR 25-1. Official online content must remain relevant and appropriate. 
o. In keeping with the commander's communication strategy, conduct PA activities while deployed and in garrison to fulfill the commander's requirement to inform the American people, elected officials, and other external publics of Army activities and initiatives.

$p$. Synchronize PA operations and activities with the operations plan, the communication plan, and other information related capabilities.

q. Maintain records in accordance with AR 25-400-2 and DA Pam 25-403.

$r$. Submit PA training after action reviews; tactics, techniques, and procedures; and any other lessons learned to APAC for review, collation, and input into future PA policy, doctrine, and training development.

\section{2-6. Army personnel}

Any individual who intends to release official information to the public must consult with a PAO. If material in its intended release form (book manuscript, magazine article, internet posting, and so forth) has a potential security, policy, or propriety violation, it must be submitted for a prepublication review. Retired personnel, former Army employees, and non-active duty members of the RCs will use the security review process to ensure that information they submit for public release does not compromise national security (see para 7-44).

\section{Chapter 3 Policies}

\section{3-1. Public affairs restrictions, limitations, and other considerations}

a. Selective benefit. Army participation must not selectively benefit or appear to benefit any person, group, or corporation (whether profit or nonprofit); religion, sect, religious or sectarian group, or quasi-religious or ideological movement; fraternal organization; political organization; or commercial venture. ACOMs or organizations that provide support to a nonfederal entity must be willing and able to provide equal support to comparable events sponsored by similar nonfederal entities.

b. Avoid endorsement. Activities will not support any event involving or appearing to involve the promotion, endorsement, or sponsorship of any individual, civilian enterprise (CE), religious or sectarian movement, organization, ideological movement, or political campaign unless it is clear that the support primarily benefits the community at large or the Army as opposed to benefiting the sponsoring organization. Examples of such instances include as follows:

(1) Using a shopping mall or center as a site for an event when space is made available as a community service and not as a promotion.

(2) Using a local airport for an aviation event. Air shows are of general community interest. Air show sponsors, who may be single CEs, routinely donate excess revenues to local charities. Consider such benefits to the local community during the evaluation process.

(3) Closed events may also be considered of common interest and mutual benefit to the community and the Army if invitations are extended to a cross section of a broadly represented community. For example, an association convention representing an entire industry could be considered of common interest; a meeting of representatives from only one business in that industry would not be considered of common interest.

(4) Testimonials to individuals generally are not of common interest or benefit to the community at large.

(5) Support to religious organizations and activities. Religious facilities are often used as nonsectarian centers for community events and activities of common interest and benefit; therefore, Army support of community activities conducted in such facilities may be authorized if the program is community-wide, nonsectarian, and of common interest and benefit and the program is broadly publicized.

(6) Lending or otherwise employing Army equipment, logistical support, or personnel for any outreach or activity cannot involve (or appear to involve) the endorsement, promotion, or sponsorship of any private individual, group, organization, or venture.

(7) Support may be provided to nonpartisan events sponsored by the Federal Government, State or local governments, schools, civic organizations, veterans associations, or recognized organizations whose primary purpose is fostering public service, stimulating patriotism, promoting understanding of national security issues, or fostering public appreciation of our national heritage.

c. Support to veterans service organizations. Participating in events sponsored by veterans service organizations may be authorized as long as such participation supports programs oriented to the veteran rather than to the sectarian, fraternal, or national origin aspects of the organization's objectives.

d. Support to nonpublic school activities. This may be authorized when such participation is clearly educational, patriotic, or in support of Army recruiting programs. 
e. Nature of sponsoring organization. Army participation in events sponsored by organizations with a narrow membership base may be supported if-

(1) The chief beneficiary of the support is the community at large rather than the organization.

(2) The result of such participation does not produce a special interest or benefit to the sponsoring organization.

f. Restricted access to organizational data. Community outreach support or participation is not authorized for events sponsored by organizations whose constitution, bylaws, membership qualifications, or rituals are withheld from the public.

g. Role of the Army in the event. Army participation must be incidental to the event. Exceptions are patriotic programs, national holiday celebrations, or other appropriate events. Such events must be open to the public.

h. Prohibited use of Army personnel in events. Army personnel will not be tasked as ushers, bag handlers, guards, escorts at beauty pageants or similar events, messengers, attendants for parking lots, or in similar capacities during public events conducted off military installations or in demeaning or inappropriate capacities to support unofficial programs conducted off military installations.

i. Prohibited use of public affairs resources. PA is a commander's program and use of PA equipment and personnel will only be for events that support the commander's approved communication strategy. Any use of PA resources for activities such as personal social events or any purpose not designed for public release is not authorized.

$j$. Support of recruiting. Recruiting potential will be weighed when evaluating requests for Army participation. This regulation applies to Army participation in public events and community outreach activities undertaken in direct or indirect support of recruiting, whether such activities are initiated or sponsored by either of the following:

(1) Recruiters or other DA elements.

(2) Elements of the civilian community.

$k$. Support to commercial entities. Army participation is not authorized for events clearly designed or conducted primarily for commercial benefit. This includes events to stimulate sales or increase business traffic. However, participation may be authorized in direct support of Army recruiting in a shopping center or mall.

l. Competition with commercial entities. Army personnel, equipment, transportation, or other resources or services will not be provided to civilian-sponsored activities if commercial resources and services available in the public domain could reasonably provide such support. Army support could be provided if documented evidence shows local labor unions and CEs waived this requirement; however, all other stipulations cited in this regulation must still be met. Army resources or services include items such as communications equipment, transportation, VI support, ambulances, public address systems, food handling equipment, bleachers, tents, or earthmoving or other construction equipment.

m. Monetary remuneration. No Army personnel or unit will receive a monetary profit or accept a gratuity or remuneration in any form not permitted by public law or by Army regulations.

n. Support to Armed Forces Day and Armed Forces Week. Community outreach emphasis during the month of May will be on Armed Forces Day (AFD) and Armed Forces Week (AFW). These observances will be used as occasions to demonstrate the unity and common purpose of the Armed Forces in fulfilling our national security requirements.

o. Speaking invitations. Army personnel are encouraged to accept speaking invitations at public events to inform the public of the Army's mission and its contribution to national security.

p. Response to public interest. Maximum effort is made to satisfy public interest in the Army, either upon request or by invitation, through-

(1) Orientation visits and tours.

(2) Periodic open houses.

(3) Briefing and discussion programs.

(4) Army National Guard of the United States (ARNGUS) and USAR participation. ARNGUS and USAR organizations are encouraged to participate in community outreach activities to the maximum extent possible.

q. Energy and environmental considerations. Energy conservation and environmental impact issues will be considered in planning and conducting community outreach activities.

r. Support of political activities. Community outreach activities cannot be associated with vote soliciting in any political election (see DoDD 1344.10 for further guidance).

s. Participation in confrontational programs. Army PA support of, or participation in, community events or programs in which a public confrontation is planned or likely (or where the apparent purpose is to stage controversy) is unauthorized. This does not prevent Army participation where the purpose of the event is the fair and equitable exchange of diverse opinions. However, where the apparent purpose of the event is to increase a group's public or media visibility through direct public confrontation rather than through open and constructive discussion, Army participation is inappropriate. 
t. Endorsement of, and participation in, membership drives or fundraising activities. See DoD 5500.07-R and AR 600-29 for additional guidance. Generally, Army PA support will not officially endorse or appear to endorse fundraising activities for any nonfederal entity. However, an ACOM commander or the head of organization may, after consulting with the designated agency ethics official or designee, authorize the official endorsement of, and participation in, fundraising activities for the following:

(1) Combined Federal Campaign (CFC).

(2) Emergency and disaster appeals approved by Office of Personnel Management.

(3) Army Emergency Relief.

(4) Fundraising activities of organizations composed of primarily Army employees or their Family members, if the fundraising is conducted among the members, will benefit the welfare funds of the members or their Family members, and is approved by the head of the ACOM or organization.

(5) On an occasional basis, fundraising in support of on-post private organizations and other limited fundraising activities to assist those in need.

$u$. Limited authorization. The head of an Army organization may provide limited authorization to use Army facilities and equipment (and the services of Army employees necessary to make proper use of the equipment) as logistical support of a charitable fundraising event sponsored by a nonfederal entity. Such support will be provided only when the head of the ACOM or organization considers criteria identified in paragraph 3-1b.

$v$. Voluntary support to charities. This regulation does not prevent Army members from volunteering in their private capacity support to charities of their choice. Such efforts are encouraged if they do not imply DA endorsement.

w. Support requests from other federal agencies. Support such as logistics, audiovisual, band, or color guard requested by other Government agencies for an official government event is not considered a community outreach activity and is not subject to the guidance in this regulation. However, if the official nature of the event is questionable, seek guidance from OCPA.

$x$. Army resources. Army resources will only be used to support events and activities of common interest and benefit to local, state, regional, national, or broadly represented publics. Commanders must be willing to give equal consideration and support to comparable events and sponsoring organizations. However, operational constraints may preclude the Army from responding positively to every valid request for support.

(1) Local events and publics are restricted to a single community area of responsibility.

(2) Regional events and publics include participation or interest from more than one state in a section of the United States.

(3) National events and publics include participation or interest from the United States as a whole.

(4) The PAOs and their staffs will not initiate or conduct psychological operations and will not permit PA resources to be used to support such activities. Violations will be immediately reported to OCPA.

\section{3-2. Use of unmanned aerial systems for public affairs activities}

Consult with the installation commander and review all applicable guidance from local and national government, the Secretary of Defense, and HQDA before using unmanned aerial systems to photograph military installations or activities. Unmanned aerial systems requests must be submitted through DroneZone to be reviewed by applicable service area for concurrence or denial. Per the Federal Aviation Administration (FAA), drones must not exceed 55 pounds and the pilot must maintain line of sight with the drone at all times.

\section{3-3. Visual information}

VI is defined as various visual media with or without sound that generally includes still and motion photography, audio video recording, graphic arts, and visual presentations. PAOs will ensure accurate portrayal in situations reflecting Army activities, missions, and uniforms. No release is required to use images of military personnel serving on active duty, including cadets or midshipmen from the U.S. service academies, or DoD Civilians performing their official jobs in PA photos and videos.

a. Photographs authorized by this regulation will support PA goals, objectives, and principles.

$b$. No one acting for or on behalf of DA will alter official imagery. The following modifications are authorized:

(1) Photographic techniques such as dodging, burning, color balancing, spotting, and adjusting contrast to accurately record an event or object are not considered alterations.

(2) Photographic and video image techniques for enhancing, exploiting, and simulating unique cartography; geodesy; intelligence; medical; research, development, test, and evaluation; scientific; and training requirements are authorized, if they do not misrepresent the subject of the original image.

(3) Masking portions of a photographic image for specific security or criminal investigation requirements is authorized. 
(4) Cropping or enlarging a portion of a photograph or video image to selectively isolate, link, or display it is not considered alteration. However, cropping, editing, or image enlarging that misrepresent the facts or circumstances of the event or object as originally recorded constitutes a prohibited alteration.

(5) Digitally converting and compressing photographic and video imagery is authorized.

(6) Photographic and video postproduction enhancements (including animation, digital simulation, graphics, and special effects) for dramatic or narrative effect in education, recruiting, safety, and training illustrations, publications, or productions is authorized under either of the following conditions:

(a) The enhancement does not misrepresent the subject of the original image.

(b) It is clearly apparent from the context or content of the image or accompanying text that it is a representation of an actual event.

c. When releasing VI of U.S. and allied forces personnel killed, wounded in action, hospitalized, detained as a result of hostile action, or missing in action, give consideration to the rights of the individuals concerned and the effect publishing information or photographs would have on Families and friends.

$d$. Common sense, good taste, and awareness of safety and security concerns are used when authorizing media access to operational locations.

$e$. The following provisions apply while a wounded person is in an area of hostile action, at a point of embarkation or entry, at a hospital or other military convalescent installation, or in transit. Unless the individual or individuals shown have given permission to release and a notation is placed at the end of the identifying caption, official release of the following is prohibited:

(1) Photographs or video recordings of recognizable wounded or deceased personnel not identified by name.

(2) Photographs or video recordings of recognizable wounded personnel identified by name until next of kin have been notified, unless the release has been approved by the wounded or the individual requested that their next of kin not be notified.

(3) Surgical or other major medical care photographs or video recordings that identify the patient.

(4) Photographs or video recordings showing deceased or wounded personnel in large numbers. Official photographs of combat deceased under field conditions normally will not be released to the public or media. Photographing graves, registration facilities, or temporary cemeteries is prohibited.

(5) Photographs or video recordings showing mangled bodies, obvious expressions of agony, or expressions of severe shock.

(6) Photographs or video recordings of psychiatric or other mental patients.

(7) Photographs or video recordings of plastic surgery or severe disfigurement cases.

(8) Photographs or video recordings of blind or deaf patients.

(9) Photographs or video recordings of amputees demonstrating prosthetic appliances.

$f$. All personnel are accountable for adherence to OPSEC and privacy regulations in the acquisition, distribution, and use of personal video, audio, and photographic material.

\section{3-4. Archiving visual information}

$a$. If a PA product meets the definition of VI as established in DoDI 5040.02 then DoD policy mandates that strategic, operational, tactical, and joint interest imagery will be centrally received, managed, and distributed as a shared asset. In accordance with DoD policy, PA offices will coordinate and facilitate the flow of VI to the Defense Imagery Management Operations Center through the Defense Visual Information Distribution Service.

$b$. PAOs must comply with the provisions of DA Pam 25-91 concerning the usage of Defense VI activity numbers and the disposition of VI documentation.

\section{3-5. Visual information products by Army agencies and commands}

$a$. VI products made by the Army and intended primarily for public release (excluding materials to be used locally or dealing with spot news events that occur without prior planning or knowledge) must be approved by OCPA prior to committing military funds. (See DA Pam 25-91 for policies and procedures on producing VI products. See AR 601-208 for Army branding guidance for externally released materials.)

$b$. Commanders may use commercial and copyrighted audio and visual products if all fees have been paid and all rights to use the product have been obtained. Commanders must consult with their PAO, their servicing staff judge advocate (SJA), and their printing control officer, when appropriate. 


\section{3-6. Exhibits, loans, explosives, and donations}

PA projects or programs may be supported by Army exhibits, equipment, and facilities. All conferences will be approved in accordance with current Army conference policy before committing or obligating any Army appropriated funds.

a. Purposes for Army exhibits. Exhibits consist of displays such as mission exhibits, models, devices, and other information and orientation materials at conventions, conferences, seminars, demonstrations, exhibits, fairs, or similar events. Also included are exhibits displayed on military installations during open house programs. While Army exhibits contribute to the PA program, their primary purpose is to accomplish either of the following:

(1) Support recruiting and retention efforts.

(2) Further Army professional, scientific, and technical interest.

b. Standards for Army exhibits.

(1) Exhibits at international trade shows are not community engagement events since the purpose of these events is to sell military equipment or for other commercial reasons. These exhibits are governed by 10 USC 113 and require the Secretary of Defense to make a determination that DoD participation in such an event is in the national interest (including business and industry groups).

(2) Senior commanders, down to and including garrison commanders, may approve exhibit participation at local events.

(3) Exhibits may be displayed-

(a) In any location or event, including commercially owned spaces such as shopping centers and malls, if the general public gathers in such areas and the exhibit is not used specifically to draw the public to that location.

(b) In conjunction with events conducted at shopping centers or malls, if a civic group sponsors such events and Army participation is not used in advertising or promotional activities.

(4) U.S. Army Center of Military History maintains the inventory of Army historical artifacts and art. Loan of these items may be available to military installation museums and similar activities, to federal museums and agencies, and to nongovernment museums and similar agencies. (See AR 870-20 for details about the loan program.)

(5) Policy regarding public display of opposing forces material is in AR 350-2.

(6) The period authorized for exhibits to remain on display is based on of the type of event and the proper use of Army personnel and resources. Normally, an Army exhibit may remain for the duration of the event.

(7) Indemnity insurance is normally only required for Army exhibits described in paragraph 3-6b(5).

(8) PA units will request approval and coordinate with OCPA, when necessary, for Army exhibits at public events when national or international media could potentially cover participation. This includes exhibits at national conventions as well as nongovernment organization and professional association conferences, seminars, and symposia. Local PA offices should forward their intent to participate in these events to OCPA at least 60 days prior to the date of the event. OCPA, in turn, will inform ATSD (PA) of the support.

c. Exhibits at the Pentagon. Armed Forces exhibits may be displayed in designated exhibit space on the Pentagon concourse and other areas in and around the Pentagon.

(1) Exhibits will conform to this regulation.

(2) No classified material will be displayed.

(3) The maximum permissible weight of an exhibit on the Pentagon concourse is 150 pounds per square foot.

(4) Proposals, projects, or products offered by commercial concerns can be construed as a promotional device benefiting or favoring commercial ventures. Therefore, only items currently in the military inventory or in a servicetesting program may be displayed. Reference to a commercial concern is limited to a standard nameplate on military equipment or a 4-by 6-inch plaque, giving credit to the lender, placed in the lower right corner of an exhibit.

(5) Requests are forwarded for display space to OCPA for ATSD (PA) approval at least 40 calendar days before the first day of the desired display period. The requests will contain the following data:

(a) Size of the area desired (maximum space available on the Pentagon concourse is 30 feet by 45 feet, or three bays).

(b) Time desired (normally, the maximum period of each exhibit is 1 week).

(c) Alternate acceptable dates.

(d) Name, office, and telephone number of the person in charge of the display.

(e) Special electrical requirements, if any (110-volt or 200-ampere outlets are available).

(f) The title and a brief description of the exhibit to be displayed. If the volume can be controlled, exhibits may contain tapes, records, sound tracks, movies, or other devices that produce sound. However, the volume must be kept low at all times to avoid interference with nearby commercial establishments. 
(6) A statement that a proper security review has been made per paragraph 5-1 of this regulation. If the exhibit has not been cleared, four copies of text, diagrams, sketches, and photographs, and one copy of films, slides, and sound tracks will accompany the request.

(7) A statement that the display will contain no reference to a commercial concern other than a 4- by 6-inch plaque, credit line, or standard nameplate (on equipment).

d. Lending or leasing materiel and facilities.

(1) General Army policy on lending or leasing materiel and facilities is in AR 700-131.

(2) Army policy on lending property to veterans and scouting organizations (Boy Scouts and Girl Scouts of America) is in AR 725-1.

(3) Army policy on lending, selling, or donating flags is in AR 840-10.

(4) Army policy on using the DA Seal and using and selling the DA Plaque is in AR 840-1.

(5) Army policy on private persons or organizations using Army real estate is in AR 405-80.

(6) Army policy on lending Army property to other military and nonmilitary U.S. Government agencies is in AR 700-131 and AR 735-5.

e. Explosives and pyrotechnics. Except in rare cases, participation of Army personnel (military or civilian) in public events involving the use of explosives is not advisable because of the possibility of injury and legal liability. However, units may approve such participation when it meets established safety criteria, when a risk assessment has been performed and risk to personnel and equipment has been accepted at the appropriate level per DA Pam 385-30, and when such participation is clearly in the interest of the Army.

(1) Using explosives in connection with events conducted on a military installation will be at the discretion of ACOMs. Using antique weapons not routinely fired is prohibited, including using them for national salutes.

(2) The restrictions mentioned in paragraph 3-6e(1) do not apply to routine salutes as authorized in AR 600-25. Local commanders may approve rifle and cannon salutes conducted off-post as part of an approved PA program if a safety or risk assessment has been done.

f. Museum exhibits. AR 870-20 contains policy regarding Army museum exhibitory.

\section{3-7. Donation of obsolete or condemned combat equipment}

a. Under 10 USC 2572, the following organizations are authorized to acquire, through donations, various obsolete or condemned combat equipment for public display or ceremonial purposes (see AR 870-20):

(1) Municipal corporations.

(2) Soldiers' Monument associations.

(3) State museums.

(4) An incorporated museum operated and maintained for educational purposes only, whose charter denies it the right to operate for profit.

(5) A local post, charter, or unit of Veterans of Foreign Wars of the United States, American Legion, or any recognized war veterans association.

(6) A local or national unit of any war veterans association of a foreign nation, which is recognized by the national government of that nation (or by the government of one of the principal political subdivisions of that nation).

(7) A post of Sons of Veterans Reserve.

$b$. Recognizing veterans associations for the purpose of acquiring obsolete or condemned property is based upon the size and purpose of the organization and services rendered to veterans, if the organization is composed of honorably discharged American Soldiers, sailors, airmen, marines, coast guardsmen, merchant marines, or members of the National Public Health Service. Services rendered include efforts-

(1) To inform veterans and their Family members of employment rights and benefits.

(2) On behalf of disabled veterans.

c. For local posts, chapters, and units of veterans organizations to acquire property by donation, their national headquarters must submit a request for eligibility to ATSD (PA). The request will contain the following information and a statement that the organization is composed of honorably discharged military personnel:

(1) A citation to or copy of the act granting charter or recognition as a bona fide veterans organization (federal or state).

(2) A statement outlining the association's purpose and the intended use of the property requested.

(3) The names, titles, and addresses of all officers.

(4) A copy of the last financial statement.

(5) A copy of the association's constitution or charter and bylaws.

(6) The total membership. 
(7) Once ATSD (PA) has determined eligibility, organizations should submit requests for donations of obsolete or condemned property directly to Commander, U.S. Army Tank-Automotive and Armaments Command (AMSTA-IMOER), 6501 East 11 Mile Road, Warren, MI 48397-5000. Requests from local posts, chapters, and units of eligible veterans organizations should include written approval from their national headquarters.

\section{3-8. Other policies with public affairs impact}

a. Environmental protection and enhancement. PA responsibilities and support in connection with the Army Environmental Protection and Enhancement Program are in AR 200-1. PAOs at all levels must be familiar with environmental laws, which include the requirements of the National Environmental Policy Act (see AR 200-1) and Executive Order 12088. This order charges the Army to comply with federal, state, and local environmental standards and demonstrate leadership in environmental enhancement. PAOs should work closely with their local engineers, environmental coordinators, and environmental program managers on a continuing basis on all aspects of decision making and build mutual understanding through two-way communication. The environmental impact statement process may include public hearings of crucial interest and concern to the news media and the public.

$b$. Land acquisition. Inform and engage the public about land acquisition studies throughout the acquisition process. Congressional notification must precede or coincide with the public release. Coordinate with local and ACOM PAOs and OCPA on all land acquisition actions (see AR 405-10).

c. Defense support of civil authorities. During defense support of civil authorities operations, military PA activities, military civil authority information support elements activities, public information actions, and news media access to defense support of civil authorities operational areas are subject to approval by the primary agency. The primary agency may establish a joint information center to coordinate PA, civil authority information support elements, and public information actions. DoD forces should coordinate PA activities and comply with PA guidance from the joint field office (see DoDD 3025.18).

\section{Chapter 4 Organizations and Associations}

\section{4-1. General}

a. OCPA maintains liaison with national service-oriented organizations.

b. Support to nongovernment organizations must conform to AR 1-50, DoD 5500.07-R and this regulation.

c. DoD 5500.07-R contains the policy on meetings cosponsored by DA and industry or DA and nongovernment associations.

(1) DA personnel may participate as panel members, paper contributors, speakers, or spectators at meetings determined to be in the interest of the Army.

(2) Civic and community activities cosponsored by DA and industry or DA and nongovernment associations may be authorized if the industry or association involvement is separate from their business purpose.

$d$. OCPA must be notified in advance of command cooperation in industry or nongovernment association programs that have the potential to generate significant public interest beyond the local or regional level.

$e$. OCPA periodically sends information on DA policies, programs, budgets, and other activities in response to an organization's request. ACOMs are encouraged to provide proper materials to OCPA for inclusion in these mailings. Examples of such material include the following:

(1) Posture statements and other significant statements presented by Army officials at congressional hearings.

(2) Internal publications outlining important programs that will have a significant impact.

(3) Major policy pronouncements and speeches.

$f$. The Hatch Act.

(1) The Hatch Act restricts federal employee participation in certain partisan political activities. The political activity restrictions apply during the entire time of an employee's federal service. Certain rules prohibit both on-duty and off-duty conduct.

(2) Partisan political activities are those activities directed at the success or failure of a political party, candidate for partisan political office, or partisan political group. While most federal employees are permitted to take an active part in partisan political management and partisan political campaigns, the Hatch Act does prohibit certain participation by all federal employees. Federal employees may not seek public office in partisan elections, use their official title or authority when engaging in political activity, solicit or receive contributions for partisan political candidates or groups, and engage in political activity while on duty. 


\section{4-2. Membership in organizations and associations}

a. Policy on DA military or civilian personnel membership or participation in private organizations and associations is in DoD 5500.07-R and DoDI 1000.15.

$b$. Command memberships in local civic organizations are authorized when deemed beneficial to the Army. Only one command membership in each organization may be purchased for the headquarters of each ACOM and each installation. Commanders should, if possible, register membership in civic organizations in the name of the Army installation or command. This provides continuity and eliminates name changes that occur because of reassignments.

c. Normally, command membership in civic organizations will be purchased with appropriated funds. Commanders who control nonappropriated welfare funds at major command and installation levels may approve Army-funded expenditures for command memberships, if both of the following apply:

(1) Membership supports morale, welfare, and mission objectives.

(2) Appropriated funds are not available.

(3) Membership must be made in the name of the organization (morale, welfare, and recreation (MWR) program nonappropriated funds instrumentality or position) rather than the name of an individual.

$d$. Using appropriated funds to pay individual membership fees and dues in any society, club, or association is prohibited by 5 USC 5946. This section does not prohibit using appropriated funds to pay for professional society, club, and association memberships in the name of and for the direct benefit of federal agencies when such memberships are necessary to accomplish the agencies' authorized activities (see DoD 5500.07-R and DoDI 1000.15).

$e$. DA military and civilian personnel are prohibited from accepting an honorary office or membership in private associations whose membership includes business entities engaged in or endeavoring to engage in providing goods or services to a DoD component, including Army-funded activities. An honorary office or membership includes any position (termed governing honorary or otherwise) selection that is made on the basis of an official DA position or assignment. Questions regarding these topics can be addressed to the local ethics counselor.

\section{4-3. Liaison with organizations and associations}

$a$. The ATSD (PA) is the principal point of contact for all national nongovernment organizations as well as their local and regional chapters in the National Capital Region. ATSD (PA) authority does not apply to-

(1) Matters bearing directly on the Army.

(2) Requests for speakers.

(3) Matters involving contractual or consulting relationships.

(4) Matters properly handled by scientific and technical information services of Defense Logistics Agency.

$b$. Outside the National Capital Region, commanders may communicate directly with local and regional chapters of national organizations. However, matters pertaining to Army as a whole or its principal headquarters will be referred to OCPA.

\section{4-4. Support to national military association annual conferences}

$a$. General. The type and extent of national military association support requested varies with each organization. Support must conform to 10 USC 2558, DoDD 5410.18, DoD 5500.07-R, AR 58-1 and this regulation.

b. Approval authority. SECARMY has approval authority to provide military support to specified national military associations. This authority is delegated to the CNGB and may be further delegated to Director, ARNG, as deemed appropriate. The specified national military associations eligible for military support must be designated and approved in advance by the ATSD (PA).

c. List of approved national military associations. The ATSD (PA) retains the authority to modify the list of associations granted approval for DoD support. Requests to support associations not appearing on the list of approved associations must be submitted in writing, through appropriate Army channels, to OCPA, at least 90 days before the association's scheduled event. OCPA maintains a copy of the list of approved national military associations. Requests must include a copy of the statute (federal or state) granting charter or recognition to the association; a statement outlining the purpose of the association; a list of the association's national officers, total membership, and the locations of regional or local chapters; and a copy of the association's constitution or charter and bylaws. Associations approved for such support generally will be added to the DoD-designated association list.

d. Limits on annual support. Army support to approved national military associations is limited to the annual conference or convention of each designated association (one conference or convention per calendar year). Attending and supporting the conference will be approved in accordance with current Army conference policy before committing or obligating appropriated funds. 
e. Eligibility requirements. Military associations must be noncommercial in nature, must be national in scope, and must focus their efforts on Regular Army, ARNG, or USAR activities. Examples of ineligible criteria include associations primarily oriented toward a specific group of military veterans (whether veterans in general or of a specific military service) or associations oriented toward a specific gender, military unit, campaign, ethnic group, religious group, or region.

f. Authorized support. While on duty status, Army members are restricted to performing duties that relate directly to their designated military specialties. The use of personnel and equipment must be at no additional cost to the Government. All logistical support must be incorporated into legitimate, scheduled training missions.

(1) Air. Conference attendees who are military members traveling on official orders or traveling space available without orders may travel to and from conferences aboard military aircraft. Civilian spouses not designated by the military services cannot use military air transportation. All such flights must be legitimately scheduled training missions.

(2) Ground. The use of Army-owned or Army-controlled nontactical vehicles is restricted to official purposes only Official conference attendees (military and civilian personnel) may travel to and from conferences, and official conference functions, by Government-owned or Government-contracted ground transportation. A commander will determine whether the event in question is of significantly high interest as to warrant the use of official Government transportation for general attendance. As required by AR 58-1, all requests for general transportation will be reviewed by both the senior public affairs and legal officials prior to review by the commander. When official travel is authorized for general attendance, the mode of travel provided will be via mass transportation rather than separate vehicles.

(3) Medical assistance. Medical support may be provided only for support of emergency and lifesaving functions.

\section{4-5. Activities involving contractors and military related organizations and associations}

Accepting gratuities from private companies in connection with an association's activities is prohibited. Questions on these policies should be directed to the local ethics counselor. Except as specified in Part 2635, Title 5, Code of Federal Regulation (5 CFR 2635) and DoD 5500.07-R, this policy prohibits Army personnel from-

a. Attending social functions, including those related to association meetings, as guests of any contractor or potential contractor.

b. Accepting hospitality from any such contractor.

c. Accepting invitations to association banquets, luncheons, and similar events, unless the sponsoring organization assures, by demonstrating in advance, that the following criteria have been met:

(1) The event will have open seating.

(2) Seating is neither selected nor influenced by contractor interests.

d. Accepting gifts of other than specialty advertising items of trivial intrinsic value for themselves or their Families.

e. Accepting invitations to association functions, unless the sponsor assures that no single contractor or industry developed guest lists or seating plans to reflect their special interests.

\section{4-6. Business and industry organizations and associations}

a. The Army is obligated to contract for its products and services in the most economical manner. The American business and industrial community can only respond effectively to Army requirements if its members are aware of Army policies, programs, proposals, plans, budgets, and activities. One of the most effective means of maintaining a continual flow of information to those potential product and service providers is through nongovernment associations and organizations. Such groups represent many like-oriented companies. Commanders are encouraged to cooperate with industry and organizations representing the industry in PA programs and projects that are consistent with DA interests and DoDI 5410.20.

b. Normally, Army participation will be limited to the following types of events sponsored by industry or associations:

(1) Luncheons, dinners, meetings, and similar gatherings hosted by an organization representing diverse business interests.

(2) Public ceremonies of mutual interest to industry and the Army (for example, equipment demonstrations or first flights).

(3) Industrial programs (such as the following examples) that support Government policy:

(a) Industry-sponsored seminars to explain Government policies.

(b) International exhibits which promote U.S. scientific and technological achievements.

(4) Civic and community-oriented projects where industry relationship is separate from business purpose and objectives.

(5) Business-sponsored scouting activities for military Family members. 
(6) Industry-subsidized awards to military personnel or Family members and civilian employees for civic or community achievement.

(7) Special events in which Army interests dictate participation, if such participation is consistent with the provisions of DoD 5500.07-R.

c. Unclassified material and records for release outside of DA will be made available upon request to industry representatives or associations representing the industry (see AR 25-55 and chap 7 of this regulation).

$d$. These guidelines will not be interpreted to prohibit Army support available to nongovernment organizations. Specifically, such traditional community engagement support can include-

(1) Designating DoD and Army coordinators.

(2) Providing bands, troops, or speakers.

(3) Lending or leasing materiel.

(4) Supporting major conventions of veterans organizations.

(5) Supporting the myriad of community engagement activities conducted by Army units governed by OCPA guidance.

\section{Chapter 5 \\ Public Affairs Resourcing}

\section{5-1. Public affairs funding authority}

Defense Finance and Accounting Service-Indianapolis (DFAS-IN) Manual 37-100 provides fiscal authority on funding of PA equipment and activities. PA personnel should consult with the command or activity resource management office for clarification and guidance on funding issues.

\section{5-2. Use of Army funds and other resources}

Organizational PA funds may be used to defray the costs of activities that are part of the command's approved PA program. Directors of resource management or G-8s should consult with the PAO prior to reprogramming PA funds.

$a$. Funding requirements may include, but are not limited to, costs for-

(1) Civilian pay.

(2) Travel.

(3) Commercial printing (see AR 25-30).

(4) Contracts, subscriptions, and memberships.

(5) Supplies.

(6) Speaking engagements (requires legal review).

(7) Support for civic events.

(8) Public announcements of Army support to community events of mutual support to the Army and the public (for example, advertising an open house or town hall meeting).

(9) Equipment or software to manage or produce PA and VI content.

(10) PA training and education.

(11) Commercial internet media monitoring and product content transmission and distribution to digital platforms.

$b$. The following are exceptions as authorized by this regulation:

(1) The use of Army resources to support public events will be at no additional cost to the Government; that is, costs incurred solely for participating in or supporting unprogrammed activities or events.

(2) Costs for Army participation in public events will be paid by the event sponsors.

(3) Costs that the Army would have incurred notwithstanding support to PA activities are not reimbursable. Such costs may include, but are not limited to, local travel and transportation pay and allowances, local telephone calls, and aviation fuel when support is provided as part of an ongoing training activity.

$c$. The Army will pay all unprogrammed costs of supporting PA programs that are specifically authorized by public law, Executive order, Secretary of Defense, or SECARMY, and the following types of programs when they are in the primary interest of DA:

(1) Official Federal Government functions.

(2) Army or civic-sponsored observances of the United States or host country national holidays.

(3) Official civil ceremonies and functions.

(4) Official speaking engagements.

(5) Army organizations may participate in events that do not meet the criteria stated in paragraphs 5-2 and 5-3 if event sponsors pay the associated costs. 
(6) Direct support of recruiting and personnel procurement activity, when the costs of such support are charged to recruiting or personnel procurement program funds.

\section{5-3. Events or engagements qualifying for Army funding}

The Army may fund support to the following types of activities, if such participation is in the best interest of the Army and authorized funds are available:

a. Official Federal Government functions not political in nature.

$b$. Public observances of national holidays, when sponsored by either military or civilian organizations.

c. Public observance of Armed Forces Day and Armed Forces Week, when sponsored by either military or civilian organizations.

d. National conventions of veterans associations.

$e$. Official civil ceremonies and functions.

$f$. Speaking engagements.

g. Activities in support of recruiting, including ROTC programs.

$h$. Appearances or demonstrations by special units.

i. Other events considered in the national, congressional, scientific, or technical interests of the Army. Such events must be approved by the Secretary of Defense or by an overseas unified combatant commander.

$j$. Local events held within the PA's community outreach area of responsibility.

$k$. Other events held in recognition of military service.

\section{5-4. Events or engagements qualifying for outside funding}

a. Army organizations may participate in events that do not meet the criteria stated in paragraphs 5-2 and 5-3 if event sponsors pay the associated costs. If an event does not qualify for funded PA support and assistance, official assistance must satisfy the three criteria in 10 USC 2012(d):

(1) Providing assistance accomplishes valid unit training requirements or involves tasks directly related to the military occupational specialty of the Soldiers providing assistance.

(2) Providing assistance will not adversely affect the quality of training or otherwise interfere with the ability of a Soldier or unit to perform assigned military functions.

(3) Event sponsors pay the associated costs of providing the assistance.

$b$. The event sponsor will pay the additional costs ordinarily financed from funds available to the Army organization furnishing the Government resources. Additional costs normally include-

(1) Travel and transportation of military personnel and equipment.

(2) Meals and lodging or per diem allowances payable under provisions of the Joint Travel Regulations.

(3) Transportation, handling, and costs of aviation fuel, if such fuel is not available at military contract price at the staging point.

(4) Exhibit space, rental, utilities, and custodial services.

(5) Public liability and property damage insurance, if required.

(6) Other services deemed necessary per agreement with the sponsor.

(7) Using routine training to transport military personnel, which may be considered as an Army share of costs for a PA activity of mutual benefit.

c. PA funds will not be expended for hosting and representational purposes such as luncheons, dinners, buffets, cocktail parties, theater tickets, gifts, and similar items or activities that would constitute entertainment events. Official hosting and representational expenses may be charged only to the SECARMY's contingency fund for events such as official receptions involving civic dignitaries and extending official courtesies to certain foreign officials (see AR 37-47 for criteria).

$d$. Army operation and maintenance (OMA) funds may be used to pay for incidental costs associated with unprogrammed community engagement activities when the event sponsor agrees to pay for the activities.

\section{5-5. Finance guidelines}

$a$. Funds programmed and expended for PA activities, programs, and equipment are an integral part of each component's OMA account (Army working capital fund for depots, arsenals, and Government-owned ammunition plants). Funding requirements for these purposes will be kept to the minimum necessary to accomplish the Army's objectives. Beyond these OMA funds, PA activities will be at no additional cost to the Government.

$b$. Using PA funds to purchase and distribute promotional items for command-approved PA objectives are authorized within the limits of DoD 7000.14-R. Promotional items must clearly support the mission and the PA objectives 
of the activity or command. An example is printed materials, such as posters, pamphlets, information papers, and booklets.

c. Financing will be accomplished according to the DA Planning, Programming, Budgeting, and Execution System (see AR 1-1 for budgeting guidance).

$d$. Procedures for reimbursement by other Government agencies are in DFAS-IN 37-1. Reimbursement procedures for support to nongovernment programs are also in DFAS-IN 37-1.

\section{5-6. Advertising for environmental hearing notices}

Events and activities required by environmental laws, such as environmental hearings, will be paid with funds from the environmental program budget.

\section{5-7. Contracted services}

The PA office may contract with commercial firms for services and products. These contracts will be awarded according to applicable laws, regulations, and policies.

\section{5-8. Contracting for Army-Funded video and television production}

a. Centralized visual information contracts. The PAOs may use the Production Acquisition Division (PAD), Army Multimedia and Visual Information Directorate, under the Administrative Assistant to the Secretary of the Army, as a source for establishing multimedia and television production contracts. Using PAD contract offerings may make contracting more efficient, thereby simplifying and centralizing contract management throughout the Army enterprise.

b. Production Acquisition Division. Use of the PAD helps to ensure that all applicable Federal Acquisition Regulation (FAR) required rights and data clauses are included in contracts acquiring multimedia, VI productions, or services to ensure that the Army owns all rights to the productions and master materials. The Army will not be required to pay royalties, recurring license or run-time fees, use tax, or similar additional payments for any production or associated materials developed for the Army.

\section{5-9. Use of military transportation assets}

$a$. Military transportation assets will not be used to compete with commercial carriers of U.S. registry (to include sea, air, or land transportation) if commercial transportation is available, adequate, and meets the PA objectives of the proposed travel.

$b$. Travel or transportation for PA purposes must be primarily in the interest of DA or DoD.

c. No commitment of military transportation for PA purposes will be made until the request has been coordinated and approved by the command with primary interest.

$d$. Orders covering transportation will be issued by the command with primary interest.

e. DoD must approve PA travel or transportation arranged with another federal agency or foreign government.

$f$. Travel to serve humanitarian purposes or increase goodwill does not, by itself, meet the criteria for PA travel.

g. Approval authority to use military carriers for nonlocal community engagement travel by non-DoD persons rests with SECARMY. That authority is delegated to all commanders (in the grade of major general (MG) or above) and CNGB and may not be further delegated.

$h$. Each commander with primary interest may grant approval for local travel or transportation for PA purposes if:

(1) PA impact will be confined primarily to the vicinity of that command.

(2) Transportation is provided for an approved local PA program.

(3) PA subject matter is not properly the responsibility of a higher command.

$i$. Military transportation for media representatives, authors, and writers will be on a space available, nonreimbursable basis.

\section{5-10. Local media travel procedures and approvals}

a. Local travel is travel within the community outreach area of responsibility.

$b$. The commander in whose area the travel occurs may approve local travel for local news media representatives.

c. News media representatives may be authorized travel or transportation in connection with an assignment to cover

Army programs or operations when the travel is an integral part of a story and is provided on a space available basis.

$d$. All local travel or transportation provided for national or international media representatives will be brought to the attention of OCPA.

e. See DoDI 4515.13 for more information on aviation requests and check with respective service requirements for media on other service aircraft. 


\section{5-11. Nonlocal travel procedures and approvals for media}

a. All nonlocal media travel requires DoD approval. PA personnel should review DoD instructions, operation orders, and approved PA guidance as there may be, at any given time, preexisting DoD instructions granting approval to travel that-

(1) Is primarily in the interest of the DoD.

(2) Exists when commercial transportation is not available or is otherwise inadequate to fulfill mission objectives, or an individual is in immediate danger of loss of life, limb, or sight.

(3) Is available on a space available, noninterference basis on previously scheduled flights.

$b$. Nonlocal media travel may be approved under the following conditions:

(1) Travel by military transportation is an integral part of the story or stories being covered by the news media representatives (for example, evacuations, maneuvers, or the movement of troops). In such cases, transportation will be limited to the extent and duration of the assignment requiring travel. Transportation will not be used solely for point-to-point movement.

(2) The proposed news coverage is of a major emergency nature and the coverage will be impaired or delayed to the serious detriment of the Army if military transportation is not provided. A request based on this paragraph will be submitted by the fastest means, including telephone, directly to OCPA Media Relations Division. Intervening headquarters will be notified subsequently.

(3) The travel is a matter of special interest to the Army or the command involved and is a part of an approved PA project.

c. Approval procedures for nonlocal travel requests are as follows:

(1) Forward requests for nonlocal travel through command channels to OCPA Media Relations Division.

(2) Ensure that the requests contain the dates of travel, destinations, justification, and a point of contact who will-

(a) Be familiar with all regulations and directives on such travel for all services.

(b) Ensure that the military and civilian news media representatives are properly briefed on the purpose of the travel and on appropriate security matters.

(c) Ensure that news media representatives are briefed on passport, visa, immunization, and other requirements.

(d) Ensure that news media representatives have proper protective gear, if required.

(e) Submit a news roll-up to include news media clippings or summaries of radio and television coverage resulting from the travel through channels to OCPA following the event.

$d$. PAOs are not required to accompany media representatives on nonlocal travel.

\section{5-12. Special travel categories}

a. State adjutants general approve PA travel within their respective states. NGB-PA office approves local travel to facilities outside their states or territories. Other media travel involving ARNG units requires DoD approval.

$b$. Air transportation procedures for Members of Congress and their staffs are in AR 1-20.

\section{5-13. Use of Army aircraft for nonmedia public affairs travel}

$a$. The following are examples of PA activities that may qualify for travel in Army-owned or -controlled aircraft:

(1) Invitational and other authorized travel or transportation to support approved PA activities. This includes tours and conferences sponsored by DA and DoD.

(2) Tours and other PA activities arranged jointly with another federal agency or with a foreign government.

(3) Authors and writers covering approved Army programs or stories when the travel is an integral part of the story is provided on a space available basis.

(4) Guests of the Secretary of Defense or SECARMY participating in official programs, such as Joint Civilian Orientation Conference (JCOC).

$b$. Approval may not be provided under this regulation for-

(1) An aircraft flight during which a record attempt is made.

(2) A first flight on an aircraft just entering the inventory.

(3) A first flight over an isolated geographical area.

(4) Any other flight of a similar or special nature where abnormal conditions may exist.

c. Army aviation assets are not used to transport persons costumed as Santa Claus, Easter bunnies, witches, or any other holiday-related character whether the person is military or civilian on or off a military installation.

$d$. The purpose of orientation flights to support community engagement is to improve understanding of the Army mission.

(1) Such flights may be provided only in suitable passenger-carrying aircraft.

(2) Travelers must wear proper organizational uniforms, if applicable, and must present proper identification. 
(3) Written parental consent is required for passengers 18 years of age or under.

(4) Orientation flights will normally originate from an installation or agency and terminate at the point of origin or a point nearby. Commanders of ACOMs, ASCCs, and DRUs may grant exceptions on a case-by-case basis.

\section{Chapter 6 Media Coverage}

\section{6-1. Facilitating media visits}

Facilitation of news media representatives is a PA function. An active media relations program is an essential part of the commander's PA program and communication strategy. PA staff should build and maintain positive professional relationships with news media representatives. News reporters manage key channels that PA must leverage to communicate with American and international audiences and maintain public confidence in the command and the Army.

$a$. Media representatives may visit exercises, deployments, activities, or areas of an installation normally open to the public continental United States (CONUS) and outside the continental United States (OCONUS) to cover subjects of local interest or news events without prior planning when the information is releasable under existing regulations. Media representatives like the rest of the public are restricted from areas where access must be controlled for OPSEC, Privacy Act, criminal justice, or other security concerns. Senior commanders will cooperate in a timely manner with bona fide media representatives who request permission to visit an Army installation. OCPA may assume release authority for controversial topics or subjects of national interest.

$b$. Local procedures will be developed to facilitate news media personnel during disaster and civil disturbance conditions.

c. Commanders will establish basic ground rules that ensure the free flow of information while safeguarding classified materials, operational plans, and other sensitive information.

$d$. Media representatives are responsible for adhering to ground rules established by the commander. Those media representatives who violate the ground rules will risk losing credentials and future access to the installation.

e. Sometimes sensitive information is accidentally revealed to a media representative in the course of covering a story. When this happens, the PA representative will explain that the piece of information is sensitive or classified and request that the media representative does not publish that piece of information. This discussion takes care of the issue in the vast majority of incidents. When a media representative refuses to cooperate, the PA representative will report the incident to the commander. The commander has the option to notify the media representative's supervisor, cancel the credential, or direct the military police to escort the media representative off of the installation.

$f$. Commanders and PA staff are permitted to share or comment on media coverage specific to their unit on unit social media channels, but not to the media organization's website.

\section{6-2. News media accreditation}

$a$. Accreditation is defined as a means of validating credentials of media representatives. Accreditation does not provide media representatives with special privileges.

$b$. Commanders may supplement accreditation systems for media in connection with covering a specific event. However, accreditation will not be made cumbersome, overly extensive, or obtrusive for the purposes of making coverage of an event difficult.

c. Stars and Stripes reporters will be treated as civilian news media in every regard, to include credentials as civilian news media representatives (see DoDD 5122.11).

\section{6-3. Official discussions with the media}

Army personnel at all echelons are encouraged to speak with the media candidly about unclassified matters on which they have personal knowledge and expertise. Senior commanders and staff officers are expected to discuss military matters within their purview with media representatives. PAOs will seek out experts to brief the media in support of media queries or request for further information.

\section{6-4. Unofficial discussions}

Army personnel at all echelons may agree to a media request for an interview in an unofficial capacity and may express personal opinions unless limited by law or regulation. Army personnel are still required to inform their PA office that the interview occurred or will occur. They should discuss candidly matters about which they have personal knowledge if the information is unclassified and releasable. When questioned on policy, classified matters, or anything outside their scope of knowledge they will state they cannot speak for the Army or DoD and refer the media representative to 
the command PA office. When speaking in an unofficial capacity as an individual, Soldiers will not be in uniform, except as appropriately authorized by AR 670-1.

\section{6-5. Photographing and recording personnel in a hostile area}

Common sense, good taste, and awareness of safety and security concerns are used when authorizing media access to operational locations. PAO will encourage media compliance with official release proprieties specific to the local command. If a photographer persists in taking photographs related to their story or coverage, the PAO should not take any action to recover the recording medium, but will immediately report the problem through PA channels to higher headquarters.

\section{6-6. Media coverage of equipment testing and evaluation}

Media coverage of developmental, technological validation, or operational testing and evaluation of Army systems is prohibited.

\section{6-7. Media coverage of battle labs and advanced warfighting experiments}

All media coverage of Army battle labs and Army warfighting experiments requires OCPA approval.

\section{Chapter 7 \\ Public Communication}

\section{7-1. Release of official information}

DoDI 5230.29 requires any official information intended for public release that pertains to military matters, national security issues, or subjects of significant concern to DoD be cleared by appropriate security review and PA offices prior to release. This includes materials placed on the internet or released via similar electronic media. All Soldiers, DA Civilians, and contractors who publish, administer, or moderate information or documents on the public domain for official purposes will complete Army OPSEC Training for External Official Presences online training.

\section{7-2. Impartial and objective dissemination}

Information about the United States and its allies will be disseminated impartially and objectively.

\section{7-3. Crisis communication}

A crisis is any sudden, unpredictable incident or situation involving a threat to the United States, its citizens, military forces, or vital interests that has the potential to negatively impact the mission, relationships, and reputation with stakeholders, partners, employees, and the public. Crisis situations develop rapidly, have the ability to affect longterm public opinion and trust in an organization, and have the potential to create conditions of diplomatic, economic, or military importance.

$a$. The commander is ultimately responsible for crisis communication. The PAO is the commander's agent for crisis communication planning and execution. Timeliness is critical during a crisis; commanders should mitigate withholding information and release what is known as soon as possible. PA and SJA must work closely on crisis communication efforts to determine the legality of releasing information available during the crisis.

$b$. As a member of any crisis mitigation team, the PAO is responsible for helping to mitigate public issues before they become crises by providing timely and accurate public information releases and providing informed counsel to commanders. The PAO should create crisis communication plans.

c. If the crisis involves a felony crime, after immediate public safety concerns are addressed, coordination for any investigative-type release of information must be coordinated with U.S. Army Criminal Investigation Command (USACIC) and OCPA.

\section{7-4. Personal privacy}

The Privacy Act of 1974 (5 USC 552a), implemented by AR 25-22, generally prohibits publicly releasing certain items of information about an individual without that individual's consent. All Army personnel and releases will comply with these prohibitions. 


\section{7-5. Health information security}

Public Law (PL) 104-191, implemented by DoDM 6025.18 and DoDI 8580.02, generally prohibits publicly releasing certain items of information about an individual without that individual's consent. All Army personnel and releases will comply with these prohibitions.

\section{7-6. Authority to release information}

a. Department of Defense. Office of the Secretary of Defense (OSD) normally releases general military information on the overall plans, policies, programs, or operations of DoD, DA, or Federal Government. State adjutant generals should be referenced as the release authority for state information. Questionable cases will be submitted to OSD for clearance. Prior unofficial publication of information does not constitute authority for an official release. Information that meets any of the criteria below will simultaneously be coordinated and submitted to OCPA Media Relations Division for OSD clearance prior to release-

(1) Information that originates from, or is proposed for, release at the seat of government.

(2) Information that is or has the potential to become an item of national interest or international interest.

(3) Information and public statements with foreign policy or foreign relations implications.

(4) Information and public statements concerning high-level military or DoD policy.

(5) Information concerning U.S. Government policy or policy within the purview of other Government agencies.

(6) Information regarding casualties for release by OSD.

(7) Information on subjects of potential controversy among the military services or with other federal agencies.

(8) Initial information on new weapons, weapon systems, significant modifications, or improvements to existing weapon systems, equipment, or techniques.

(9) Information on significant military operations, potential operations, and military exercises.

(10) Information on military applications and operations in space.

(11) Information on weapons of mass destruction (including nuclear weapons) and the components of weapons including:

(a) Nuclear weapons effects research.

(b) Chemical warfare and defensive biological and toxic research.

(c) High-energy lasers and particle beams technology.

(d) Chemical, biological, radiological, nuclear, and high yield explosives defense testing and production, policies, programs, and activities.

(12) Information on National Command Authorities and National Command Authority command posts.

(13) Information and materials, including submissions by defense contractors, involving critical military technology.

(14) Information concerning communications security, electronic warfare, signal intelligence, and computer security.

(15) Initial announcement of general officer assignments.

(16) Initial announcement of awarded Army contracts will be made in accordance with the applicable provisions of the FAR, the Defense Federal Acquisition Regulation Supplement (DFARS), and the Army Federal Acquisition Regulation Supplement (AFARS).

(17) Lists of names or duty addresses of military personnel assigned to units that are sensitive, routinely deployed, or stationed in a foreign territory (see app D).

(18) Casualty information on key U.S. Government personnel or equivalent foreign government personnel (see para 7-11).

(19) Information on activation, inactivation, or reorganization of Army brigade or larger units.

(20) Information on DoD counterterrorist activities as defined by DoD policy.

b. Headquarters, Department of the Army.

(1) OCPA has authority to release information about the Army as a whole. Such information is normally obtained from the ARSTAF agency having primary interest and is cleared, as necessary, with OSD and the Secretariat. ARSTAF agencies with technical liaison officers or PAOs may respond directly to requests for routine information.

(2) OCPA will coordinate with Office of the Chief of Legislative Liaison (OCLL), other DA staff agencies as appropriate, and ATSD (PA) on all replies to congressional inquiries, requests, or other transmittals of information, which may have significant PA implications prior to such information being forwarded to Congress by OCLL.

(3) Interviews and press conferences at the Pentagon will be coordinated with OCPA. These events will be monitored by the PAO or by the PA liaison officer of the ARSTAF agency concerned.

c. Commands below Headquarters, Department of the Army level. 
(1) Commanders below HQDA level are authorized to release information that is wholly within the mission and scope of their commands and is not restricted by the provisions of paragraphs 7-6a and 7-6b. Normally, such information is submitted to the appropriate PAO who will prepare material for release and conduct a security review as required. The PAO will either obtain clearance from the commander or forward the information to the appropriate headquarters for clearance. Local commanders have maximum flexibility in releasing information.

(2) Commanders below HQDA level will inform OCPA directly while simultaneously coordinating through command channels when national news media requests have been received. National media are defined as network television (to include local affiliates if national interest is likely), national news magazines, and metropolitan newspapers with national distribution, or digital media of significant interest.

(3) In a deployed environment, Army elements will also adhere to guidance from other higher level headquarters, such as combatant commanders or North Atlantic Treaty Organization (NATO), before releasing information.

(4) If a crisis or emerging event occurs in an area of PA responsibility, the first PAO contacted or on the scene will coordinate with the next higher headquarters to define PA responsibilities and proper release authority to ensure appropriate information is released as quickly as possible.

(5) When DoD is supporting other federal agencies, such as Federal Emergency Management Agency (FEMA), Federal Bureau of Investigation, Department of Homeland Security (DHS), or Department of Interior on issues not pertaining to ongoing criminal investigations, PAOs will use the operational chain of command and the PA channels of the supported agencies to coordinate visits, media opportunities, and information release.

(6) Releasing military intelligence and intelligence related information, such as photographs, video, and audio, must be authorized by INSCOM or the appropriate intelligence authorities.

(7) Releasing operational information on all ARSOFs will be coordinated with USASOC.

(8) Releasing felony-related criminal investigative information, including photographs, video, audio, and crime scene information or reports, must be coordinated with and authorized by USACIC.

(9) When PAOs are considering releasing information regarding training and movement of their units, they should also coordinate with the PAO responsible for the area to which those units may be deploying. For instance, a PAO for a CONUS-based unit deploying OCONUS for training would coordinate with the OCONUS PAO, whose command would be the release authority for any unit activities in theater.

(10) The OCONUS PAOs may be NATO or other allied country PAOs depending on the operation and unit mission. PAOs should also coordinate with the State Department before releasing any information on unit activities that are in support of another nation, whether or not that nation's military is involved. For instance, there may be State Department consideration to account for before releasing information about U.S. forces supporting humanitarian operations in other countries.

\section{7-7. Safeguarding information}

a. Safeguarded information will not be discussed, shown, or made available to unauthorized individuals. All Army personnel must be aware of and support the Army's OPSEC program. Information, materials, or records must be reviewed for OPSEC considerations in accordance with AR 530-1 prior to public release. The staff office or agency providing the information, materials, or records to the PA office for release should accomplish OPSEC reviews.

$b$. Additionally, releasable information must be accurate and must adhere to published DoD and Army policies.

\section{7-8. Release of Army records}

a. Army records will only be released when approved by the appropriate authority, in accordance with AR 25-22 and AR 25-55. Officials who release Army records will inform their PAO if the records contain controversial information. PAOs will then notify their commanders and OCPA.

$b$. If a record would be released if requested under FOIA, then it should be released to media representatives if requested through PA channels. This precludes invoking FOIA and provides timely information to the public (see AR 25-55).

\section{7-9. Missing in action or duty status whereabouts unknown}

All information released will be in accordance with DoDI 1300.18.

\section{7-10. Military accidents}

$a$. Consistent with national security, military authorities will give maximum cooperation to U.S. news representatives covering military accidents occurring outside military installations. This does not apply to accidents or incidents involving chemical, biological, radiological, nuclear, and high yield explosives weapons or research or to military 
accidents occurring OCONUS, U.S. territories, or possessions. Guidance for these circumstances is given in treaties, international agreements, and laws of other nations in coordination with respective combatant commands (COCOMs).

$b$. Civilian law enforcement and emergency response agencies may be on the scene before the military. Commanders or activities will coordinate and plan with agencies before an incident. Commanders will advise the agencies that they may be called upon for assistance and cooperation when military accidents occur in their areas and advise them of the provisions of 18 USC 793(d), 18 USC 793(e), 18 USC 795, and 18 USC 797. These USC sections make it unlawful to photograph, publish, or refuse to surrender classified information.

\section{7-11. Release of accidents involving military personnel or equipment}

Public release of information on injured or deceased personnel (including names) will be made as soon as possible, within Privacy Act constraints, after coordination with OCPA and HQDA and confirmation from the local casualty assistance officer that the next of kin have been officially notified. Combat related accidents will be released by OSD.

$a$. When circumstances permit, one-story, single-release coverage of accidents or incidents is preferred. Normally, information released will be as follows:

(1) Announcement that an accident or incident occurred.

(2) Location and time of the accident or incident.

(3) Names, city, and state of injured will be withheld until consent has been given by injured or next of kin have been officially notified.

(4) Names, city, and state of deceased will be withheld until 24 hours after next of kin notification.

(5) Before official findings are available, state, "An investigation is being conducted to determine the cause."

(6) To remove or lessen the anxiety of other personnel on the installation, names should be released as soon as possible.

$b$. For this regulation, a civilian aircraft under military charter is considered a military aircraft and information concerning casualties will be released accordingly.

$c$. When accidents involving civilian or military vehicles, trains, commercial or private airplanes, or when any other types of accidents occur outside Army installations (whether overseas or within CONUS), the PAO nearest the scene will coordinate with local law enforcement officials, representatives of transportation companies (if applicable), and Army casualty personnel to ensure that the next of kin are notified prior to public release of names and addresses of military personnel.

$d$. If additional personal information is requested from news media representatives on deceased, injured, or missing Soldiers, it must be approved by the Service member or next of kin.

$e$. Because of national and international interest and implications, casualty information on key U.S. Government personnel or equivalently ranked foreign government visitors killed, injured, or listed as missing while on a military installation or while being transported by military vehicle will be released at the following levels:

(1) White House Press Secretary has sole approval authority for release of news about the following:

(a) President of the United States.

(b) Vice President of the United States.

(c) Speaker of the House of Representatives.

(d) President Pro Tempore of the Senate.

(e) Members of the Cabinet.

( $f$ ) Foreign visitors of political or royal rank equivalent to the above listed U.S. Government officials.

(g) Members of foreign governments below the rank cited in paragraphs 7-11e(1)(a) through 7-11e(1)(f), when guests of the United States.

(h) Chiefs of foreign military services below the rank cited in paragraphs 7-11e(1)(a) through 7-11e(1)(f), when guests of the United States.

(2) The ATSD (PA) will approve the release of news about the following:

(a) United States Senators.

(b) United States Representatives.

(c) Secretaries of the military departments.

(d) Chairman, Joint Chiefs of Staff.

(e) Chief of Staff, U.S. Army.

(f) Chief of Naval Operations.

(g) Chief of Staff, U.S. Air Force.

(h) Commandant, U.S. Marine Corps.

(i) Commanders, unified and specified commands. 
(3) The commander concerned will handle information on accidents involving military or civilian personnel designated as special interest according to AR 638-8 (for example, general officers, general officer designees, selected commanders, and civilians of comparable status) and visiting foreign students and officers. If possible, OCPA duty officer will be informed of the accident prior to release of any information.

(4) Local PAOs are authorized to release follow-up information in response to press queries about named individuals. OCPA should be immediately notified through proper channels.

(5) Accidents occurring OCONUS require additional coordination with U.S. Embassy or consulate personnel to ensure proper notification of the host government.

(6) Names of special operations personnel will be coordinated with USASOC prior to release.

$f$. Information resulting from official investigations regarding line-of-duty status or findings of misconduct by individuals will not be released to the public without the approval of Adjutant General, HQDA for USAR or retired Army members, or HQDA for Regular Army members.

\section{7-12. Personnel under treatment in Army medical facilities}

a. Information about patients under treatment in Army medical facilities will be released only in accordance with FOIA, Privacy Act of 1974, and PL 104-191. Biographical data, other than that releasable under AR 25-22, as well as protected health information, and any descriptions of the patient's specific condition, will not be released without the prior consent of the individual or, if the individual is unable to function for him or herself, by his or her representative. The consent will be recorded on DA Form 4876 (Request and Release of Medical Information to Communications Media).

$b$. Authority to release information on personnel from other military services or Government agencies under treatment or hospitalized in an Army medical facility, rests with the other service or agency. Army PAOs will assume such responsibility upon the official request of the other service or agency concerned and in accordance with the policies of AR 25-55, AR 25-22, and paragraph 7-12a.

c. Permission to photograph or record a patient in an Army medical facility will be given only when prior informed written consent of the patient has been obtained. In addition, the attending physician or medical facility commander must determine that such activity will not jeopardize the condition or welfare of the patient or nearby patients. Photographing a patient will be prohibited when it infringes on the patient's right to privacy or causes embarrassment. Photographing patients must always meet accepted standards of propriety.

$d$. Releasing information about or permitting interviews with psychiatric or other mental health patients is prohibited.

\section{7-13. Personnel participating in alcohol and drug abuse control programs}

Public release of information regarding personnel who are or were participating in alcohol and drug abuse control programs is prohibited.

\section{7-14. U.S. Army Criminal Investigation Command personnel or activities}

Public release of information about USACIC personnel, activities, governing regulations or investigations must be coordinated in advance with OCPA and USACIC.

\section{7-15. Release of criminal investigations}

Generally, no information should be released concerning ongoing investigations without close coordination with appropriate law enforcement agencies. PAO may acknowledge the existence of an investigation after coordination has been made, however, released information cannot violate the Privacy Act or impede an ongoing criminal investigation.

\section{7-16. Coverage of courts-martial}

In court-martial cases, the judge is the final approval authority on whether news media representatives may attend, photograph, video, use social media, or in any other way record or disseminate information about court-martial proceedings. Approving news media requests to photograph or video record a trial by court-martial will be guided by the following, unless more restrictive measures are necessary to ensure a fair trial:

$a$. Photographing or video recording the courtroom interior may be permitted when persons involved in the proceedings are not present.

$b$. During the trial, photographing or video recording the accused may be permitted when outdoors in public view. Photographing or video recording the accused in a courtroom, cell, cellblock, prison yard, or similar area or in the presence of other prisoners is not permitted. 
c. PAO will coordinate a means to accommodate media coverage to include courtroom pool reporting and a separate media center near the courtroom.

\section{7-17. Litigation and debarment cases}

A close liaison with Office of the General Counsel or SJA concerned must be maintained to preclude the premature release of information about litigation or debarment cases.

a. Litigation. As discussed in AR 27-40, matters in litigation or with the potential for litigation will not be discussed unless the information is a matter of public record. The PAO and SJA will coordinate and execute responses to queries.

b. Debarments. PA offices will not release information about debarment of a company holding a Government contract prior to consultation with the SJA Office and judge advocate confirmation of a final decision. In the interim, PAOs may acknowledge that a specific company has been proposed for debarment. The PAO will refer media without comment to the contractor when questions arise about the basis for the case or the status of the proceedings.

\section{7-18. Inspector general activities}

Inspector general (IG) records are privileged documents and contain sensitive information and advice. All IG records, including USAR IG records and ARNGUS IG records concerning federal matters, are the property of SECARMY. IGs maintain these records on behalf of SECARMY. Unauthorized use or release of IG records can seriously compromise IG effectiveness as a trusted advisor to the commander or state adjutant general and may breach IG confidentiality. IG is the designated release authority for all IG records (see AR 20-1).

\section{7-19. Release of information on units}

a. Unit deployments. DoD will provide the initial public release for deployments of units at the brigade combat team level and above. OCPA will coordinate with OCLL to ensure congressional notification occurs prior to an official announcement. Commanders will make every effort to notify Families and coordinate congressional notification through OCLL prior to the initial announcement. OPSEC should always be considered when releasing information on units (see fig 7-1). Separate units below the brigade combat team level, whose deployments are not announced by DoD or OCPA, may make a public announcement following receipt of deployment orders and Family notification.

b. Unit activations, inactivations, and reorganizations. Normally, the initial release of information on activations, inactivations, and reorganizations of Regular Army units of brigade or larger size will be made at HQDA level through OSD. Activations, inactivations, or reorganizations of smaller Regular Army units may be announced by ASCC, ACOM, or DRU concerned, except when such actions involve one or more of the criteria in paragraph 7-6. In such instances, an initial public announcement will be made at HQDA, through OSD, for units smaller than brigade size as well. Regardless of units involved, initial public release will not be made at any level until authorized by DCS, G-3/5/7 and following the release of the information for Members of Congress, as applicable. Provisions of this paragraph do not apply to announcements of such actions for RC units (see AR 5-10).

(1) Safeguarded information contained in paragraphs 7-19b(1) through 7-19b(3) is generally not releasable, except as provided in paragraph $7-19 c$, in any phase of unit activations, inactivations, redesignations, reorganizations, training, or movements within CONUS or OCONUS.

(a) Exact personnel strength and composition of units.

(b) Status, amounts, or quality of equipment.

(c) Combat efficiency.

(d) Deployment of units to combat areas.

(2) When an activation, inactivation, redesignation, or reorganization involves a RC unit, information will be released as follows:

(a) U.S. Army Reserve units. ARHQ-FB will release information listed in paragraphs 7-19b(1) through 7-19b(3) about the local unit.

(b) Army National Guard units. The CNGB will ensure that the National Guard Bureau notifies the unit concerned. The CNGB will ensure that when such notification has been received, the state adjutant general concerned understands that he or she may release information listed in paragraphs 7-19b(1) through 7-19b(3) about the local unit.

(3) When an activation or restationing involves another nation, HQDA level coordination will be conducted with the ASCC, COCOM, U.S. Embassy PA teams and the appropriate host nation authority.

c. Installation activation, inactivation, or realignment, facilities, or activities and associated personnel reductions. Accurate and timely information, consistent with security and the policies of AR 5-10, will be released to the public when the decision has been made to activate, inactivate, or realign an installation, facility, or activity, and associated personnel reductions. Criteria for initial announcements of such actions are made at HQDA level through 
OSD when the action requires prior notification of Congress, as specified in AR 5-10, because of military or civilian personnel reductions, which will go into effect either in the near-term or by attrition over an 18- to 36-month period; involves reductions in Government personnel as a result of commercial activity actions; involves accessing Government installations or facilities; has generated congressional or public interest; or has been a subject of public controversy during the decision-making process.

(1) The criteria are flexible and OCPA may make exceptions as to the level at which initial public announcements will be issued. The commands concerned will be notified when such exceptions are to be made.

(2) OCPA will issue guidance to the commands concerned prior to the scheduled announcement date for actions discussed in paragraph 7-19a.

(3) Army personnel will avoid making statements that can be interpreted as official and may invite speculation about possible inactivations, realignments, strength reductions, or weakness in readiness and capabilities.

(4) Commanders will provide a mechanism to the public to provide feedback to the command on installation, unit, or personnel realignments.

d. Training and movement of units. Information on unit training or movement that is not safeguarded or restricted by paragraph 7-7 or other provisions of this regulation may be released by the responsible commander, except in the cases of major or joint exercises. Initial release of information on major Army exercises will be made at HQDA through OSD. Initial release of information on major joint exercises will be made by OSD with later announcements by the joint commander. 


\section{Current Deployment Announcement Process}

1.

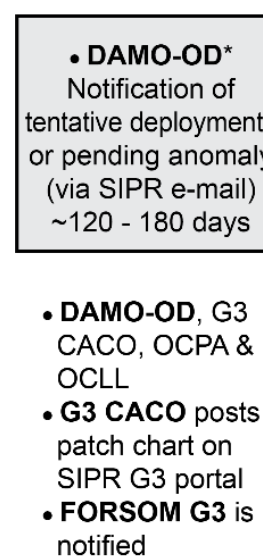

2.

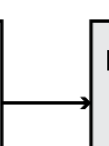

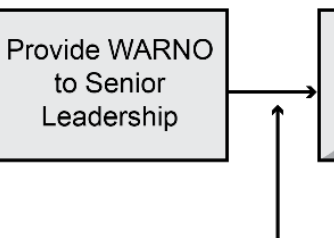

- OSD-PA announces

by exception

- OCPA request

Commander quotes

(BCT and above)

- FORSCOM

coordinate with units

on local release (BN

and below)

- NGB/OCAR

coordinate with States/

units on local release
3.

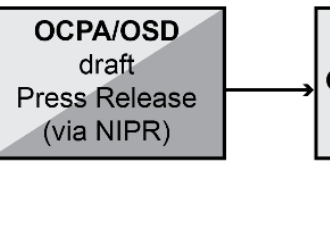

- OCLL drafts announcement timeline \&

Members to be notified

- OCPA drafts press

release

- AO staffing with

OSD-PA
4.

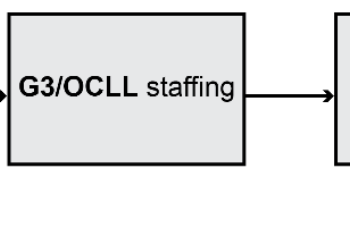

- Staff draft Press

Release/IMC w/

Form 5 with:

- OCLL

- OCPA

- DAMO-OD

- G1

- SAFM-BUL

- OGC

- NGB / OCAR if

applicable
5.

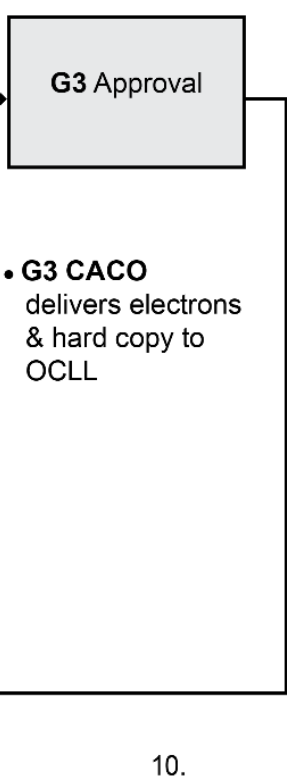

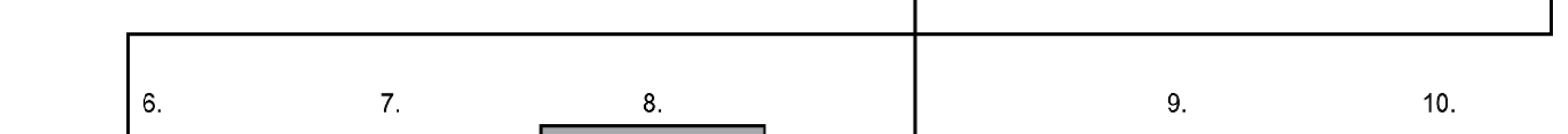

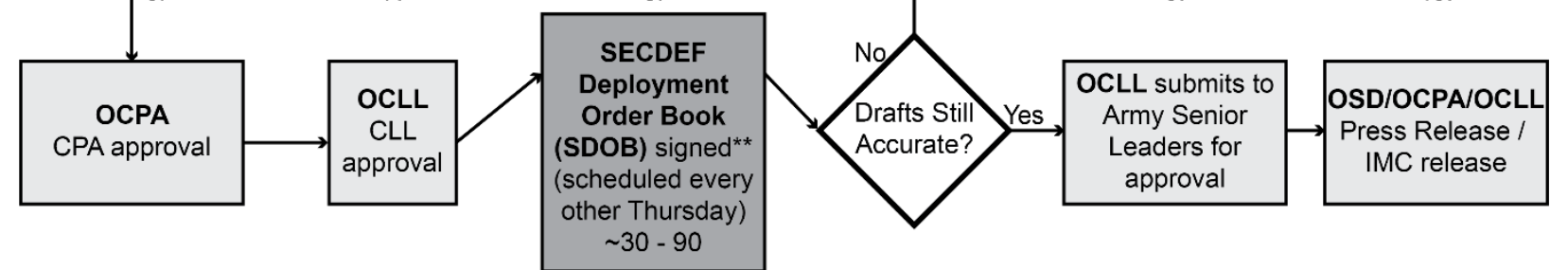

Bold type indicates ownership of action
- Joint Staff - PA notifies OCPA via SIPR
- OSD-PA announces
by exception
- FORSCOM coordinate with units on local
release (BN and below)
- NGB/OCAR coordinate
with States/units on

local release
- OCPA

- DAMO-OD

- OCLL

Figure 7-1. Current Deployment Announcement Process

\section{7-20. Photographing military installations or equipment}

a. Public access to Army installations is determined by local commands. Photographing historical buildings or areas of public interest for private use is generally permitted, but also subject to approval by the local command.

$b$. Ground or aerial photographs, sketches, or graphic representations of classified military equipment or installations designated as restricted areas are punishable by law (18 USC 795). Reproducing, publishing, or selling this type of material is also punishable by law unless the photograph, sketch, or graphic representation indicates it has been reviewed and cleared for release by proper authorities.

7-21. Releases about foreign military personnel attending U.S. Army schools

Coordinate interview requests with the proper country's senior officer in residence for approval. 


\section{7-22. Release of Army studies}

Premature release of emerging results of Army studies and analyses before official approval is prohibited.

\section{7-23. Release of information by manufacturers, research organizations, educational institutions, and other commercial entities holding Army contracts}

$a$. Army policy is to make available to the public the maximum accurate information on Army contractual relationships, industry accomplishments, and scientific achievements. Exceptions to this policy include-

(1) Safeguarded information, as well as data, that offers unfair and competitive advantages to specific entities and individuals.

(2) Nonexportable commercial information or data and information subject to international traffic in arms control.

(3) Information about materiel in the Militarily Critical Technologies List. This list is available in military contracting and research and development offices.

$b$. PAOs will not release or authorize release of material that contains implied DA endorsement of a commercial firm, product, or service; comparison of the merits of one item of military materiel with another; DoD specification details or results of acceptance tests; or information involving critical military technology.

c. Public release clearance at the lowest level of responsibility is authorized and encouraged. When higher headquarters release is required, or when a question exists on release authority, PAOs will send the proposed release material and a recommendation to OCPA to coordinate clearance within HQDA and with OSD.

$d$. Procedures for reviewing and clearing material are in appendix E.

\section{7-24. Community outreach}

Community outreach is defined as those PA activities that support the relationship between military and civilian communities. Outreach and engagement with the public is a command PA function. Viewing communication as a social process of dialogue and interaction among people versus a technical process of delivering a message to a specific audience, the PA team proactively facilitates communication with American and international publics (including key leaders) in all OEs at home and abroad.

\section{7-25. Activities to support community outreach}

a. Policies for planning and conducting Army PA activities, evaluating requests for access to military facilities, and Army participation in public events are based on public law, Executive orders, DoD directives and DA regulations.

$b$. Army PA in coordination with the SJA will leverage every means possible to foster and sustain good relations with veteran and military service organizations and nonprofit nonfederal entities requesting event support, access, available space, and certain logistical support under guidance set forth in 10 USC 2670 and 10 USC 2667 and current DoD directives and instructions.

c. Strict adherence to this regulation and ethics rules in 5 CFR 2635 and DoD 5500.07-R and sound judgment serve to enhance public support and confidence in the Army.

$d$. Official Army participation in any public event may be authorized only if admission, seating, and all other accommodations connected with the event are available to all Service members and afford them equal opportunity in an environment free from harassment and unlawful discrimination. Installation activities and, when possible, off-installation activities must be open to all military personnel and their Families to the fullest extent permitted by law and DoD policy. (See AR 600-20 for additional guidance on extremist organizations and activities.)

e. Support to public events must primarily or mutually benefit DA and conform to the following conditions:

(1) The support cannot interfere with official duty performance and will not detract from operational, training, or other readiness requirements.

(2) No additional fee may be charged specifically to observe Army participation. A general admission fee does not necessarily preclude Army participation in an event, if such participation is incidental to the event and other proper criteria have been met.

(3) Other statutes or regulations do not restrict Army participation. (See DoD 5500.07-R and AR 600-29 for additional guidance on fundraising and membership drives.) Questions on these matters should be referred to the local SJA.

\section{7-26. Department of Defense-coordinated activities}

When military participation at certain public events occur and more than one service is involved, the ATSD (PA) may appoint a DoD representative to coordinate the event for all services. When a DoD coordinator is appointed, Army participation will be coordinated in advance through channels with OCPA. Participation may include bands, color guards, marching units, drill teams, and equipment displays. This policy does not apply to U.S. Army Military District 
of Washington (MDW) when it acts as DoD coordinator for events in the National Capital Region. Any coordinated OCONUS activity must be processed through the respective COCOM.

\section{7-27. Use of military assets for public affairs}

a. Army commanders at all levels are encouraged to provide Army marching units, bands, color guards, drill teams, ceremonial units, other personnel formations or units, aerial demonstrations, static displays, exhibits, and similar support to events and activities conducted in the public domain. Such units will be used to maximize the number of public events that can be supported (see AR 220-90).

$b$. Requests for support that require DoD or DA approval will be forwarded through command channels to OCPA. For ARNG units, requests should be sent to NGB-PA.

c. Requests from local event sponsors will be submitted using a DD Form 2535 (Request for Military Aerial Support) or DD Form 2536 (Request for Armed Forces Participation in Public Events (Non-Aviation)) to the nearest military installation and forwarded, if required, through command channels to the appropriate approval authority with local command recommendations.

$d$. ASCC commanders with troops assigned temporary duty or deployed in foreign locations may authorize nonaerial participation by personnel and equipment for public activities deemed necessary for host nation relations. Such activities will use resources under the operational control of the theater commander or with the concurrence of the parent command.

\section{7-28. Authorized Army musical, ceremonial, and troop asset support participation}

Army musical, ceremonial, and troop unit support participation is authorized for-

$a$. Official military functions whether on or off military installations.

$b$. Official civil ceremonies and functions sponsored and conducted by Federal, State, county, and municipal governments. This includes those conducted in overseas areas with corresponding authorities of the host nation and the U.S. Embassy. Official civil ceremonies include inaugurals, dedications of public buildings and projects, ceremonies for officially invited governmental visitors, and the convening of legislative bodies.

c. Civilian-sponsored public events such as parades, rallies, and concerts intended to stimulate interest in the Armed Forces, support the Army recruiting mission, stimulate patriotism, or celebrate a U.S. national holiday.

$d$. Civilian-sponsored social, civic, and cultural events such as, but not limited to, community concerts, banquets, dinners, receptions, carnivals, festivals, sports season openings, and commemorations, if the musical participation includes patriotic music as opposed to pure entertainment and clearly establishes the support as an appearance by an Army unit. The patriotic portion of an Army presentation normally consists of military or patriotic songs, honors, or music to accompany the presentation of the colors.

$e$. An event that is a traditional military event is intended to foster the morale and welfare of members of the Army and their Families. This would include such events as military balls, dining-ins, mess nights, in accordance with 10 USC 974.

$f$. Sports events or games, when possible, to provide maximum support to recruiting programs. Requests are authorized under the following conditions:

(1) The game is a scheduled regular season event in which a military team competes and when such participation is in the best interests of the Army.

(2) The game is an amateur regular season event, even though admission is charged, and neither of the competing teams is military. Army support must be incidental to the event and in the best interest of DA (see the glossary for the definition of incidental support). In addition, the event must be local or regional.

(3) Local commanders may authorize color guards and Army musical units to participate in pregame activities at professional sports events following the submission of a DD Form 2536 by the requesting organization.

g. Activities in shopping centers and malls to support recruiting. Local commanders must authorize such participation. The following guidelines must be met:

(1) All musicians must be in uniform which clearly identifies them as Army musicians.

(2) Community engagement support must not be advertised or presented as a promotion for the shopping center or mall, or for special business activities, such as promotional sales.

(3) The primary purpose of the musical activity must be to gain attention and attract visitors to the recruiting display.

(4) The relationship between the location or event and the band members will not impact unfavorably on the Army, and such appearance is not otherwise contrary to this regulation.

h. OCONUS ASCC commanders may authorize color guards and Army musical unit participation in foreign public events such as parades and concerts when deemed in the best interest of the United States. Such activities must have 
the concurrence of appropriate U.S. State Department representatives and must be coordinated with the geographical COCOM PA office.

$i$. The duration of Army band and musician participation will normally not exceed three days per event. This is to ensure proper use of Army personnel and resources.

j. See AR 220-90 for additional policy guidance on participation by Army bands in public events.

\section{7-29. Prohibited participation}

$a$. Army musicians on official duty are prohibited from providing background, dinner, or dance music at events funded solely by nonappropriated funds. As an exception, background, dinner, and dance music is permitted at an event sponsored by a military welfare society identified in 10 USC 2566. Per ATSD (PA) guidance, performances are restricted to events that do not receive support or donations from prohibited sources and the event is held only for Service members and their immediate Families. Military musical events are prohibited from performing at events sponsored by a military welfare society when solicitation is not limited to the historical "by our own, from our own, for our own” premise. The sponsor's charter or objective will not be grounds for an exception.

$b$. Army bands and musicians on official duty are prohibited from receiving remuneration for furnishing music away from an installation in competition with local civilian musicians.

c. Unless specifically authorized by law or by DoDD or DoDI, an Army band, band member, or Army per-former may not receive pay in any form for an official performance of duty in support of public events.

$d$. Generally, off-duty Army officers, warrant officers, and enlisted personnel are not barred from receiving pay for performing music outside the limits of a military installation, unless a complaint is received and verified by subsequent investigation that they are competing with local civilian musicians. Once a complaint has been received and verified, the person may not return to that specific place of employment. Complaints of competing with local civilian musicians will be verified by facts on a case-by-case basis.

$e$. All Army band personnel are subject to the provisions of 10 USC 974 and DoD 5500.07-R, this regulation, and other local regulations governing off-duty employment.

$f$. Army participation and support is not authorized for the following:

(1) Motion picture premieres or regular movie presentations, fashion shows, golf tournament pin holders, or similar events sponsored or conducted solely for commercial interests.

(2) Parades sponsored solely to support commercial or promotional aspects of a holiday or event. Participating in a parade sponsored by the community as a whole may be authorized if the orientation of the parade is civic or patriotic rather than commercial. Regardless of sponsorship, certain events, such as holiday parades, attract crowds in the local business district. When evaluating requests for support to such events, commanders must determine if the sponsor is cooperating with the spirit and intent of the foregoing policy and if the event will benefit the Army.

(3) Civilian-sponsored beauty contests, political rallies, or similar events.

\section{7-30. Bands and other musical units}

\section{a. Tour procedures.}

(1) All military service touring bands are assigned touring areas by the ATSD (PA). Tour areas are coordinated by the services biannually (1 January-15 July and 16 July-31 December). A touring band performing outside its assigned area requires the approval of OCPA, the ATSD (PA), and the military department to which that area is assigned. The U.S. Army Field Band is the official touring band of the Army.

(2) All Army bands (including special bands) in CONUS participating in public events requiring travel outside the area of operations established by their senior mission commander must coordinate through channels with OCPA in advance. All Army bands stationed outside of the United States will coordinate through command channels with OCPA prior to scheduling public performances in the United States.

(3) All Army musical units in CONUS desiring to conduct concert tours must obtain prior approval from OCPA. A tour is defined as a series of public performances requiring more than two nights of temporary duty away from the band's home station. Support to military ceremonies or other official events held on a military installation do not require OCPA approval. Small ensemble performances in schools or universities in support of Army recruiting generally do not require approval.

(4) CONUS bands require COCOM, ATSD (PA), and OCPA approval before they perform outside the United States. Band tours OCONUS will not exceed 15 days without ATSD (PA) approval. Tours to single locations will not exceed seven days.

b. Guidelines.

(1) Musical support includes, but is not limited to, parades, concerts, choral presentations, patriotic openers or presentations, and other events where a band or band element performs. 
(2) No event will receive the support of more than one band or choral group from any service without prior ATSD (PA) approval. Requests for exception are to be forwarded through command channels to OCPA, which will review, and forward to the ATSD (PA). Commands, receiving requests for such support will ensure that other DoD musical units are not scheduled to support the same event.

(3) Musical support of events sponsored by nonfederal entities is limited to patriotic, military, and other musical selections clearly demonstrating the professionalism of the performers and focusing attention on the performance as an Army music presentation. Authorized programs include concerts, parade participation, and patriotic presentations. Dinner music, background music, and dance music are not authorized at civilian-sponsored events unless the event sponsor is a military welfare society as identified in 10 USC 2566.

(4) Local commanders must authorize participation in activities to support recruiting in shopping centers and malls. The following guidelines must be met:

(a) All musicians must be in a uniform which clearly identifies that they are Army musicians.

(b) Community engagement support must not be advertised or presented as a promotion for the shopping center or mall, or for special business activities, such as promotional sales.

(c) The primary purpose of the musical activity must be to gain attention and attract visitors to the recruiting display.

(d) The relationship between the location or event and the band members will not impact unfavorably on the Army and such appearance is not otherwise contrary to this regulation.

(5) Background, dinner, or other social music programs are authorized for official U.S. Government events supported solely, or in part, by appropriated funds, regardless of location.

(6) Musical units will only support memorial services if the deceased is authorized a state funeral, customary military honors, or is ATSD (PA) approved. Additional restrictions on supporting nonfederal events are contained in DoD 5500.07-R.

(7) Musical units may not perform backup support for other entertainers at public programs held away from military installations, unless the military musical unit performs as a featured participant and it has received a waiver from American Federation of Musicians and approval by the ATSD (PA).

(8) United States-based Army musical units may perform OCONUS only with the prior approval of OCPA, the ATSD (PA), the appropriate OCONUS commander, and the host nation provided:

(a) The event sponsor sends the request for support to the unified combatant commander or the ATSD (PA), as appropriate.

(b) The unified COCOM determines that no appropriate in-theater assets are available and the event is sufficiently important to warrant CONUS assets.

(c) The ATSD (PA) evaluates the request and, if approved, forwards it to the appropriate military service for action.

c. Additional guidance. See AR 220-90 for additional policy guidance on participation by Army bands in public events.

\section{7-31. Ceremonial units}

$a$. Ceremonial units include special or unit color guards, drill teams, and other specialized units that are appropriate for military and patriotic ceremonies in the civilian domain. These units may be either of the following:

(1) Activated according to an approved table of organization and equipment or table of distribution and allowances.

(2) Composed of volunteers serving in an official or unofficial capacity as authorized by the local commander.

$b$. Locally authorized volunteer units should be-

(1) Well-trained and have professional bearing.

(2) Operated at no additional cost to the Government.

\section{7-32. Color guards}

$a$. In public programs for which Army support has been authorized and at which the display of colors is appropriate, a Joint Armed Forces Color Guard will be employed, when available, using the following composition:

(1) Two Army flag bearers with national and Army colors.

(2) One each Marine Corps, Navy, Air Force, and Coast Guard flag bearer with individual military service colors.

(3) One Army and one Marine Corps rifleman as escorts.

$b$. When a Joint Armed Forces Color Guard cannot be formed, the senior member of the senior military service in the color guard will carry the national colors. Soldiers, when present, will carry the colors since the Army is the senior service.

c. Army personnel may carry flags of foreign nations in official civil ceremonies when an official of the nation concerned is present in an official capacity and the official is one for whom honors normally would be rendered. In 
all other public programs or ceremonies, Army personnel in uniform and in an official capacity are not authorized to carry flags of foreign nations, veterans groups, or other nonmilitary organizations.

\section{7-33. Aerial activities}

Aerial demonstrations include performances by U.S. Army Parachute Team (Golden Knights), flyovers, command parachute demonstration teams, tactical demonstrations, aerial reviews, static displays, and other aerial activities as defined in DoDI 5410.19.

\section{7-34. Criteria for Army aerial demonstrations}

a. DoDI 5410.19 defines a flyover as a "straight and level flight, usually limited to one pass, by no more than four military aircraft of the same type from the same military service over a predetermined point on the ground at a specific time and not involving aerobatics or demonstrations.” For Army flyovers in support of PA missions, the following constraints apply and may not be waived:

(1) The event or observance must be of sufficient size and significance to justify the use of Army aircraft, and must be flown in conjunction with a previously scheduled training mission and at no additional expense to the Government. Although audience size is not stipulated, estimates may take into account both physical attendance and relevant digital media. The event should benefit the Army, have significant community interest, and be patriotic in tone.

(2) Aerial demonstrations must be planned in tandem with a communication plan executed by the unit public affairs office to highlight the Army and ensure broad public awareness of the Army's capabilities.

(3) Event sponsors must agree to formally recognize the unit and individual crewmembers supporting the event or observance during the event or observance.

(4) Units will complete flyovers during daylight hours only (that is between local official sunrise and sunset).

(5) Units will not attach or suspend flags, banners, streamers, or external loads from Army aircraft during the flyover mission.

$b$. Army aerial demonstrations may be authorized at public events if the display of Army aviation units and assets contributes to Army recruitment, public engagement, and the demonstration of national pride. All requests for flyover support will use DD Form 2535 (Request for Military Aerial Support).

c. Command PA offices will forward all completed aerial demonstration support request memorandums (as defined in Annual Outreach Guidance) to OCPA for approval pursuant to the following requirements:

(1) Flyovers must be received no later than 40 calendar days before the requested event. This timeline will ensure the appropriate use of resources, tracking of funding, and deconfliction with other DoD support for community outreach activities.

(2) Aerial activities (tactical demonstrations) other than flyovers must be received 60 calendar days in advance and must include a risk assessment and concept of operations approved at the appropriate level and acknowledged by the senior commander.

$d$. Before submitting a flyover support request through command channels, the senior commander will certify that the request fully complies with applicable policy and regulatory requriements. Senior commanders may approve mission execution for aircraft under their command only after they receive concurrence from OCPA. This authority cannot be further delegated.

$e$. The CNGB will ensure that state adjutants general will certify in writing that a request for a flyover fully complies with applicable policy and regulatory requirements before submitting the flyover support request. The CNGB will ensure that state adjutants general are aware that they may approve mission execution for aircraft under their command only after they receive concurrence from OCPA. This authority cannot be further delegated.

$f$. The Vice Chief of Staff, Army has the authority to suspend a command's authority to approve flyover support activities for a failure to comply with the Army's flyover policies. The CNGB will follow appropriate higher authority for supporting flyover activities.

\section{7-35. Qualifying air shows and other outdoor events}

$a$. Aerial demonstrations may be performed at air shows and other outdoor events sponsored by either nonprofit or for profit civilian organizations. Approval of static display and parachute team demonstrations may be made by a commander in the grade of $\mathrm{O}-6$. Participation is not authorized when they are held to promote the sale of weapons systems or other defense articles. Participation is authorized only when the following criteria are met:

(1) The logistical support does not interfere with the performance of official duties and does not detract from readiness.

(2) Army community engagement with the immediate community or other legitimate PA or military training interests are served by the support. 
(3) The involvement of the Army with the event is in the best interest of DoD.

(4) The event is of interest and benefit to the local civilian community as a whole, to the ACOM or military organization providing the support, or to any other part of DoD.

(5) ACOM or organization is able and willing to provide similar support to comparable events that meet the criteria of paragraphs 5-4b(1) through 5-4b(7), sponsored by similar nonfederal entities.

(6) Army or DoD participation is not restricted by other statutes or regulations that limit support not based on customary community engagement or PA activities.

(7) No admission fee (beyond what will cover the reasonable costs of sponsoring the event) is charged for the event or for the portion of the event supported by DoD or Army or DoD or Army support is incidental to the entire event.

$b$. Aerial demonstrations may also be performed at broadly based fundraising events (or events sponsored by broadly based charities and nonprofit groups) that focus on the community as a whole. Army and DoD support should be incidental to the overall event or for profit organizations that donate at least half of any excess event revenues (revenue beyond what will cover the reasonable costs of sponsoring the event) to local broadly based community organizations, such as the local CFC.

c. Participation in events conducted in overseas theaters will use resources under the operational control of the theater commander or with concurrence of the parent command on temporary duty within the theater. Requests for participation must be submitted to OCPA for approval. Any coordinated OCONUS activity must be processed through the respective COCOM.

d. Performances by the U.S. Army Parachute Team (Golden Knights) are considered for events open to the public such as air shows, sporting events, fairs, and other outdoor activities that help connect the public with America's Army and enhance the U.S. Army's marketing and recruitment efforts. Appearances on military installations are only approved in support of official open house programs. All sponsors, military or civilian, must provide vehicles, hotel rooms, and a daily show fee.

$e$. The following policies pertain to aerial demonstrations performed by Army demonstration teams or aircraft other than Golden Knights:

(1) Any aerial demonstration will be dependent on the Army's ability to provide such resources at the time of the event.

(2) When aircraft are on static display, qualified military personnel must be available at the aircraft to answer questions on aircraft performance and missions. Placards placed near the aircraft describing basic aircraft specifications and missions are encouraged.

(3) When flight demonstrations involving several maneuvers or capabilities are scheduled at military or civilian air shows, the appropriate unit describing the maneuvers performed will provide a narrator or narration.

$f$. The CNGB will ensure that military flyovers of gubernatorial inaugural ceremonies by state ARNG assets are authorized only when flown in conjunction with a previously scheduled training mission and at no additional expense to the Federal Government under the following conditions:

(1) The governor's office must request the flyover with a DD Form 2535.

(2) The participating aircraft are limited to those ARNG resources assigned to the state or territory concerned. States may not request ARNG aircraft from another state or territory.

(3) The flyover is limited to no more than four aircraft and one service component, either ARNG or Air National Guard, not both.

(4) Multiple flyovers or aerial reviews are prohibited.

(5) The military flyover must occur during the actual inauguration ceremony at a patriotic juncture in the ceremony, such as the playing of the national anthem, a specific salute to the governor, or during the pass in review by National Guard units. States must coordinate the flyover with the appropriate federal and state aviation agencies.

g. Army aerial assets (to include parachute demonstration teams) may not compete for prize money.

$h$. Charges for admission to Army aircraft or other equipment are prohibited. The sale of photos of attendees seated in Army aircraft or equipment is also prohibited.

i. Army aerial demonstrations are normally limited to 2 days in any one aerial event. However, parachute demonstrations may extend to a 3-day period. These provisions may be waived when-

(1) Extended participation does not compromise another event because of travel time.

(2) It is determined that the audience will change each day.

(3) The event is national or international and participation will be in the best interests of the Army.

(4) Normally, no two aerial demonstrations of the same type will be approved for a single public event. However, when DoD aerial demonstration teams are performing at an event, other aerial demonstrations may be authorized if they are performed on alternative days. 
(5) Aircraft performance record demonstrations are restricted to aircraft assigned to an operational unit of a military service for at least 6 months. Demonstrations that imply competition between military services are not authorized.

(6) If a flyover or demonstration involves only Army aircraft, a nonparticipating Army aviator will be designated to act as an Army controller. When two or more services are participating, the military coordinating commander will designate a senior military controller. (Safety and operational procedures are in AR 95-1.)

(7) The controller is responsible for-

(a) Coordinating between the event sponsor and the Armed Forces participants.

(b) Ensuring that flight and safety regulations of the military departments and FAA are observed.

(c) Flying time devoted to aircraft participation will be used to the fullest extent for combat readiness or training purposes.

(8) Assault aircraft demonstrations and helicopter troop landings under simulated tactical conditions, when conducted for public viewing, are restricted to military installations capable of supporting such activities.

(9) The event sponsor is required to obtain an FAA waiver for any public demonstration by military aircraft or parachutists. Final authorization for such demonstration depends upon the event sponsor securing a waiver far enough in advance to permit adequate planning. An FAA waiver is normally required at least 60 days prior to the event.

(10) Support for aerial demonstrations depends on the availability of resources.

(11) Maximum advantage for Army recruiting will be taken at public events where aerial demonstrations are authorized. Coordination should be made with the appropriate Army recruiting battalion and PA office.

\section{7-36. Public engagement programs and activities}

a. Official programs. A number of command-initiated programs are effective in informing the public about the Army and in developing and maintaining a viable relationship with the civilian community, such as-

(1) An active speaker's bureau program.

(2) Ongoing liaison with external organizations (including those at local, state, and regional events).

(3) Participatory membership in civic, business, and professional organizations.

(4) Using exhibits, bands, color guards, and other ceremonial units in the public domain.

(5) Periodic open houses.

(6) Regular Army installation tour program.

(7) Participating in national holiday observances.

(8) Supporting overseas host nation activities (youth, holiday, and traditional programs).

(9) Supporting local veterans and military service organizations.

b. Unofficial programs.

(1) Programs that involve direct contact with the civilian community are the most effective unofficial means of improving relations with the community. Commanders should encourage military and civilian personnel and their Family members to participate as private persons in local community activities.

(2) Military personnel lending voluntary support during off-duty time to a community activity may be authorized to participate in uniform if such participation is consistent with DoD 5500.07-R. (See AR 670-1 for appropriate offduty uniform wear.)

c. Liaison with persons and organizations in the civilian community. Commanders must maintain continual liaison with persons and organizations in the local community to help resolve common problems and develop cooperation and understanding between the installation and the local community by-

(1) Developing an effective two-way channel of communication between the Army and the community.

(2) Fostering cooperation among civilian and military agencies.

(3) Providing maximum support of Army activities, such as, AFW, and other special events.

(4) Supporting the Army recruiting mission and better community understanding of the benefits of an Army enlistment.

(5) Participating in and hosting civic, professional, and business clubs at regular luncheons with one of the military units at the installation.

(6) Promoting United States Military Academy (USMA) and ROTC scholarship opportunities through educators and counselors.

(7) Promoting the use of ARNG armories or USAR centers by civic organizations.

(8) Any official civilian advisory committees and councils must comply with AR 15-1.

d. Informal community engagement working groups. Commanders are encouraged to organize informal community engagement working groups consisting of key military and civilian staff members and subordinate commanders. This forum should be composed of personnel assigned to a particular installation and their counterparts from the civilian community. At a minimum, these forums should- 
(1) Plan a continuous community engagement program.

(2) Establish and maintain contact with civilian service, business, economic, professional, minority, veterans, and military service organizations.

(3) Establish and maintain contact with key civilian community officials.

(4) Evaluate the possible effects of command operations and policies on community engagement, and advise the commander of actions that can reduce or prevent an adverse reaction.

(5) Maintain a consistent orientation program on community engagement for all members of the command.

(6) Promote new ways for members of the command to participate actively in local community activities.

(7) Conduct a periodic appraisal of public attitudes toward the command to see if modification or new procedures are needed for community engagement policies and operations.

e. Community survey and analysis. Community surveys and analyses are helpful in developing a sound public engagement program. Surveys will not violate FOIA or Privacy Act regulations or AR 380-13, which concerns the acquisition and storage of information on nonaffiliated persons and organizations.

f. Fundraising.

(1) Army support may be provided to-

(a) United, federated, or joint fundraising campaigns authorized by AR 600-29.

(b) Other appeals authorized by the President of the United States or the Director, Office of Personnel Management.

(c) Efforts sponsored by military service aid societies.

(2) DoD 5500.07-R governs Army support for local fundraising events.

(3) Volunteer efforts by Army personnel as private individuals on behalf of charities of their choice is permissible.

(4) Fundraising concerts by military bands, including U.S. Army Band and U.S. Army Field Band, will be limited to those sponsored by or held to benefit the campaigns and appeals cited in paragraphs 7-36f(1)(a) through 7$36 f(1)(c)$. Exceptions may be made if DA determines that benefits are sufficiently widespread throughout a community.

(5) Commanders of COCOM may authorize exceptions to this policy in overseas areas, except Hawaii and Alaska, to permit participation in athletic or sports competitions within their commands to support local fundraising efforts.

\section{7-37. Consultation with state and local officials}

$a$. Presidential, DoD, and HQDA policies require that within national security and congressional constraints, state and local officials be consulted at the earliest stages of planning and developing major policy, budget, or reorganization proposals that have significant state and local impact.

$b$. Commands or activities should contact OCPA when they know of or receive an inquiry about a particular local or congressional issue. ASCC, ACOM, or DRU and activities will then advise HQDA, OCPA, and OCLL of these situations through the local PAO and congressional affairs contact officer.

c. OCPA will provide consultation guidance to ASCC, ACOM, or DRU and activities involved in the proposal, based on DoD guidance. If no problems are perceived, OCPA will coordinate with ACOMs and activities to begin consultation at the earliest time. However, no early consultation with state and local officials will take place without HQDA guidance.

\section{7-38. Significant days and observances for the Army}

a. Army birthday. June 14 is observed as the anniversary of the founding of the U.S. Army as the Continental Army. Commanders at all levels are encouraged to remind their personnel of the proud traditions they have inherited by reading the Resolution of the Continental Congress at troop formations.

b. Army Reserve birthday. April 23 is observed as the birthday for the Army Reserve.

c. Armed Forces Day and Veterans Day. By presidential proclamation, the annual observance of AFD is celebrated on the third Saturday of May each year. AFW includes AFD plus the preceding 6 days. Veterans Day is celebrated on November 11 of each year.

(1) AFD and Veterans Day are holidays that pay tribute to the past and present members of the Armed Forces. DoD announces the theme annually.

(2) It is DoD policy to provide military support for-

(a) AFD and Veterans Day observances at communities designated as official DoD regional sites by DoD and the Veterans Day National Committee.

(b) Smaller local observances held in communities not designated as official DoD regional sites, as resources permit. 
(3) AFD commemorative editions of unit, installation, or activity newspapers that stress the Army's contribution to national security may be published. Editions may include AFD messages from commanders and senior personnel and other special features and articles.

\section{7-39. Open house}

$a$. An open house is a military program conducted on an installation or other military facility to which the general public is invited. It is designed to present military missions, equipment, facilities, and personnel to a local or regional civilian community to satisfy public interest in the defense establishment and its role in national security affairs. An open house can establish and maintain cordial relationships between military installations and surrounding civilian communities.

$b$. Commanders of military installations are encouraged to hold at least one open house annually within the limits of available resources and operational capabilities. Commanders should also ensure a proper security review is conducted. Open house displays, events, and attractions should come primarily from the resources of the host installation or local community. Commanders may invite military assets and Soldiers from other installations to demonstrate equipment or capabilities not found at a local installation.

c. Open houses, demonstrations, displays, and traveling exhibits should encourage attendance and participation by Family Readiness Groups (FRGs) and the general public.

d. Commanders should encourage maximum use of ARNG armories and USAR and Air Force Reserve centers for open houses, exhibits, and other programs of interest to the general public.

\section{7-40. Support to state governor's inaugural activities}

$a$. Joint military service support to state governor's inaugural ceremonies and parades is appropriate, subject to the availability of resources.

$b$. When military personnel and equipment are not sufficient for the level of support desired, a request for additional assets may be made by the chain of command.

c. If military service support is desired, but no troops or resources are stationed within that state, the circumstances should be reported to the ATSD (PA) for resolution.

$d$. Unless approved by the ATSD (PA), bands, troop units, and equipment from outside the local area may be provided only if no additional cost to the Federal Government will be incurred.

$e$. Support should be limited in size and scope, bearing in mind the potential demands that may be generated from state to state.

$f$. ARNG may be ordered to state duty by appropriate state authority even though federal funds are not made available.

g. The duties performed by ARNG and Air National Guard personnel in federal status or involving federal assets will conform to the policies in this regulation and DoDI 5410.19.

$h$. Approved military aviation flyovers of inaugural ceremonies by ARNG assets are authorized when flown in conjunction with a previously scheduled training mission and at no additional expense to the Government.

\section{7-41. Joint Civilian Orientation Conference}

$a$. JCOC is the only civilian orientation program sponsored by Secretary of Defense and offers an in-depth orientation to the military services' missions and programs. Selected professional and civic leaders attend briefings in the Pentagon and visit field installations in the United States that are representative of each military service. Participants are expected to share their JCOC experiences with colleagues and peers after the conference.

$b$. Nominees must be influential leaders in their professions and in their communities. They cannot possess extensive knowledge of DoD or have existing strong relationships with senior members of the military. The only U.S. citizens not eligible are prior participants, partisan public officials, political candidates, persons engaged in paid partisan activities, persons (working or retired) drawing any federal paycheck, or salaried employees of Government contractors whose primary work duties are military related.

\section{7-42. Army support to non-U.S. Government authors and producers of documentaries and entertainment-oriented publications and audio and audiovisual products}

$a$. Army installations, commands, agencies, and activities are authorized to assist authors and producers without prior HQDA approval. Requests must be forwarded to OCPA when the subject matter is of regional or national interest, or when the product will be distributed outside a command's local area.

$b$. Support will be provided only when cooperation will benefit DA and DoD or when assistance is in the national interest. 
(1) The product must be authentic in its portrayal of actual persons, places, military operations, and historical events. If the portrayal is fictional, the product must depict military life in a plausible manner.

(2) The product must foster an improved understanding of the Army.

(3) The product cannot appear to condone or endorse activities that are contrary to U.S. Government policy or that are not in the best interest of the Army or DoD.

c. OCPA-West processes requests for support to film, television, and multimedia entertainment-oriented projects. Upon receiving request for support, PAOs should request a copy of the OCPA-West guide to working with the entertainment industry. Requests for participation by ARNG units, personnel, and installations are processed by NGB-PA for approval by ATSD (PA).

(1) Appearances by Army personnel in an official capacity or unofficially while in uniform must be approved by the appropriate authority based on the level of interest (local, regional, or national).

(2) Army personnel participation in talk shows with either regional or national interest requires coordination with OCPA.

(3) Any Army personnel participation or support must be unique in character, must not have a commercial counterpart, and must be in the interest of DA and DoD. The participation or support must not interfere with the customary employment and regular engagement of civilian performers. The sponsor must agree before the broadcast to satisfy all copyright requirements.

(4) Prior approval for appearing on audience participation programs is usually not possible due to the spontaneity of the program. Conduct on such programs should reflect favorably on the Army.

(a) Promotional assistance to publishers or producers of entertainment-oriented products and commercial promotions will be submitted, with recommendations, to OCPA.

(b) Army branding and PA policies prohibit using Army themes, materiel, uniforms, or insignia in advertisements and promotions for entertainment-oriented products and commercial promotions that could imply Army endorsement of the product or service unless part of an approved marketing initiative, campaign approved by the Army Marketing and Research Group.

\section{7-43. Army support to disaster relief and civil disturbances}

$a$. Policy related to disaster relief and civil disturbances is found in DoDD 3025.18. PAOs will coordinate with FEMA, DHS, Northern Command, U.S. Army North, and OCPA during disaster relief operations. Upon conclusion of disaster relief activities, PAOs will provide OCPA with a narrative summary of PA activities and their results. Information copies of the report will be provided to intermediate headquarters.

$b$. OCPA is responsible for PA activities in connection with civil disturbances. Questions on public information matters related to civil disturbances will be referred to OCPA by Regular Army elements or RC units on active federal duty status. ARNG units on non-federal status (state active duty and Title 32) should respond to query as appropriate in coordination with NGB-PA. All elements should coordinate crisis communication with U.S. Army North and OCPA and transmit VI content to OCPA via the Defense Visual Information Distribution Service.

\section{7-44. Clearance of speakers, speeches, and manuscripts}

a. Speaking and manuscript clearance guidelines. Speaking engagements with and writing for key publics and influential audiences are critical to maintaining public awareness and support for the Army. Commanders down to installation level will make every effort to engage with the American public.

(1) Clearance through security review and PA channels is required for all official speeches and writings that are presented or published in the civilian domain, to include materials placed on the internet or released via similar digital media. (See DoDI 5230.09 for additional information and guidance on releasing information).

(2) Individual speechwriters, authors, and speakers are responsible for ensuring content review and clearance of official speeches and writings prior to release to the public.

$b$. Clearance authorities. HQDA or OSD clearance is required for all speeches, manuscripts, or other communication products containing information or otherwise meeting the criteria outlined in paragraph 7-6. Information proposed for posting on publicly accessible internet websites must also be reviewed and approved by the appropriate proponent office prior to release. PAO will be consulted if questions arise on the public release of information under the purview of this regulation.

(1) This regulation authorizes completing PA clearance review actions at installation or ACOM level to the maximum extent possible.

(2) In accordance with DoDI 5230.09, any anticipated or otherwise proposed communication products (such as book manuscripts) mentioning names of military personnel or DoD employees, military operations, or any of the subjects specifically listed in paragraphs 7-6a(1) through 7-6a(20) must be submitted for prepublication review 
through Army PA channels. The material will be submitted prior to any release to non-DoD persons, including, but not limited to, ghostwriters, literary agents, editors, or publishers.

(3) Unofficial materials not dealing with the military do not require clearance. These include materials produced on personal time, using personal equipment and open sources. Unofficial letters to the editor, book or similar reviews, and works of fiction (to include those based upon real events) do not need clearance. It is the author's responsibility to ensure that security has not been compromised. Information that appears in open sources does not constitute declassification. The combination of several open source documents may result in a classified document.

c. Speakers at nonfederal entities. Army personnel serving as speakers or panel members at conferences must comply with AR 1-50 and DoD 5500.07-R. Speakers and panelists must take care to safeguard and prevent the dissemination of Army procurement, technology, classified, and nonpublic information and must make sure they do not appear to endorse the nonfederal entities. Approval authorities should consult with their legal advisor before authorizing participation as a speaker or panel member at a nonfederal entity conference.

d. Medal of Honor recipient speakers. Commanders will give special attention to public appearances by Medal of Honor (MOH) recipients. These persons, by their acts of gallantry, have earned the respect and admiration of the nation and the right to public recognition. Likewise, they also have the right to be protected from exploitation and overexposure. Special attention is required to achieve a balance.

(1) In acting on requests for appearances by $\mathrm{MOH}$ recipients, the following policies are observed:

(a) The person's personal preferences should be considered along with a careful evaluation of the event and its value to the Army. Each of these factors should be given equal consideration.

(b) Discourage public appearances of $\mathrm{MOH}$ recipients attending military or civilian schools to permit them to devote maximum efforts to training or education.

(c) Obtain proper clearances if absence from instruction or regular duty is necessary.

(d) The public event sponsor will be responsible for the costs of transportation, food, and lodging if required.

(e) Local commanders may approve appearances outside the local community engagement area.

(2) The supporting PAO for the unit of assignment when the MOH is awarded will forward a biography and photograph of the awardee to OCPA. After award, the PAO supporting the awardee's unit of assignment will maintain, update, and forward the biography as needed.

e. Official speaking or writing guidelines. Speeches or remarks must address a subject within a speaker's official expertise. This policy does not prevent DA military or civilian members from speaking on matters unrelated to the official concerns of the U.S. Government when such activities are consistent with other laws and regulations and do not conflict with official duties or imply Government endorsement.

(1) Official speeches, text, and written materials must be reviewed through PA channels and cleared for security, accuracy, policy, and propriety by proper authority at the lowest level possible. PAO who has subject matter expertise and knows the audience will review and clear speeches and writings at the lowest level. If the material cannot be cleared at the local level, clearance will be done at the next appropriate level.

(2) The review and clearance process is not a censorship activity. Its purpose is to act as a safeguard for both authors and speakers and the Army to prevent the accidental release of classified or otherwise inaccurate or inappropriate information. The process also assists PAOs in staying knowledgeable of their command's public communication activities.

(3) For review and clearance purpose, full text format speeches are preferred. Speech outlines, slides without text, or bullet format presentations may be reviewed and cleared to allow PAOs to remain informed of their command's public communication activities and to facilitate appropriate unofficial advice regarding proposed content.

(4) Official speeches and writings must not contradict U.S. Government policy or law. They must adhere to DoD 5500.07-R.

(5) In general, Army employees will not officially endorse, or appear to endorse, membership drives or fundraisers for any nonfederal entity (see 5 CFR 950, DoD 5500.07-R, and AR 600-29).

(6) Except for fundraising events and membership drives, the head of an Army organization may provide Army employees in their official capacities to express Army policies as speakers, panel members, or other participants.

(7) Situations where an event's real or apparent purpose is to stage controversy or confrontation will be avoided. OCPA must be consulted before providing speakers for events where public confrontation or debate of national policy is planned or likely.

(8) The material must not endorse, promote, or sponsor any private individual, group, or venture or give the appearance of doing so. The event itself should be of common public interest and benefit. Participating in any public program is authorized only if admission, seating, and all other accommodations and facilities connected with the program are available without regard to race, creed, color, national origin, gender, or mental or physical disabilities. 
Army support or participation is authorized for programs sponsored by organizations whose qualifications for membership are based on gender or national origin only when the program so supported is oriented to the broad community rather that those particular aspects or objectives of the organization itself.

(9) Press, radio, and television interviews in conjunction with speaking engagements are encouraged, subject to this regulation and Army PA policy in effect at the time. Army speakers should consult the appropriate Army PA office for guidance before participating in media interviews.

(10) Advance distribution of copies of cleared material may be arranged and is encouraged to gain the widest possible public dissemination of Army information. Speech texts may be distributed in cooperation with the host organization.

(11) When requesting active participation by Army speakers in partisan political gatherings, Soldiers should review AR 600-20 for appropriateness. Army civilian personnel should review 5 CFR 734 or contact their local legal office for additional guidance.

(12) Prior to repetitively using a previously cleared speech or manuscript, the clearance should be revalidated by the approving PAO.

f. Unofficial and special case writing and speaking guidelines. Individuals may write articles for official DoD publications if the manuscripts are cleared prior to publication. Individuals preparing material may use military facilities and clerical assistance. Official DoD publications do not include commercial service-oriented publications.

(1) Materials that require review must be approved or cleared before such materials are provided, or are committed to being provided, to non-DoD publications or other public forums.

(2) To ensure a climate of academic freedom and to encourage intellectual expression, students and faculty members of an academy, college, university, or DoD school are not required to submit papers or materials prepared in response to academic requirements for review when they are not intended for release outside the academic institution.

(a) Information intended for public release or made available in libraries to which the public has access will be submitted for review. Clearance will be granted if classified information is not disclosed, DoD interests are not jeopardized, and the author accurately portrays official policy, even if the author takes issue with that policy.

(b) The review is delegated to the lowest level competent to evaluate the content and implications of public release of the information that falls within the exception granted by DoDI 5230.29. Otherwise, material will be submitted to the Chief, Defense Office of Prepublication and Security Review in accordance with DoDI 5230.29.

(c) Local policies of Army academic institutions must comply with the sources referenced in this AR.

(3) Any individual who uses a title or other identification connected with DoD in an unofficial writing or speech will include with such material a disclaimer stating that "the views expressed in this article (book) are those of the author and do not necessarily reflect the official policy or position of Department of the Army, DoD, or U.S. Government." The writer will not use a title or other DoD identification in connection with the material if requested to refrain from doing so by the reviewing authority.

(4) Individuals may accept payment for unofficial speeches or writings in accordance with the provisions of 5 CFR 2635.807, DoD 5500.07-R, and SJA guidance.

(5) Notes, abstracts, manuscript, or speech outlines will not be cleared as a substitute for the complete text, but may be reviewed unofficially as a courtesy. However, abstracts to be published in advance require clearance. An abstract clearance does not substitute for clearance requirements for the full and final text manuscript.

(6) Retired personnel, former DoD employees, and non-active duty members of RCs will use the DoD security review process to ensure that information they submit for public release does not compromise national security.

(7) DoD personnel, while acting in a private capacity and not in connection with their official duties, have the right to prepare information for public release through non-DoD media. This information must be reviewed for clearance if it meets the criteria in DoDI 5230.29. Such activity must comply with the ethics rules at 5 CFR 2635 and DoD 5500.07-R and may not have an adverse effect on duty performance or the authorized functions of DoD.

g. Speaking and manuscript clearance procedures. PAO will establish local clearance procedures. Most clearances will be completed at the local level. There is no requirement for submitting material for clearance to HQDA based solely on the rank of the author or speaker.

(1) Materials that require HQDA or OSD clearance will be submitted to OCPA using the following procedures:

(a) The full and final text of material requiring review, including any supplemental VI material, will be submitted.

(b) Manuscripts, speeches, or other materials will be submitted in sufficient time to allow the review before the desired release date.

(c) Denial of clearance or directed mandatory changes of any material submitted for review may be appealed through the channels of original submission to OCPA.

(2) Manuscripts lacking proper clearance, which authors submit to official Army publications, will be sent by the editor to the proper clearance authority at the lowest command level appropriate. 
(3) Material originating in Army components of the unified or joint commands will be cleared according to the procedures established by those commands.

\section{7-45. Writing style}

The Associated Press (AP) Stylebook and DoD Visual Information Style Guide are the primary references for writing effective captions and stories. The Army.mil Style Guide supplements the AP Stylebook and pertains to DoD-specific issues not addressed, such as military terms describing Service members, equipment, places, and entities.

\section{Chapter 8 \\ Digital Media Management and Publications}

Digital media is defined as text, audio, and VI content that can be transmitted over the internet or computer networks. Army PA content that is released on a website, blog, or social media platform will fall into this category. Using digital media to communicate with the public and intended audiences on behalf of the Army is a PA function.

\section{8-1. General social media guidance}

$a$. Social media are websites and applications that allow people to communicate and share information on the internet using a computer or mobile device.

$b$. Social media provides an important opportunity to inform, educate, and engage key publics. While providing useful capabilities to the Army, social media has created new responsibilities and considerations for commanders and PA professionals. A social media presence must have a well-defined purpose, clearly align with the command's communication objectives, and remain a credible source of information for the public.

c. Army social media platforms are official representations of the U.S. Army and must demonstrate professionalism at all times. Commercial social media sites are not owned by the Army, therefore guidelines are required for social media management.

$d$. Commanders are responsible for both their official external presence and for all social media platforms under their command. Echelon PAOs are authorized to release official information on their behalf and comply with the guidelines outlined in this regulation.

$e$. Commanders at brigade level and above are encouraged to use social media platforms as part of their communication strategy. For lower echelon units, if the higher echelon PA office views the unit as having enough consistent content to warrant a separate social media presence, it will ensure the subordinate unit has the training and assistance needed to establish an effective social media program with the right platforms based on a communication plan. If the needs of a subordinate unit can be met with the higher echelon's social media presence(s), the subordinate unit should work with that PA office to coordinate content publication.

\section{8-2. Functions}

a. Official Army social media accounts are all accounts open to the public created and managed using Federal Government resources, including time, manpower, equipment, and funds to communicate the Army's story. Social media managers are Soldiers or DA Civilians responsible for managing their organization's or leader's official social media platform.

$b$. The OCPA Digital Media Division is responsible for the Army social media program. The Army Social Media Guide explains standard operating procedures for official external presences. The Army Social Media Guide is located at https://www.army.mil/socialmedia. OCPA Digital Media Division will-

(1) Serve as the Army's main representative and liaison for commercial social media platforms.

(2) Manage HQDA level social media platforms.

(3) Develop guidance for the Army social media program.

(4) Maintain the Army Social Media Guide.

(5) Develop social media guidance governing responsible and effective use of social media.

(6) Maintain a list of approved social media training for social media managers.

(7) Approve all official social media sites for registration with the Army social media directory at https://www.army.mil/socialmedia/directory.

(8) Maintain a working group with major command, ASCC, and DRU social media managers to coordinate social media activity.

c. Commanders will-

(1) Provide authorization to establish official social media accounts in compliance with local network restrictions.

(2) Authorize social media managers to release information on the command's behalf. 
(3) Ensure that social media managers are properly trained and certified and follow guidelines outlined within this regulation.

(4) Ensure social media manager has the proper equipment and network access to conduct social media operations.

d. PAOs for ACOMs, ASCCs, DRUs, or their designated representatives will-

(1) Ensure approved social media sites within their command operate within the guidelines in this regulation and provide accurate information to the public.

(2) Ensure social media platforms are registered in the Army social media directory.

(3) Maintain a roster and network of all social media managers within the command.

$e$. Social media managers will-

(1) Manage accounts using only authorized Government equipment and devices.

(2) Ensure approved social media sites within their command operate within the guidelines in this regulation and are compliant with stated policies.

(3) Update content regularly and consistently, ensuring all content and engagement appropriately reflects the command.

(4) Publish properly reviewed, released, and public domain information and imagery. Unreleased or for official use only (FOUO) content is not authorized for release.

(5) Actively engage the public through timely and accurate information sharing while maintaining security and privacy.

(6) Archive and close inactive or noncompliant accounts.

(7) Develop and update local standard operating procedures for social media management and will ensure that efficient operations continue during personnel transitions. Treat social media access and passwords with as much care as PII.

(8) Maintain a continuity book or file for approved social media sites used in support of the brigade or installation mission. Continuity should include:

(a) A roster of all authorized social media accounts and a contact roster of social media administrators within their command.

(b) Social media processes and strategy, to include a public defacement response plan along with a short justification on how the platform meets the needs of the office.

(c) Appointment letters for each approved unit's social media manager(s).

(9) Ensure appointment letters and social media sites are reviewed annually to ensure compliance.

(10) Ensure social media platforms are registered in the Army social media directory.

(11) Review content for OPSEC before publication.

\section{8-3. Social media and blogs}

The following provides guidance on routine social media items for official Army social media platforms:

a. Training. Personnel who manage and release information on official Army social media platforms must be OPSEC level II certified, and be current with required social media training.

b. Registration. The social media directory registers official social media accounts of organizations with a 1035 civilian or 46 series military occupational specialty with release authority that is OPSEC level II trained and fulfills all training required of social media managers. The Army social media directory is located at https://www.army.mil/socialmedia/directory. Pages must be open to the public. Private groups, accounts, or feeds will not be registered on the U.S. Army's social media directory.

c. Release authority. Social media managers on official Army social media accounts must be granted release authority by the commanding officer. The authority to manage and release information must be renewed during command and personnel changes.

d. Disclaimers and settings. Army social media platforms must adhere to the following requirements:

(1) Labeled as an official account.

(2) Classified as a Government organization.

(3) User terms of agreement must include:

(a) General disclaimer.

(b) Privacy and security disclaimers.

(c) Copyright and trademark disclaimers.

(d) Moderated account disclaimer.

(e) FOIA notice.

(f) Specific wording, which can be found at the General Services Administration's Negotiated Terms of Service located at https://www.digital.gov/resources/negotiated-terms-of-service-agreements/. 
(g) Contact information, which must be a valid .mil or .gov utility email address.

(h) Official uniform resource locator.

e. Social media content. Organizations will have a list of communication priorities as a basis for items that should be posted, as well as a working list of topics that should be avoided, perhaps due to sensitivity or controversial issues. These lists are determined by the commander's priorities and the public's needs.

f. Audience engagements. Social media managers will engage with their audience at every opportunity. Managers must exercise caution when conducting audience engagements as all responses, interactions, and endorsements are considered a reflection of the commander and the organization rather than the individual.

g. Inappropriate material and prohibitions. The following items are inappropriate for social media sites:

(1) Inappropriate links. Army public sites will not link to offensive or unrelated commercial material.

(2) Personnel security. Army social media sites will not post references to any information that would reveal sensitive movements of military assets or personnel or the locations of units, installations, or personnel where uncertainty is an element of security of a military plan or program.

(3) Operational security and information security. All content on an Army public social media site must be cleared for public release. Do not include material that is classified or FOUO. Do not include scientific and technical information that has not been cleared for public release.

(4) Personal information. Use of personal information protected by the Privacy Act (see AR 25-22) is prohibited.

(5) Copyright information. Copyrighted material may only be used with written permission from the owner (see AR 27-60). U.S. laws on copyright, primarily 17 USC Chapter 1, preserve for the owner of copyrighted material, the benefits and earnings to be derived from the reproduction and distribution of such works. Material that is subject to copyright protection includes "original works of authorship fixed in any tangible medium...," (17 USC 102(a)). It is now accepted that computer software and sequences of code and instructions are subject to copyright. Per 17 USC 105 , Government works are not copyright protected.

(6) Political activity. Official Army social media platforms will not engage in political conversations and will not show any form of endorsement such as a share, like, or other reaction to political statements, posts, graphics, or other types of content.

(7) Comments. Social media managers will never post or make comments that are graphic, obscene, explicit, racial, abusive, hateful, vindictive, or intended to defame anyone or any organization.

(8) Legal. Social media managers will not post details about an ongoing investigation or legal or administrative proceeding.

h. Leaders. Command sergeants major and commanders from ACOMs, ASCCs, and DRUs will be registered to the social media directory. All leaders' social media platforms must follow the requirements of official accounts.

i. Family Readiness Group pages. Unit FRG pages must adhere to DoD and Army requirements even if they do not qualify to be in the social media directory. FRG pages can be set as open or closed groups, however, they must not exclude any member of the FRG's parent unit. Content created or shared through FRG sites must be approved by the unit's release authority.

j. Recruiting pages. Pages created and managed by U.S. Army recruiters and their commands represent the U.S. Army and are considered official pages. Therefore, those sites must abide by the same standards of conduct outlined in this chapter. It is the unit commander's responsibility to enforce these policies and refine their digital footprint.

$k$. Transparency. Transparency is defined as portraying oneself online in a truthful manner without falsifying identity or credentials. Do not forge or otherwise manipulate identifiers in your post in an attempt to disguise, impersonate, or otherwise misrepresent your identity or affiliation with any other person or entity.

l. Anonymous posts. If the technology allows for users to post anonymously, then organizations will allow the posts to be published.

m. Private social media presences on third party platforms. Official government use of private or closed social media groups are not authorized. Nonpublic information may not be released outside of the DoD network to include discussions on third party platforms. Doing so would constitute an unauthorized release of nonpublic information per 5 CFR 2635.703. If an organization is interested in hosting an official closed group, the group should be hosted behind firewall on a DoD approved network such as milSuite or Intelink.

n. External links. Linking to external sources via social media is permitted and encouraged. PA professionals will be educated consumers of information and be sure that an external source of information not only is an appropriate link coming from an official social media site, but also follows security, accuracy, propriety, and policy guidelines. Links will follow the user terms of agreements. Links will be related to the Army mission or its people.

o. Commercial news links. Social media managers are permitted to share individual commercial news articles and content on official accounts only if they support commander's objectives, do not endorse the commercial news organization (soliciting the audience to follow, like, or subscribe is considered an endorsement), and the post represents 
factual information and not opinion. Organizations must avoid the appearance of preferential treatment when determining who to follow. If the organization elects to follow one local news organization, then all local news networks should be followed.

p. Terms of service. Federal compatible terms of service agreements are special agreements negotiated between the Federal Government and vendors who offer free social media, mobile, business, and other digital tools. Refer to General Services Administration for further guidance.

q. Reporting impostors and scams. Social media impostors are fake accounts masquerading as U.S. Army personnel. Units are responsible for reporting impostors of their leaders and personnel to the appropriate social media platform. OCPA Digital Media Division provides further guidance and reporting directions at https://www.army.mil/socialmedia/scams.

r. Security and password management. Access to official social media accounts will be carefully managed and included in unit standard operating procedures. Security settings will be maximized and include a two-step verification, if available, by the platform.

s. Live streaming. All live streamed events should be constantly manned with a contingency plan to take them offline in the event of violence, crime, or imagery unsuited for public consumption.

t. Content boosting and advertising. Units and social media managers are not authorized to use funds to advertise or boost content.

u. Archiving. Per guidance from National Archives Item A1, Section A, Part II of Office of Management and Budget Memorandum M-12-18, electronic messages created or received in the course of Army official business on social media platforms are federal records. Electronic messages must be scheduled for disposition. Army imagery used in social media platforms is considered a permanent, released DoD record. Social media managers will develop processes and procedures for regular archiving of content and all VI will be archived in accordance with paragraph 3-4 of this regulation.

\section{8-4. Nonaccredited social media accounts}

Social media accounts are considered nonaccredited if the organization is not brigade level or above, is not open to the general public, or does not meet the guidance outlined in paragraphs 8-3a through 8-3c. Nonaccredited social media accounts are required to be compliant with the guidelines outlined in this chapter.

\section{8-5. Social media in crisis communication}

Social media platforms are the fastest way to inform and educate the public regarding matters in emerging or breaking news. Social media operations must be integrated into PA planning as part of crisis communication efforts. (See chap 7 for policies on crisis communication and release of official information.) Release of casualty information is outlined in DoDI 1300.18.

\section{8-6. Personal use of social media and appropriate online conduct}

The U.S. Army views personal websites and social media positively, and it respects the right of Soldiers to use them as a medium of self-expression. However, all Army personnel have limitations on what they can discuss. In addition to specific ethics and Hatch Act limitations, civilians are prohibited from discussing the intricacies of the Army and the DoD. Soldiers on active duty must abide by certain restrictions to ensure good order and discipline. All Soldiers are on duty 24 hours a day, 365 days a year, and their actions are subject to the Uniform Code of Military Justice. Soldiers should also remember OPSEC when posting information in the digital environment.

$a$. Soldiers are free to further release and share publicly released DoD and DA unclassified information on their personal social media accounts provided no laws or regulations are violated.

$b$. Soldiers should use their best judgment, remembering that there are always consequences to what is written or photographed. If they are about to post something that is questionable and may reflect negatively on the Army, they should review this and other relevant guidance thoroughly.

c. If still unsure, and the post is about the Army, they should discuss the proposed post with their supervisor or the PA office. Ultimately, however, Soldiers are solely responsible for what they post.

$d$. Do not post any defamatory, libelous, vulgar, obscene, abusive, profane, threatening, hateful, racially, ethnically, or otherwise offensive or illegal information or material.

$e$. Do not post any information or other material protected by copyright without the permission of the copyright owner.

$f$. Do not use any words, logos, or other marks that would infringe upon the trademark, service mark, certification mark, or other intellectual property rights of the owners of such marks without the permission of such owners.

g. Do not post any information that would infringe upon the proprietary, privacy, or personal rights of others. 
h. Do not post any nonpublic information (as defined in 5 CFR 2635.703) this includes, but is not limited to, classified or sensitive information, unless such release is a protected disclosure per an appropriate whistleblower statute.

$i$. Do not forge or otherwise manipulate identifiers in posts in an attempt to disguise, impersonate, or otherwise misrepresent their identity or affiliation with any other person or entity.

$j$. Soldiers cannot use their service affiliation for fundraising purposes on personal social media accounts except for approved fundraisers such as CFC and the Army Emergency Relief.

$k$. Soldiers should not use Government email accounts to establish personal accounts.

l. Soldiers cannot invite other Government employees to participate on social media accounts via a Government email address.

$m$. Employees should not use their official position on personal accounts unless it is accompanied by biographical facts including official photos.

$n$. All political activity on personal pages must be in compliance with the guidance provided by the Office of The Judge Advocate General.

\section{8-7. Official U.S. Army webpage and content management platform}

Army.mil is the official webpage of the U.S. Army. CORE is the content management platform and publishing tool provided to Army PA personnel. Units and organizations are permitted to have a CORE organization page. All PA officers are encouraged to register for an account on CORE to publish content on Army.mil. All content submitted to CORE must be reviewed and approved by authorized personnel for release in accordance with their local chain of command. The CORE website is available at https://www.army.mil/core.

\section{8-8. Organizational website publishing guidance}

$a$. All information residing on a publicly accessible website is public information. Information contained on websites is subject to the policies and clearance procedures listed in this regulation for releasing information to the public. Official websites hosted, sponsored, or controlled by U.S. Army must comply with the policies contained in AR 25-1, AR 25-2, AR 25-22, AR 380-5, AR 381-12, AR 530-1, DoDD 1344.10, DoDI 5230.09, DoDI 5230.29, and JP 3-13.

b. Official public websites or social media platforms should not have any information that is considered nonreleasable (see DA Pam 25-1-1 for additional guidance). Nonreleasable information is any official information that is generally not available to the public and that would not be released under FOIA. Examples of information prohibited from public release include, but are not limited to-

(1) Classified information.

(2) Casualty information before verification that the next of kin has been formally notified by the military service concerned.

(3) Information protected by the Privacy Act (for example, age, date of birth, home address, marital status, and race).

(4) Information regarding incidents under ongoing investigation.

(5) Information or imagery of U.S. Coalition Forces without an official release signed by the individuals in advance or of enemy personnel killed, wounded in action, or hospitalized.

(6) Information that misrepresents the Army or statements in conflict with good order, morale, discipline, and mission accomplishment.

(7) Photographs containing sensitive images, especially those showing the results of improvised explosive devices strikes, battle scenes, casualties, and destroyed or damaged equipment.

(8) Information protected by the Health Insurance Portability and Accountability Act of 1996.

c. PA officials responsible for posting unclassified information to official websites and social media platforms, regardless of domain must complete the website training course offered through ALMS at https://iatraining.us.army.mil. This training also applies to Soldiers, DA Civilians, and supporting contractors who review, post, and maintain Army content on non-Army.mil websites.

\section{8-9. Publication guidelines}

The Army defines a publication as a newspaper, newsletter, or magazine that supports the commander's communication strategy and is distributed either through print or digital means.

a. Editorial content. News coverage and other editorial content in DoD publications will be factual and objective. News and headlines using morbid, sensational, or alarming details not essential to factual reporting will be avoided. 
b. Editorial and news policies. Editorial and news policies must support the commander's responsibility to keep the readership informed. However, they should be only one part of a total information program. The editorial and news policies are as follows:

(1) Provide a free flow of news and information to all DA personnel without censorship or news management. The calculated withholding of news unfavorable to DA is prohibited.

(2) Army publications will distinguish between fact and opinion, both of which may be part of a news story. When an opinion is expressed, the person or source will be identified. Accuracy and balance in coverage are paramount.

(3) Distinguish between and clearly identify editorials (command position) and commentaries (personal opinion).

(4) Attribute opinions and information sources. Attribution is essential to credibility.

(5) News content in Army publications will be based on releases, reports, and materials provided by DoD components and their subordinate levels, DoD newspaper staff members, and other U.S. Government agencies. Army publications will credit sources of all material other than local, internal sources.

(6) To avoid the appearance of bias, commercial news and opinion articles will be balanced with news and opinion articles supporting the opposing point of view and will appear in the same issue and the same page whenever possible.

(7) Overseas command newspapers, news bulletins, and news summaries authorized to carry national and world news may include coverage of U.S. political campaign news from commercial news sources. Such political campaign news will be presented on a balanced, impartial, and nonpartisan basis.

(8) Army publications will not contain campaign news (except as specified in DoDI 5120.04), partisan discussions, cartoons, editorials, or commentaries dealing with political campaigns, candidates, or issues, or which advocate lobbying elected officials on specific issues.

(9) Army publications will support the Federal Voting Assistance Program by carrying factual information about registration and voting laws as specified in DoDI 5120.04.

(10) Army publications will comply with DoDI 1100.13, DoDI 8910.01, and DoDM 8910.01, Volumes 1 and 2 when conducting polls, surveys, and straw votes.

(11) DoD components may authorize polls on matters of local interest, such as Soldier of the week and favorite athlete.

(12) Army publications will only support officially authorized fundraising campaigns, such as CFC, within DoD in accordance with DoDI 5035.01.

c. Publication name. The publication name may include the command or installation name or emblem or the command or installation name may appear separately in the nameplate (flag). The command or installation emblem may also be included in the nameplate. However, the use of DA or other defense organization plaques or shield emblem is prohibited except as authorized by AR 840-1.

(1) Except in cases where the CE printer already owns the name of a publication, all appropriate steps should be taken to ensure that Army owns and controls the names of all publications produced under authority of this regulation. The contract will stipulate that the publication name may be used by the CE printer only for the duration of the contract. Commanders will contact Regulatory Law and Intellectual Property Division at U.S. Army Legal Services Agency to discuss any proposed new publication name before the name is used or revealed to a CE. Commanders will work with U.S. Army Legal Services Agency concerning possible registration of publication names as trademarks. For information about trademarks, please refer to AR 27-60, or write to: Trademark Attorney, U.S. Army Legal Services Agency (JALS-RL/IP), 9275 Gunston Road, Fort Belvoir, VA 22060.

d. Mastheads. In accordance with DoDI 5120.04, the masthead of all DoD publications, both hardcopy and digital, will contain a disclaimer stating the publication is authorized for DoD members and the contents are not necessarily the official views of, or endorsed by, U.S. Government, DoD, or publishing DoD component.

(1) The masthead of all funded publications must contain additional language as stipulated in DoDI 5120.04.

(2) Army newspapers and magazines produced exclusively in electronic format must include the statements listed in DoDI 5120.04.

(3) The masthead of CE publications must contain the following paragraphs printed in type no smaller than 6 points:

(a) "This Department of Defense (newspaper, magazine, guide, or installation map) is an authorized publication for members of the DoD. Contents of (name of the DoD newspaper, magazine, guide, or installation map) are not necessarily the official views of, or endorsed by, the U.S. Government, the DoD, or (name of publishing DoD Component)" (see fig 8-1).

(b) "Published by (publishing company's name), a private firm in no way connected with the (DoD, U.S. Army, U.S. Navy, U.S. Air Force, U.S. Marine Corps) under exclusive written contract with (name of DoD Component or subordinate level). The editorial content of this publication is the responsibility of the (name of command or installation) PA office." 
(c) "The editorial content of this publication is the responsibility of the (name of command or installation) PA office."

(4) The masthead of CE guides and installation maps must list the mailing address and telephone number of the editorial staff. List the names of the commanding officer, PAO, and primary staff of the publication (with their editorial titles) only if the publisher elects to list his or her name and the names of their employees (see fig 8-1 for a sample masthead).

e. Use of color in publications. Using both spot color and full-color processes in publications will be governed by AR 25-30. Color must be functional and add value to the publication. Color will not be used just for color's sake or availability. PAOs will be sensitive to funding availability and to the degree to which using color contributes to the communication process.

f. Archiving. Publications are considered VI and will be archived in accordance with paragraph 3-4 of this regulation. 


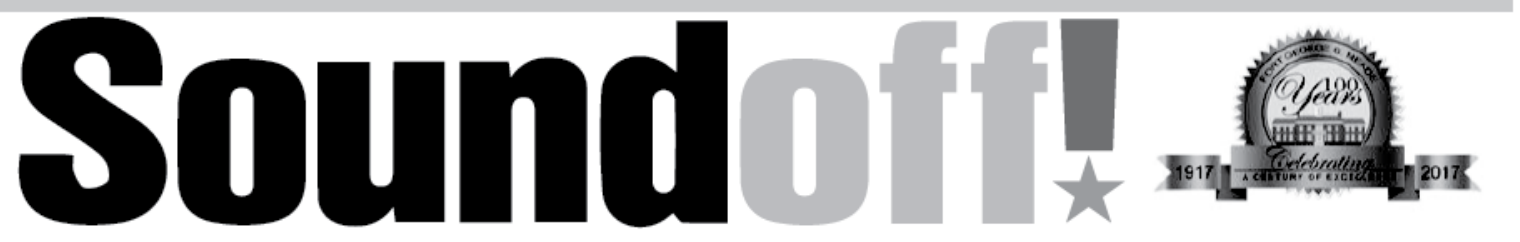

THE ONUNE VERSIUN OF FT. MEADES BOMMUNITY PAPER.

\begin{tabular}{l|l|l|l|l|l|l} 
HOME & COMMUNITY NEWS & EDUCATION $\vee$ & SPORTS $/$ WELLLNESS $\vee$ & UPCOMING EVENTS $\vee$ & ARCHIVE $\vee$ & FT.MEADE HOME
\end{tabular}

\section{About Soundoff! EDITORIAL STAFF}

Garrison Commander

Col. Thomas S. Rickard

Garrison Command Sergeant Major Brian S. Cullen

\section{Public Affairs Officer}

Chad T. Jones 301-677-1301

Chad.T.Jones.civ@mail.mil

Chief, Command Information

Larry Whitley Sr. 301-677-5602

Larry.Whitley.civ@mail.mil

Editor

Assistant Editor \& Senior Writer

Rona S. Hirsch 301-677-1438

rhirsch@baltsun.com

\section{Staff Writer}

Lisa R. Rhodes 301-677-1432

Irhodes@baltsun.com

\section{Staff Writer}

Maddie Ecker 301-677-5159

mecker@baltsun.com

\section{Design Coordinator}

Timothy Davis 301-677-1431

trdavis@baltsun.com

Supplemental photography provided by The Baltimore Sun Media Group

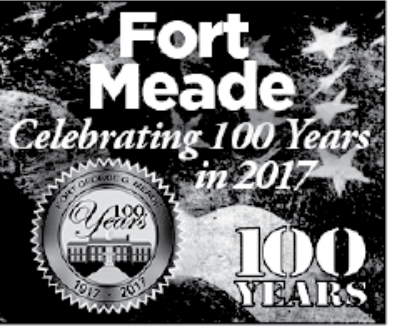

CIRCULATION

If you would like information about receiving Soundoff! on Fort Meade or are experiencing distribution issues, call 877-886-1206 or e-mail TP@baltsun.com.

Office hours are Monday through Friday, 8 a.m. to 4 p.m., and Saturday through Sunday, 8 a.m. to noon.

Printed by offset method of reproduction as a civilian enterprise in the interest of the personnel at Fort George G. Meade, Maryland, by The Baltimore Sun Media Group, 501

N. Calvert St., Baltimore, MD 21278, every Thursday except the last Thursday of the year in conjunction with the Fort Meade Public Affairs Office. Requests for publication must reach the Public Affairs Office no later than Friday before the desired publication date. Mailing address: Post Public Affairs Office, Soundoff! IMME-MEA-PA, Bldg. 4409, Fort Meade, MD 20755-5025. Telephone: 301-677-5602; DSN: 622-5602.

Everything advertised in this publication must be made available for purchase, use or patronage without regard to race, creed, color, national origin, marital status, handicap or sex of purchaser, user or patron. A confirmed violation or rejection of this policy of equal opportunity by an advertiser will result in the refusal to print advertising from that source.

Printed by The Baltimore Sun Co., LLC, a private firm, in no way connected with the Department of the Army. Opinions expressed by the publisher and writers herein are their own and are not to be considered an official expression by the Department of

the Army. The appearance of advertisers in the publication does not constitute an endorsement by the Department of the Army of the products or services advertised.

Figure 8-1. Sample masthead

\section{8-10. Civilian enterprise operations}

$a$. CE publications are newspapers, magazines, installation guides and maps, and websites that support internal communication. In accordance with DoDI 5120.04, the commander may establish publications in this category if feasible.

$b$. Only one CE guide and one CE installation map is authorized for each command or installation. 
c. Guidelines for contracting for CE publications are contained in DoDI 5120.04. The CE newspaper contracting is not subject to the FAR; however, commanders can opt to use procedures spelled out in the FAR in the contracting process.

d. The relationship between PA staff and CE contractor employees is that of Government employees working with private contractor employees. The CE contractor is responsible for rating performance, setting pay rate, granting vacation time, exercising discipline, and assigning day-to-day administrative tasks for CE employees.

(1) Military or DA civilian personnel will not be assigned duty on the CE contractor's premises.

(2) Military or DA civilian personnel will not perform job functions that are part of the CE contractor's business activities or contractual responsibilities at the contractor facility or the Government facility. The PAO and staff who produce the nonadvertising content of the CE publication may perform certain installation liaison functions on the contractor's premises, to include monitoring and coordinating layout and design and other publishing details set forth in the contract to ensure effective information presentation.

(3) Civilian-owned newspaper publishing software and equipment may be placed in the command or installation PA office under contractual agreement. These terminals will be used by the PA staff to coordinate layout and ensure preparation of editorial material has been performed to enhance the efficiency and effectiveness of the printing and publication functions performed by the CE contractor.

(4) Conflicts of interest must be avoided. Situations that may give rise to conflicts of interest, such as the employment of spouses and children of PA staff, must be brought to the attention of the servicing SJA. Appropriate action must be taken to resolve any potential conflicts of interest, in accordance with DoD 5500.07-R.

$e$. The contracting officer is responsible for contract modifications.

f. Army publications will not-

(1) Contain any material that implies that DoD components endorse or favor a specific commercial product, commodity, or service.

(2) Subscribe, even at no cost, to a commercial or feature wire or other service whose primary purpose is the advertisement or promotion of commercial products, commodities, or services.

(3) Carry any advertisement that violates or rejects DoD equal opportunity policy as established in DoDD 1020.02E. (See DoDI 5120.04 for specific wording and instructions on how to deal with advertisements that violate this policy.) All commercial advertising, including advertising supplements, will be clearly identified. Paid advertorials and advertising supplements must be clearly labeled as advertising and be readily distinguishable from editorial content.

g. The following provisions apply specifically to CE publications other than newspapers published at the discretion of the commander with prior approval by the ACOM.

(1) CE installation maps are normally contained within a CE guide and printed as part of one contract. CE installation maps, however, may be published separately from the CE guide as a separate contract only if the last edition of the CE guide does not contain an installation map. If published separately from the CE guide, the requirements listed in paragraph 8-10g(2) apply to CE installation maps.

(2) If a CE guide contains an installation map, over-run copies of the map are authorized. The requirements listed in DoDI 5120.04 apply to CE guides and CE installation maps.

(3) Syndicated comics purchased as part of a clip art collection may be reprinted under that clip art collection's licensing agreement.

(4) Before publication, a proof copy of the CE installation map will be reviewed by the installation geospatial information and service program office to eliminate potential OPSEC risks.

(5) The name of a CE guide or map may include the name and emblem of the installation. Include the name of the printer in the disclaimer.

(6) Senior commanders may include a telephone directory section in the installation CE guide in lieu of printing an installation telephone book. Separate contracts for CE telephone directories are not authorized.

(a) The telephone section will be part of the guide contract specifications.

(b) Overrun printing of the telephone directory and yellow page section of the guide is authorized. The numbers of guides with integral telephone directories and the number of overrun copies of the telephone directory and yellow pages will be clearly specified in the single guide contract.

(7) Required communication security information will be printed on the first page of the telephone section and not on the cover of the guide. The cover of the guide may tell users the publication contains the telephone directory.

(8) In addition to other contract provisions in this regulation, guide and map contracts will also require the following:

(a) CE contracts for guides and installation maps will establish firm delivery dates and contain provisions to ensure distribution is controlled by the command. 
(b) Delivery dates may vary for guides and installation maps to make them more attractive to advertisers.

$h$. Only the commander or PA officer (as the commander's representative) will approve and provide material to appear in the editorial portion of the CE publication. This authority may be delegated in writing, but the commander retains ultimate responsibility. The printer may recommend material to the PA office, but the commander decides what will be used. The paper may publish civilian community news and announcements that benefit the readership.

\section{8-11. Appropriated funded operations}

$a$. Appropriated funded (AF) newspapers and magazines, websites, and external online presence support the command communication requirements of DA and its subordinate commands. Normally AF publications are printed by a commercial printer under contract or in a Government printing facility.

$b$. AF publications may be distributed through official channels. Appropriated funds and manpower may be used for distribution of AF publications, as required.

$c$. The expense of publishing and distributing AF newspapers is charged to appropriated funds of the publishing command.

$d$. Recommended minimum circulation (copy-to-reader ratio) is one copy to three readers based on total intended audience for AF publications. The number actually printed will determine published circulation figures.

$e$. Both AF and CE publications will comply with AR 25-22.

$f$. Both AF and CE publications may be distributed through local official channels. Appropriated funds and personnel may be used for distribution of AF newspapers, as required. Compliance with AR 25-51 on using official mail is mandatory.

\section{8-12. Contracting for appropriated funded publications}

a. Army-funded publications normally are printed by a civilian printer under contract or in Government printing facilities. The editorial content of these publications and their distribution are accomplished by the PA office. These are evaluated on a case-by-case basis with the defense printing service office.

$b$. Printing an Army-funded publication will be in coordination with the PA office. Using four-color process is authorized if the commander and PAO determine it enhances communication.

c. The Army-funded publications will not carry commercial advertising. As a service, the Army-funded newspaper may carry nonpaid listings of personally-owned items and services for sale by members of the command. Noncommercial news stories and announcements concerning MWR activities and commissaries may be published in Armyfunded publications.

\section{8-13. Editorial contributions}

a. Editorial contributions may include articles and products produced outside official channels by stringers or local organizations, providing permission has been legally obtained, and they do not otherwise violate provisions of this regulation.

$b$. Editors may use bylines over stories. Using rank is optional but will be consistent in style.

c. Commercially sponsored Armed Forces Entertainment and MWR events may be mentioned with other pertinent facts in news stories and announcements. Event titles using the name of commercial sponsors may be included if newsworthy and if the use clearly meets Army needs. (See AR 215-1 for policy governing commercial sponsorship.)

$d$. Book, radio, television, movie, restaurant, and other entertainment reviews may be included if there is no implication of DA selective benefit or endorsement. Accepting gratuities in connection with these reviews is prohibited by DoD 5500.07-R. This paragraph does not prevent PA staff members from accepting press credentials or passes.

$e$. All private organizations approved to operate on the installation may have meetings announced and other material considered for use. No organization will receive preferential treatment, including authorized veteran organizations.

f. CE and AF publication editors will edit letters to the editor at their discretion. Commands are not obligated to respond to or return unsolicited editorial material.

g. Covering ongoing test or evaluation programs is prohibited. Exceptions to policy are through channels to OCPA (see para 6-6).

h. All commercial advertising should be clearly identified, including advertising supplements. Paid advertorials and advertising supplements may be included but must be clearly labeled as advertising and readily distinguishable from editorial content.

$i$. Although DA websites are normally discouraged from linking to commercial activities, the commander may authorize an installation's website to be linked to the website carrying the authorized CE publication.

j. Publications and websites will not-

(1) Contain any material implying Army endorsement of a commercial product, commodity, or service. 
(2) Subscribe, even at no cost, to a commercial or feature wire or other service whose primary purpose is advertising or promoting commercial products, commodities, or services.

(3) Carry any advertisement that violates or rejects DA equal opportunity policy. 


\section{Appendix A}

\section{References}

\section{Section I}

\section{Required Publications}

AD 2018-05

Army Flyovers for Public Affairs Missions (Cited in the title page.)

AGO 2020-01

Assignment of Functions and Responsibilities within Headquarters, Department of the Army (Cited in para 1-8.)

AR 25-1

Army Information Technology (Cited in para 2-5n.)

AR 25-22

The Army Privacy Program (Cited in para 7-4.)

AR 25-30

Army Publishing Program (Cited in the title page.)

AR 25-51

Official Mail and Distribution Management (Cited in para 8-11f.)

AR 25-55

The Department of the Army Freedom of Information Act Program (Cited in para 4-6c.)

AR 27-40

Litigation (Cited in para 7-17a.)

AR 58-1

Management, Acquisition, and Use of Motor Vehicles (Cited in para 4-4a.)

AR 95-1

Flight Regulations (Cited in para 7-35i(6).)

AR 200-1

Environmental Protection and Enhancement (Cited in para 3-8a.)

AR 381-12

Threat Awareness and Reporting Program (Cited in para 8-8a.)

AR 530-1

Operations Security (Cited in para 7-7a.)

AR 601-208

The Army Brand and Marketing Program (Cited in para 3-5a.)

Army Social Media Guide

(Available at www.army.mil/socialmedia) (Cited in para 8-2b.)

\section{Section II}

\section{Related Publications}

Related publication is a source of additional information. The user does not have to read it to understand the regulation. The United States Codes are available at http://uscode.house.gov.

\section{AR 1-1}

Planning, Programming, Budgeting, and Execution

AR 1-20

Legislative Liaison

AR 1-33

The Army Memorial Program 
AR 1-50

Army Conference Policy

AR 5-10

Stationing

AR 5-22

The Army Force Modernization Proponent System

AR 11-2

Managers' Internal Control Program

AR 15-1

Department of the Army Federal Advisory Committee Management Program

AR 20-1

Inspector General Activities and Procedures

AR 25-2

Army Cybersecurity

AR 25-50

Preparing and Managing Correspondence

AR 25-400-2

The Army Records Information Management System (ARIMS)

AR 27-60

Intellectual Property

AR 37-47

Official Representation Funds of the Secretary of the Army

AR 40-33

The Care and Use of Laboratory Animals in DoD Programs

AR 50-5

Nuclear Surety

AR 50-7

Army Reactor Program

AR 70-31

Standards for Technical Reporting

AR 190-24

Armed Forces Disciplinary Control Boards and Off-Installation Liaison and Operations

AR 190-45

Law Enforcement Reporting

AR 190-47

The Army Corrections System

AR 195-2

Criminal Investigation Activities

AR 195-6

Department of the Army Polygraph Activities

AR 210-7

Personal Commercial Solicitation on Army Installations

AR 215-1

Military Morale, Welfare, and Recreation Programs and Nonappropriated Fund Instrumentalities

AR 220-90

Army Bands 
AR 350-2

Operational Environment and Opposing Force Program

AR 380-5

Army Information Security Program

AR 380-10

Foreign Disclosure and Contacts with Foreign Representatives

AR 380-13

Acquisition and Storage of Information Concerning Nonaffiliated Persons and Organizations

AR 380-49

Industrial Security Program

AR 380-86

Classification of Former Chemical Warfare, Chemical and Biological Defense, and Nuclear, Biological, Chemical Contamination Survivability Information

AR 381-14

Technical Surveillance Countermeasures

AR 381-20

Army Counterintelligence Program

AR 385-10

The Army Safety Program

AR 405-10

Acquisition of Real Property and Interests Therein

AR 405-80

Management of Title and Granting Use of Real Property

AR 420-1

Army Facilities Management

AR 525-13

Antiterrorism

AR 550-1

Processing Requests for Political Asylum and Temporary Refuge

AR 600-3

The Army Personnel Development System

AR 600-20

Army Command Policy

AR 600-25

Salutes, Honors, and Courtesy

AR 600-29

Fund-Raising Within the Department of the Army

AR 638-8

Army Casualty Program

AR 670-1

Wear and Appearance of Army Uniforms and Insignia

AR 700-131

Loan, Lease, and Donation of Army Materiel

AR 725-1

Special Authorization and Procedures for Issues, Sales, and Loans 
AR 735-5

Property Accountability Policies

AR 840-1

Department of the Army Seal, Emblem, and Branch of Service Plaques

AR 840-10

Flags, Guidons, Streamers, Tabards, and Automobile and Aircraft Plates

AR 870-5

Military History: Responsibilities, Policies, and Procedures

AR 870-20

Army Museums, Historical Artifacts, and Art

Army.mil Style Guide

(Available at https://www.army.mil/e2/downloads/rv7/armydotmil_style_guide.pdf.)

Associated Press Stylebook

(Available at http://www.apstylebook.com.)

DA Pam 25-1-1

Army Information Technology Implementation Instructions

DA Pam 25-91

Visual Information Procedures

DA Pam 25-403

Guide to Recordkeeping in the Army

DA Pam 385-30

Risk Management

DFARS

Defense Federal Acquisition Regulation Supplement (Available at https://www.acq.osd.mil/.)

DFAS-IN Manual 37-100

The Army Management Structure (Available at https://www.asafm.army.mil.)

DFAS-IN 37-1

Finance and Accounting Policy Implementation (Available at https://www.asafm.army.mil.)

DoD Public Affairs Policy Guidance Concerning Political Campaigns and Elections

(Available through the DoD message center.)

DoD Visual Information Style Guide

(Available at https://www.dimoc.mil/vi-training/dod-vi-style-guide.)

DoD 5220.22-M

National Industrial Security Program Operating Manual

DoD 5500.07-R

Joint Ethics Regulation (JER)

DoD 7000.14-R

Department of Defense Financial Management Regulations (FMRs)

DoDD 1020.02E

Diversity Management and Equal Opportunity in the DoD

DoDD 1344.10

Political Activities by Members of the Armed Forces

DoDD 3025.18

Defense Support of Civilian Authorities (DSCA)

DoDD 5122.05

Assistant to the Secretary of Defense for Public Affairs (ATSD (PA)) 
DoDD 5122.11

Stars and Stripes (S\&S) Newspapers and Business Operations

DoDD 5230.25

Withholding of Unclassified Technical Data from Public Disclosure

DoDD 5410.18

Public Affairs Community Relations Policy

DoDI 1000.15

Procedures and Support for Non-Federal Entities Authorized to Operate on DoD Installations

DoDI 1015.10

Military Morale, Welfare, and Recreation (MWR) Programs

DoDI 1100.13

DoD Surveys

DoDI 1300.18

Department of Defense (DoD) Personnel Casualty Matters, Policies, and Procedures

DoDI 4515.13

Air Transportation Eligibility

DoDI 5035.01

Combined Federal Campaign (CFC) Fundraising Within the DoD

DoDI 5040.02

Visual Information (VI)

DoDI 5120.04

DoD Newspapers, Magazines, Guides, and Installation Maps

DoDI 5230.09

Clearance of DoD Information for Public Release

DoDI 5230.29

Security and Policy Review of DoD Information for Public Release

DoDI 5400.13

Public Affairs (PA) Operations

DoDI 5405.03

Development, Submission, and Approval of Proposed Public Affairs Guidance (PPAG)

DoDI 5410.19

Public Affairs Community Relations Policy Implementation

DoDI 5410.20

Public Affairs Relations with For-Profit Businesses and Business Industry Organizations

DoDI 8580.02

Security of Individually Identifiable Health Information in DoD Health Care Programs

DoDI 8910.01

Information Collection and Reporting

DoDM 6025.18

Implementation of the Health Insurance Portability and Accountability Act (HIPAA) Privacy Rule in DoD Health Care Programs

DoDM 8910.01, Volume 1

DoD Information Collections Manual: Procedures for DoD Internal Information Collections

DoDM 8910.01, Volume 2

DoD Information Collections Manual: Procedures for DoD Public Information Collections 
EO 12088

Federal compliance with pollution control standards (Available at http://www.archives.gov.)

FM 3-21.38

Pathfinder Operations

FM 3-61

Public Affairs Operations

FM 6-0

Commander and Staff Organization and Operations

Freedom of Information Act

(Available at https://www.foia.gov.)

JP 3-13

Information Operations (Available at https://www.jcs.mil.)

JP 3-28

Defense Support of Civil Authorities (Available at https://www.jcs.mil.)

JP 3-61

Public affairs (Available at https://www.jcs.mil.)

JTR

Joint Travel Regulations (Available at http://www.defensetravel.dod.mil.)

OMB Memorandum M-12-18

Managing Government Records Directive (Available at http://www.archives.gov.)

PL 104-191

Health Insurance Portability and Accountability Act of 1996

5 CFR 734

Political Activities of Federal Employees

5 CFR 950

Solicitation of Federal Civilian and Uniformed Service Personnel for Contributions to Private Voluntary Organizations

5 CFR 2635

Standards of Ethical Conduct for Employees of the Executive Branch

5 CFR 2635.703

Use of nonpublic information

5 CFR 2635.807

Teaching, speaking and writing

5 USC 551

Definitions

5 USC 552

Public information; agency rules, opinions, orders, records, and proceedings

5 USC 552a

Records maintained on individuals

5 USC 5946

Membership fees; expenses of attendance at meetings; limitations

5 USC 7321

Political participation

5 USC 7322

Definitions 
5 USC 7323

Political activity authorized; prohibitions

5 USC 7324

Political activities on duty; prohibition

5 USC 7325

Political activity permitted; employees residing in certain municipalities

5 USC 7326

Penalties

10 USC

Armed Forces

10 USC 113

Secretary of Defense

10 USC 973

Duties: officers on active duty; performance of civil functions restricted

10 USC 974

Military musical units and musicians: performance policies; restriction on performance in competition with local civilian musicians

10 USC 2012

Support and services for eligible organizations and activities outside Department of Defense

10 USC 2558

National military associations: assistance at national conventions

10 USC 2566

Space and services: provision to military welfare societies

10 USC 2572

Documents, historical artifacts, and condemned or obsolete combat materiel: loan, gift, or exchange

10 USC 2667

Leases: non-excess property of military departments and Defense Agencies

10 USC 2670

Use of facilities by private organizations; use as polling places

10 USC 7014

Office of the Secretary of the Army

10 USC 7083

Public Affairs Specialty

17 USC Chapter 1

Subject Matter and Scope of Copyright

17 USC 102

Subject matter of copyright: In general

17 USC 105

Subject matter of copyright: United States Government works

18 USC 508

Transportation requests of Government

18 USC 793

Gathering, transmitting or losing defense information

18 USC 795

Photographing and sketching defense installations 
18 USC 797

Publication and sale of photographs of defense installations

18 USC 1307

Exceptions relating to certain advertisements and other information and to State-conducted lotteries

42 USC Chapter 55

National Environmental Policy

\section{Section III}

\section{Prescribed Forms}

This section contains no entries.

\section{Section IV}

\section{Referenced Forms}

Except where otherwise indicated below, DA forms are available on the Army Publishing Directorate website at https://armypubs.army.mil/ and DD forms are available on the Office of the Secretary of Defense website at https://www.esd.whs.mil/directives/forms/.

DA Form 11-2

Internal Control Evaluation Certification

DA Form 2028

Recommended Changes to Publications and Blank Forms

DA Form 4876

Request and Release of Medical Information to Communications Media

DD Form 254

Department of Defense Contract Security Classification Specification

DD Form 2535

Request for Military Aerial Support

DD Form 2536

Request for Armed Forces Participation in Public Events (Non-Aviation) 


\section{Appendix B}

\section{Awards}

\section{B-1. Public service awards and recognition}

Commanders at all levels may recognize private citizens, local community leaders, and citizen groups and organizations for their support of the Army by public service awards. Commanders will coordinate recommendations with the local civilian personnel office, which normally controls the supply of awards.

a. Major awards include the following:

(1) The Decoration for Distinguished Civilian Service is awarded by the SECARMY to civilians not employed by the Army or Army contractors, Federal Government officials at the policy developmental level, and technical personnel who serve the Army in an advisory capacity or as consultants who render distinguished service which contributes substantially to the accomplishment of the Army's mission.

(2) The Outstanding Civilian Service Award is awarded by the SECARMY or a major commander to civilians not employed by the Army or Army contractors, to Federal Government officials at the policy developmental level, and to technical personnel who serve the Army in an advisory capacity or as consultants for outstanding service that makes a substantial contribution or is of significance to the ACOM concerned.

$b$. Suggested recognition awards for regional and local presidents or commanders of service-oriented or veterans organizations and civic leaders at each command level include:

(1) Letters of congratulations upon election to office.

(2) Invitations to visit senior Army officials.

(3) Tours and briefings.

(4) Periodic newsletters.

(5) Invitations to Army social affairs.

(6) Establishment of a liaison contact at the command or installation concerned.

\section{B-2. Community Relations Award of Distinction}

a. The CPA presents the Kathy Canham-Ross Community Relations Award of Distinction to recognize extraordinary community relations contributions. The award is named for Kathy Canham-Ross, a distinguished director of OCPA-Los Angeles, who set an outstanding example to emulate throughout her 30 years as a PAO. Awardees may include Regular Army, ARNG, and USAR units and personnel (both military and civilian), their Family members, retirees, and Army community private organizations such as spouses' clubs, Family member youth organizations, and membership organizations like rod and gun clubs, sports parachute clubs, and aero clubs.

$b$. Entries to be considered eligible for judging during the annual MG Keith L. Ware Communications Competition must be submitted through command channels to OCPA by released deadline dates. Entries should cover planning, execution, and results, and contain a summary of not more than two single-spaced, typed pages describing the program or event.

\section{B-3. Silver Anvil award}

National recognition for outstanding PA programs and activities may be achieved through the annual Silver Anvil competition sponsored by the Public Relations Society of America. The award encourages improved performance and program techniques. Competition is open and membership in Public Relations Society of America is not a requirement nor will it affect the judging. Guidance for preparing entries is issued each fall by OCPA.

\section{B-4. Army print and broadcast media awards}

OCPA awards the MG Keith L. Ware Communications Awards Competition every calendar year in March to recognize excellence in Army communication. This includes the Army's internal and external information and community engagement programs. The competition is named after MG Keith L. Ware, a former Army CPA and a MOH recipient in World War II. MG Ware was killed in Vietnam in 1968 while commanding the 1st Infantry Division.

a. An HQDA letter to ACOM PAOs announces specific rules and categories. Entries must meet the highest standards of production, presentation, execution, professional excellence, and originality.

$b$. The MG Keith L. Ware communication award is presented to individuals and organizations in recognition of excellence in journalism, community relations, and communication categories. Judges also consider the following:

(1) The Paul D. Savanuck (Military) Writer of the Year Award recognizes the Soldier-writer who best exemplifies excellence in Army storytelling for that year. This one-time award is named in honor of Staff Sergeant Paul D. Savanuck, who was killed in Vietnam in 1969 while serving with the Pacific Stars and Stripes. 
(2) The Moss-Holland Civilian Writer of the Year Award recognizes outstanding writing among Army PA Civilians. The award is named in honor of John Moss and Peggy Holland, civilian writers who worked for the Oklahoma City Recruiting Battalion and died during the 1995 bombing of the Murrah Federal Office Building in Oklahoma City.

(3) The James P. Hunter Award for Outstanding New Military Writer Award recognizes excellence in Army journalism among enlisted Soldiers with less than 24 months in career management field (CMF) 46. This award is named in honor of Staff Sergeant James P. Hunter, who died as he covered a combat patrol while serving with the 502d Infantry Regiment, 2d Brigade Combat Team, 101st Airborne Division in southern Afghanistan in 2010.

(4) The John T. Anderson Military Videographer Journalist of the Year Award recognizes the CMF 46 Soldier, who best exemplifies excellence in Army broadcasting. It is named after Master Sergeant (MSG) John T. Anderson, who was captured while serving as NCO in charge of the American Forces Radio and Television Service affiliate in Hue, Vietnam, in 1968. MSG Anderson remained a prisoner of war until his release in March 1973. He retired in 1973 with 26 years of active duty service.

(5) The Clark Taylor Civilian Videographer of the Year Award recognizes the Army civilian videographer who best exemplifies excellence in Army videography. The award is named in honor of Clark Taylor, a Vietnam veteran with a Purple Heart, Bronze Star, and Combat Infantryman Badge. Taylor revolutionized Army broadcasting, retiring from civil service as director of Soldiers Radio and Television in 2006, after a career, which spanned 40 years of dedicated service to the United States Army. Taylor was inducted into the PA Hall of Fame in 2008.

(6) The Rising Star Award for Outstanding New Videographer recognizes excellence in Army broadcasting among enlisted Soldiers with less than 24 months in CMF 46.

\section{B-5. Army Public Affairs Hall of Fame}

The Army PA Hall of Fame program was established in 2000 to provide a prestigious and visible means of recognizing and honoring members of the Army PA career field who distinguished themselves through significant and lasting contributions to the field of PA. OCPA solicits nominations for induction into the Army PA Hall of Fame from the Army PA career field in November of each calendar year.

a. Any PA professional member (presently serving or retired, whether military or civilian) can nominate any living or deceased PA professional who meets the eligibility criterion for the Army PA Hall of Fame. The eligibility requirements for nomination include:

(1) Military or civilian PA professionals who have been retired at least 3 years from active federal service. However, exceptions to policy will be considered for departure from the career field for reasons other than retirement. Nominations of deceased PA professionals will not be bound by the 3-year rule.

(2) Those who did not retire from active federal service must have served for a minimum of 7 years in a superior manner in the profession while on active duty, in a reserve status, or as a civilian, or have made significant and lasting contributions to the community or Army PA career field.

$b$. The CPA chairs and presides over an annual review panel to select inductees into the Army PA Hall of Fame. The CPA sets a maximum limit of three nominees as recommended by the review panel for induction into the Hall of Fame.

c. An OCPA letter of instruction establishes the guidelines and procedures for the nomination and selection of members of the Army PA career field.

\section{B-6. Other honorary recognitions}

There are additional PA honorary recognitions that Soldiers can apply for-

a. The Sergeant Major Dawn Kilpatrick Memorial Association of the United States Army Scholarship was initiated in 1999 as a partnership between the Army and the Association of the United States Army to allow CMF 46 mid-level and senior NCOs the opportunity to compete for an educational scholarship grant. This grant is intended to assist the NCO in furthering their educational goals and give the Army a better rounded "total Soldier." The scholarship recipient traditionally receives the award at the Association of the United States Army Annual Meeting and Exposition in Washington, D.C.

$b$. The MSG Marcia Triggs Award for Excellence is an annual award intended to recognize an Army PA NCO, grade E6-E8, who has demonstrated outstanding and sustained excellence in leadership and performance through positions of increased responsibility and who sets an exemplary standard for others to emulate. The ideal candidate is one who made significant contributions to improving the professionalism of the PA career field. The candidate can come from Regular Army, ARNG, or USAR.

c. The CPA officially designated Saint Gabriel as the patron saint of Army PA in 2014. The Army PA Association, in collaboration with OCPA, designed, approved, and developed the Military Order of Saint Gabriel program to recognize those individuals who have made significant contributions to the U.S. Army PA community and practice. The 
Order of Saint Gabriel was established with two levels: the Ancient Order and the Honorable Order. Those awarded the Order of Saint Gabriel receive a medallion attached to a gold ribbed teal ribbon and a certificate signifying membership in an elite community of professional communicators. 


\section{Appendix C}

\section{Feasibility Study for Civilian Enterprise Newspapers}

\section{C-1. Overview}

PAOs should use this appendix as a guide to conduct feasibility studies concerning publishing a CE newspaper. Although there is no requirement for commanders to produce command newspapers, commanders should use digital platforms to engage their audiences. The studies' objectives are to develop a list of qualified companies potentially interested in competing for a contract to print a CE newspaper. Much of this data can be obtained from the local standard installation or division personnel office.

\section{C-2. Getting started}

Begin by coordinating with the local contracting office and SJA. Brief the contracting office on the provisions of this regulation. Inform the contracting office that printers will be contacted to determine potential interest in printing and distributing a CE newspaper. (See para 4-5 for additional information on contracting guidelines.) Invite the contracting representative to attend any scheduled appointments with the printers. Assure the contracting representative that civilian printers will be informed that a contract or agreement is not being sought at this time and that these appointments are to identify printers who demonstrate possible interest to produce a CE newspaper. To publicize the potential CE newspaper contract to commercial sources, the contracting officer should announce it in the Commerce Business Daily. Where additional publicity is necessary, use press releases or advertisements in local area newspapers to develop commercial interest.

\section{C-3. Preparing a briefing}

Prepare a briefing for potential printers. The command must sell the printer on the CE concept. (What is in it for the CE printer?) Information should include, but not be limited to, the following:

$a$. A brief mission statement of the community or unit and the newspaper. How does the newspaper meet the interests and needs of the audience?

$b$. The following demographics (the market) information:

(1) Break down the military population into the three categories of junior enlisted, senior enlisted, and officers (include RC personnel and retirees).

(2) Civilian population (number of civilians both general schedule and nonappropriated funds).

(3) Total military payroll.

(4) Total civilian payroll.

(5) Grade demographics. (Determine the number of personnel in the organization by grade.) Develop categories for $\mathrm{E}-1$ to $\mathrm{E}-4, \mathrm{E}-5$ to $\mathrm{E}-6, \mathrm{E}-7$ to $\mathrm{E}-9, \mathrm{~W}-1$ to $\mathrm{W}-4, \mathrm{O}-1$ to $\mathrm{O}-3$, and $\mathrm{O}-4$ and above. List the monthly pay for each category (for example, E-6 over 10 years of service base pay plus separate rations is XXXX). Use round figures. Do not try to calculate tax, basic allowance for quarters, or other deductions.

(6) Number of children. (If data is available from local schools, give information on the number of children).

(7) Local national employees. (If overseas, the number of local national employees and the amount of the local national payroll).

(8) Number of Family members. (Also, try to determine what percentage of Family members work and an average income. This may have to be broken into categories).

(9) Geographical dispersion of the unit. (Geographically dispersed units may want to give approximate numbers at each location).

c. Focus on purchasing power.

$d$. Emphasize that the paper reaches a captive market and the exclusive distribution access to the audience.

$e$. Any other facts about the market (for example, where people shop, work, live, and relax).

$f$. A resource study to define demographics and buying potentials.

\section{C-4. Identifying potential printers}

Identify potential printers through local chambers of commerce, business directories, and your local contracting office. Check at local post exchange, commissary, library, clubs for newspapers, television guides, or other publications distributed in your area. Check for printer names and addresses. 


\section{C-5. Contacting printers}

Contact printing representatives to indicate interest in meeting to discuss the possibility of producing your newspaper. Face-to-face contact is preferred.

a. Successful scheduling. If the attempt to schedule a meeting is successful, continue on to the procedures in paragraph C-6.

b. Unsuccessful scheduling. If attempts to schedule a meeting are unsuccessful, forward documentation through PAO channels to the ACOM PAO. (Information should contain dates, times, and brief description of each attempt. Remember, authorized funds may be used for printing Army newspapers only after it has been documented that a CE newspaper is not feasible).

\section{C-6. Meeting the printing representative}

Begin the meeting with the printing representative by informing the representative once again that seeking information is the objective. You are not authorized to imply or lead the representative to believe that you are obtaining an agreement during this meeting. State that specifications and official contacts, should they come, will be done by the contracting office.

\section{C-7. Giving the presentation}

Show the representative the newspaper during the presentation. If possible, obtain CE newspapers from other installations and units where advertising appears. Explain the difference between the newspapers. Present demographics of your organization. Show the printer profit potential. Be careful how information is presented. For example, the current press run may be 2,000, but the total population may be 8,000. Do not mislead the printing representative into believing that the circulation figure represents readership. Discuss the potential with the CE (for example, more copies of the paper or exclusive distribution). Let the representative know that local official distribution channels can be used to distribute a CE newspaper. If possible, obtain case study information from other printers serving military installations.

\section{C-8. Bidding}

Tell representatives who show an interest that their contact information, along with that of other prospective bidders, will be provided to the contracting office.

\section{C-9. Contracting}

Commands will follow the provisions of this regulation for CE requirements for contracting (see para 8-10 for more guidance on CE contracting provisions). Add realistic provisions as long as they do not contradict this regulation. The civilian printer needs to succeed for the command to get a quality publication. If the civilian printer is very successful the first year, additional specifications and improved services might be negotiated the second year. The contracting office and the SJA are key executors in negotiating contracts and any changes. 


\section{Appendix D}

\section{Guidance on Release of Information under the Privacy Act}

\section{D-1. Scope of the Privacy Act}

The term "individual" as defined in the Privacy Act applies only to living citizens of the United States or an alien admitted for permanent residence. The Privacy Act rights of a minor or an incompetent individual may be exercised by the parent or legal guardian. The Privacy Act confers no rights on deceased persons, nor may next of kin exercise any rights for them. However, information that is contained in a Privacy Act system of records may be exempt from release under the FOIA. A request for information is processed under the substantive provisions of both the Privacy Act and the FOIA. Under FOIA exemption six, the privacy interests of a deceased person's surviving Family members are considered. Information may be withheld to protect the privacy of the surviving Family members, if release of the information would cause a disruption to their peace of mind. Some examples might include autopsy reports and graphic details of murder. These examples are not intended to be all-inclusive. A complete list of FOIA exemptions can be found in AR 25-55.

\section{D-2. Age or date of birth}

Age or date of birth is not routinely or normally releasable. Reasons for disclosure must be evaluated and balanced against the degree of personal privacy invasion.

\section{D-3. Home of record and present address}

$a$. No general rule exists for disclosing an individual's home of record because of the different circumstances present when requests for this information are made. Therefore, requests are weighted on a case-by-case basis. Usually the home of record may be released if no street address is given.

$b$. Usually, in response to questions, you may provide an individual's present location (for example, Clinton, Maryland) but not the individual's street address.

$c$. Consider the desires of the individuals or next of kin in disclosing the home of record or present geographic location. Often, consent to release may be obtained, which removes the problem. However, the desires of the individual or next of kin do not necessarily control the decision to release. When an objection to release has been made, a balancing of interests under the FOIA may still require disclosure.

\section{D-4. Marital status}

An individual's marital status is not routinely or normally disclosed. Reasons for disclosure must be evaluated and balanced against the degree of personal invasion of privacy.

\section{D-5. Awards, decorations, and citations}

Award, decoration, or citation information is releasable. An award, decoration, or other proper citation presentation is usually a public event publicized in the installation newspaper. There is a visible token to be worn on the uniform for most awards and decorations.

\section{D-6. Education, schooling, and specialty}

Information on the major area of study, school, year of graduation, degree, and specialty designator is generally releasable under FOIA.

\section{D-7. Race}

In most cases, information about an individual's race is not releasable. The release of race information from departmental records may constitute an unwarranted privacy invasion. However, a specific request may be made for such information under relevant circumstances such as a racially oriented protest or altercation. An individual's race may be released to the press when it is relevant to the essential facts.

\section{D-8. Character of discharge}

a. Administrative-not releasable. The character of discharges resulting from administrative processing is not a matter of public record. Do not release any indication of whether or not a discharge is honorable, general, or under other than honorable conditions. The release of this information to the general public is viewed as an unwarranted invasion of personal privacy and is not releasable under the Privacy Act unless the individual provides written consent. 
b. Punitive-releasable. In discharges resulting from a court-martial, the proceedings and record are not restricted by the Privacy Act because that act incorporates the definition of agency found in 5 USC 551(1), which specifically excludes court-martial (5 USC 551(1)(f)). Court-martial proceedings are public. Therefore, the approved sentence and subsequent clemency action, if any, are releasable.

\section{D-9. Duty status}

Duty status information is releasable. It is permissible to release information about an unauthorized absence or desertion, hospitalization, when a Service member is in the hands of civil authorities awaiting trial, or under confinement by military authorities awaiting trial.

\section{D-10. Decisions of personnel boards}

Personnel board decision information is releasable after decision by final approving authority if the board action applies to a category of persons as opposed to an individual; otherwise, it is not releasable.

$a$. Results of personnel board actions affecting groups such as promotion boards and augmentation boards are releasable.

$b$. The results of personnel board actions affecting individuals, such as administrative discharge boards and aviator flight boards, are not generally releasable. The results of the latter category of boards traditionally have not been released. The board proceedings are not public, and the nature of the action taken, often adverse, warrants preservation of its confidentiality. Information that has become a matter of public knowledge through the action of the individual or their counsel may be confirmed.

\section{D-11. Photographs in the custody of the Department of Defense}

Photographs of DoD military and civilian personnel taken for official purposes are generally releasable unless matters are depicted that would constitute a clearly unwarranted personal privacy invasion if disclosed to public view. Generally, award ceremony photographs, official selection file photographs, chain of command photographs, and similar photographs are releasable.

\section{D-12. Name and duty address of a member assigned to a unit that is sensitive, routinely deployable, or stationed in a foreign territory}

The name and duty address of a member assigned to a unit that is sensitive, routinely deployable, or stationed in a foreign territory is not routinely releasable. Disclosing information about a Soldier's degree of involvement in military actions in support of national policy, the type of military unit to which the member is assigned, and presence or absence from his or her household poses a security threat to the Soldier. The releasing authority, normally the Soldier's unit commander, must weigh the public interest in disclosure against the invasion of personal privacy that will result from the disclosure. The ATSD (PA) is the sole approving authority for releasing rosters that list members of this type of unit by name.

\section{D-13. Protected health information}

Medical unit commanders are the release authority for their commands. Protected health information will not be released without the prior consent of the individual or, by the representative if the individual is unable to function for themselves. The consent will be recorded on DA Form 4876. 


\section{Appendix E}

\section{Clearance and Release of Contractor Materials and Scientific and Technical Information}

\section{E-1. Contractor submissions}

$a$. In prescribing procedures for submission, review, and clearance of industry-originated information materials, the DA defers to Army and industry interface guidance in the FAR, AFARS, and DFARS and the Army and industry relationship shown by the contract terms when a contract exists. These requirements also apply to educational institutions receiving information from any Army element on pre-award negotiations, contract awards, letter contracts, modifications, or grants to carry out military research and development projects.

$b$. DA agencies and contractors will not release procurement information on Army-contracted research and development projects without prior approval and clearance from the Assistant Secretary of the Army (Acquisition, Logistics and Technology).

c. A classified contract is one, which requires access to classified information (confidential, secret, top secret) either to submit a bid or proposal or to perform the contract. A contract may be classified even though the contract document is not classified. When a classified contract exists, the contractor is guided by security items in the contract and by the terms of the security agreement. Security criteria are shown on DD Form 254 (Department of Defense Contract Security Classification Specification). The DoDM 5220.22, Volume 2; DoD 5220.22-M; and AR 380-49 contain procedures to safeguard classified defense information and procedures for the proposed release of information which contractors, subcontractors, vendors, or suppliers will have access to or possess.

$d$. When unclassified contracts do not give specific instructions on releasing information, contractors will submit informational materials to a PA office designated by the administrative contracting officer prior to publication. If the submission is made to any other office, it will be referred immediately to the proper administrative contracting officer for action. Voluntary submission is simply business courtesy and affords safeguards against accidental release of inaccurate or classified information.

e. Except for information materials developed under contract requirements, PAOs act in an advisory role, reviewing material voluntarily submitted. The final decision on matters of accuracy, style, and good taste remains with the originator.

\section{E-2. Scientific and technical information}

a. The PAOs do not have the authority to clear scientific and technical information for public release. However, PAOs will assist the proponent of unclassified scientific and technical materials in determining at what level clearance can be granted. This material includes the results of research, development, test, and evaluation prepared for presentation or publication, within or outside CONUS. An exception is material that must be cleared through HQDA or OSD under this regulation and applicable industrial security directives.

$b$. Scientific and technical information will not be released if it discloses classified military applications, or, if unclassified, disclosure would be adverse to the national interest. The DoD or higher authority will release scientific and technical information that would generate national public interest.

c. Export and International Traffic in Arms Regulations restrictions may also govern the release of certain information. DoDD 5230.25 contains guidance in making this determination. Approval from the ATSD (PA) is required for such a release.

d. Information materials prepared under Joint Army or industry authorship will be processed for review and clearance in the same manner as materials of Army authorship.

$e$. Scientific and technical information for public release will be prepared under AR 70-31. This material will be forwarded for clearance to the proper headquarters or administrative contracting officer.

\section{E-3. Submission requirements}

The following requirements apply when material covered in this appendix is submitted for clearance:

$a$. Written materials and still photographs-submit three copies. Photographs must be properly captioned. Include additional copies of all materials, one for each intervening headquarters record file.

$b$. Scientific and technical papers and presentations-submit three copies. Each copy will include appropriate copies of all viewgraphs, photographs, charts, graphs, and similar material, properly captioned.

c. Fact sheets, pamphlets, and brochures-submit three copies. Each copy will include full text, layout, and all illustrative material.

d. Contractor advertisements-submit three copies. Each copy will include text and layout, including artwork and photographs, proposed for final publication. (See para 8-10 for policy concerning advertising and promotion). 
$e$. Exhibits-submit three copies. The design and layout with text of copy to appear on display material and all artwork and photographs proposed for exhibition.

$f$. For motion picture or videotape production, the following review procedures are required:

(1) Preliminary written story, concept, outline treatment-submit three copies. Include additional copies, one each for intervening headquarters record files.

(2) Final shooting script, including scene description and narration-submit three copies. Include additional copies, one for each intervening headquarters record file.

(3) One copy rough cut (film or videotape) minus the sound track.

(4) One print (film or videotape) or one copy of the final narration for the final review. 


\section{Appendix F}

\section{Internal Control Evaluation}

\section{F-1. Function}

The function covered by this evaluation is the Army PA Program.

\section{F-2. Purpose}

The purpose of this evaluation is to assist PAOs and their staffs in evaluating the key internal controls outlined below. It is not intended to cover all controls.

\section{F-3. Instruction}

Answers must be based on the actual testing of key internal controls. For example, document analysis, direct observation, sampling, simulation, or other factors. Answers that indicate deficiencies must be explained and corrective action indicated in supporting documentation. These key internal controls must be formally evaluated at least once every 5 years. Certification that this evaluation has been conducted must be accomplished on DA Form 11-2 (Internal Control Evaluation Certification).

\section{F-4. Test questions}

a. Have commanders developed PA guidance, strategies, plans, and operations?

$b$. Is the PAO assigned to the commander's personal or special staff and has direct access to the commander?

c. Are PA offices, units, sections, and functions managed and supervised only by qualified PA personnel?

$d$. Is all information intended for release through PA to internal and external audiences accurate and devoid of propaganda?

$e$. If not supported by a designated PAO, has an UPAR been appointed?

$f$. Is there a training program in place for UPARs?

$g$. Is there a PA training program in place for leaders and Soldiers (non-PAO personnel)?

$h$. Has appropriate action been taken to correct any known erroneous information about the Army that appears in public media?

$i$. Is the PAO designated as the command web content manager for review and release of official information intended for public and command websites?

$j$. Does the PAO conduct reviews of publicly accessible websites on a quarterly basis to ensure each site is in compliance with the policies of AR 25-1 and that the content remains relevant and appropriate?

\section{F-5. Supersession}

This evaluation supersedes the management control evaluation checklist previously published in AR 360-1, dated 25 May 2011.

\section{F-6. Comments}

Help make this a better test for evaluating management controls. Submit comments to CPA (SAPA-ZDA), 1500 Army Pentagon, Washington, DC 20310-1500. 


\section{Glossary}

\section{Section I}

Abbreviations

ACOM

Army command

AD

Army directive

AF

appropriated funded

AFARS

Army Federal Acquisition Regulation Supplement

AFD

Armed Forces Day

AFW

Armed Forces Week

AGO

Army general order

ALMS

Army Learning Management System

AP

Associated Press

APAC

Army Public Affairs Center

AR

Army regulation

ARHQ-FB

Army Reserve Headquarters-Fort Bragg

ARNG

Army National Guard

ARNGUS

Army National Guard of the United States

ARSOF

Army Special Operations Forces

ARSTAF

Army staff

ASCC

Army service component command

ATSD (PA)

Assistant to the Secretary of Defense for Public Affairs

CCS

Commander's communication synchronization

CE

civilian enterprise

CFC

Combined Federal Campaign 
CFR

Code of Federal Regulations

CIO/G-6

Chief Information Officer/G-6

CMF

career management field

CNGB

Chief, National Guard Bureau

COCOM

combatant command

CONUS

continental United States

CP22

career program 22

CPA

Chief of Public Affairs

CSA

Chief of Staff of the Army

DA

Department of the Army

DCS

Deputy Chief of Staff

DD

Department of Defense (forms)

DFARS

Defense Federal Acquisition Regulation Supplement

DFAS-IN

Defense Finance and Accounting Service-Indianapolis

DHS

Department of Homeland Security

DoD

Department of Defense

DoDD

Department of Defense directive

DoDI

Department of Defense instruction

DoDM

Department of Defense manual

DOTMLPF

doctrine, organization, training, materiel, leadership and education, personnel, and facilities

DRU

direct reporting unit

FAA

Federal Aviation Administration

FAR

Federal Acquisition Regulation 


\section{FEMA}

Federal Emergency Management Agency

\section{FM}

field manual

\section{FOIA}

Freedom of Information Act

FOUO

for official use only

FRG

Family Readiness Group

\section{HQDA}

Headquarters, Department of the Army

IG

inspector general

INSCOM

U.S. Army Intelligence and Security Command

JCOC

Joint Civilian Orientation Conference

JP

joint publication

MDW

U.S. Army Military District of Washington

MG

major general

MOH

Medal of Honor

MSG

master sergeant

MWR

Morale, Welfare, and Recreation

NATO

North Atlantic Treaty Organization

NCO

noncommissioned officer

NGB-PA

National Guard Bureau Public Affairs

OCLL

Office of the Chief of Legislative Liaison

OCONUS

outside the continental United States

OCPA

Office of the Chief of Public Affairs

OE

operational environment

OMA

Army operation and maintenance 


\section{OMB}

Office of Management and Budget

\section{OPSEC}

operations security

OSD

Office of the Secretary of Defense

\section{PA}

public affairs

\section{PAD}

Production Acquisition Division

\section{PAO}

public affairs officer

\section{PII}

personally identifiable information

PL

Public Law

RC

Reserve Component

ROTC

Reserve Officers' Training Corps

\section{SECARMY}

Secretary of the Army

SJA

staff judge advocate

TRADOC

U.S. Army Training and Doctrine Command

\section{UPAR}

unit public affairs representative

USACIC

U.S. Army Criminal Investigation Command

USAR

U.S. Army Reserve

USASOC

U.S. Army Special Operations Command

USC

United States Code

\section{USMA}

United States Military Academy

VI

visual information

\section{Section II}

\section{Terms}

Accreditation

A means of identifying correspondents with a legitimate need to gather news about military affairs and fostering a professional relationship between the military and the media. Accreditation does not provide correspondents with any 
special privileges. Access to military areas, receipt of information, and use of facilities remain the commander's prerogatives within the bounds of security and the provisions of this regulation.

\section{Additional cost to the Government}

Those costs incurred solely because of participation in our support of an unprogrammed activity or event. Additional costs to the Government include unprogrammed travel, transportation for personnel, meals and lodging for military personnel away from Government messes, and civilian per diem and overtime pay.

\section{Aerial demonstration}

The use or display of Army aircraft and personnel in any aerial event including the following:

a. Parachute team demonstration. A demonstration of free-fall and precision landing techniques by the U.S. Army Parachute Team (Golden Knights), other military or sports parachute team, or individual parachutist officially representing the Army. Recreational sport parachuting and competition parachuting is governed by AR 215-1.

b. Flyover. A straight and level flight by not more than four military aircraft from a single service over a predetermined point on the ground at a specific time and not involving aerobatics or demonstrations.

c. Aerial review. A flyover of multiple types of aircraft or aircraft representing more than one military service with elements in trail formation and not involving precision maneuvers or demonstrations.

d. Static aircraft display. A nonmoving ground display of aircraft and its related equipment not involving taxiing or starting of engines during the period when spectators are in the display area.

e. Other aerial activities. All other aerial demonstrations not listed in paragraphs a through d, above, designed to portray performance techniques by a single or group of aircraft and personnel. Such demonstrations include-

(1) Air-to-air refueling.

(2) Helicopter flight techniques.

(3) Low Altitude Parachute Extraction System.

(4) Maximum performance demonstrations.

(5) Performance record demonstrations.

(6) Mass parachute jumps.

(7) Air delivery of equipment.

(8) Assault aircraft demonstrations.

(9) Tactical helicopter troop landings under simulated tactical conditions.

(10) Air rescue demonstrations.

(11) Rappelling demonstrations.

\section{Aerial event}

Any occasion that involves an Army aerial demonstration as either a primary or incidental attraction to the event. Such events include air shows, festivals, official Federal Government functions, official military functions, or civic functions held on a military installation or elsewhere.

\section{Appropriate public affairs support}

That PA support the responsible PAO and their commander decides is suitable to meet a PA requirement of a unit within the installation's local area of PA responsibility. (See FM 6-0 for detailed information regarding PA support).

\section{Army accident}

An unplanned event or series of events which result in one or more of the following: occupational illness to Army military or Army civilian personnel, injury to on-duty Army civilian personnel, injury to Army military personnel on and off duty, damage to Army property, and damage to public or private property and injury or illness to non-Army personnel caused by Army operations (the Army had a causal or contributing role in the accident).

\section{Army share of costs}

The Army's share of costs includes those continuing costs to the Government, which would exist if the Army did not participate in the event. These include pay and allowances and small incidental expenses to an installation (for example, local transportation, telephone calls, and other minor expenses deemed proper). Military aircraft used to transport personnel and equipment may also be considered an Army share of costs of an event of mutual benefit.

\section{Army speaker}

All civilian and military members of the Army representing the Army in public on military subjects within the member's official knowledge. 


\section{Army support}

Any use of Army personnel, military or civilian, either as individuals or as units, or any commitment of Army facilities or materiel, to include aircraft, exhibits, and equipment, in support of community engagement programs.

\section{Background}

Remarks that may be reported only if attributed to a nonspecific source such as an Army official. A background discussion or briefing may be held to give news media representatives a better understanding of a situation. This form of attribution must be agreed upon in advance. Cameras cannot be used in background sessions. Records of background media briefings are not protected from disclosure under the FOIA.

\section{Blog}

A regularly updated website or webpage, typically run by an individual or small group, that is written in an informal or conversational style.

Business and industry organizations and associations

Private groups whose goals are to promote cooperation between DoD and industries with which they do or have potential business.

\section{Casualty}

Any person who is lost to the organization by having been declared dead, duty status - whereabouts unknown, excused absence - whereabouts unknown, missing, ill, or injured.

\section{Civilian printer}

As applies in this regulation, the civilian organization that prints publications.

\section{Clearance of information}

Approval by the reviewing authority to publish or release submitted material.

\section{Commander's communication synchronization}

The process for coordinating and synchronizing themes, messages, images, operations, and actions to support U.S. Government strategic communication-related objectives and ensure the integrity and consistency of themes and messages to the lowest tactical level. Formally known as strategic communication.

\section{Communication}

The imparting or interchange of information, thoughts, and opinions by sending themes, messages, and facts through engagements and traditional and digital media platforms to designated audiences.

\section{Community outreach}

Those PA activities that support the relationship between military and civilian communities.

\section{Community outreach area of responsibility}

Determined by the local senior mission commander, taking into account the geographic location of an installation and the community relationships that are prudent and necessary. The Army encourages commanders to work with their PAOs and SJAs to establish an area of responsibility that is best suited to the needs of the command. It is also up to the commander to decide whether to support events that are outside their areas but are still important to the command.

\section{Digital media}

Text, audio, and VI content that can be transmitted over the internet or computer networks. Army PA content that is released on a website, blog, or social media platform will fall into this category.

\section{Engagements}

Meetings or events that communicate with a purpose in order to advance, educate, strengthen, and preserve U.S. Army interests, policies, and objectives.

\section{Events}

Meetings or events that communicate with a purpose in order to advance, educate, strengthen, and preserve U.S. Army interests, policies, and objectives.

a. International. One in which the audience or participation is drawn from the United States and at least one other nation and is of international interest.

b. National. One in which the audience or participation is drawn from the United States as a whole and is of national interest.

c. Regional. One in which the audience or participation is drawn from two or more states of the United States and is of regional interest. 
d. State. One in which the audience or participation is drawn from that state as a whole and is of statewide interest. e. Local. One which centers on and is primarily of interest to a single community. The extent of anticipated or actual news media interest and coverage is one criteria for determining the level of approval authority for Army participation in a public event. For the purpose of this regulation, local, and regional events aired nationally on television or radio are considered national events.

\section{External official presence}

Any Army PA office websites, installation and unit websites, or official social media outlets used to interact with the audience on behalf of a command.

\section{Incidental support}

Support provided by DoD military and civilian personnel, individually or collectively, or DoD resources, facilities, or materiel for community engagement activities that has a minimal impact on the planning, scheduling, functioning, or audience draw of a public event. Examples of incidental support include providing a Joint Service Color Guard as a ceremonial opening to a conference or annual awards banquet or providing three DoD speakers at a business association featuring a majority of non-DoD speakers. In effect, incidental support adds minimal improvement to the perceived quality, audience draw, or other aspect of the event or activity. Support is incidental if the question, "Will the event proceed undeterred without DoD assets?” can be answered in the affirmative.

\section{Installation}

An aggregation of contiguous or near contiguous real property holdings owned or leased by Federal or State governments for military purposes and commanded by a centrally selected commander. Installations represent management organizations. Installations may be made of one or more sites and include posts, camps, stations, training and testing areas, ARNG armories, and USAR centers.

\section{Internal audience}

In PA, United States military members, DoD civilian employees, and their immediate Families.

\section{Local area of public affairs responsibility}

That area in which installation PAOs and media representatives maintain routine contact concerning installation activities. Routine contact is defined as a minimum of once each month in the context of work performed.

\section{Local interest material}

Material the local commander decides is newsworthy only in the geographical area of origin or to a specific audience. Such material will not normally generate regional, national, or international interest.

\section{Local national}

A host nation employee of the U.S. Government.

\section{Local travel}

Travel within the command's local area of PA responsibility or community outreach area of responsibility.

\section{Media operations center}

A facility established by commanders to serve as the focal point for the interface between the military and the media during the conduct of operations.

\section{Military carriers}

Any form or type of transportation (whether by land, sea, or air) provided by a military department.

\section{Military garrison}

The key location of a military installation where the command and control is coordinated, typically where the headquarters element is located.

\section{Military installation}

Property owned or leased by Federal or State governments for military purposes. This includes posts, camps, stations, training and testing areas, ARNG armories, and USAR centers. Multiple individual locales in the same vicinity can compose one installation.

\section{Military related organizations and associations}

Groups whose goals are to advance the security of the United States. These are normally private, nonprofit, educational, and patriotic groups and corporations. Members may be civilian; active, reserve, or retired military; and corporations. Most of these organizations conduct social activities and are capable of providing legal aid. 


\section{Military transportation}

Any form or type of transportation provided by a military department.

\section{Musical units}

Includes bands, glee clubs, choirs, or any combination of instrumental and choral groups that regularly constitute and activate under an approved table of organization and equipment or table of distribution and allowances.

\section{National Capital Region}

The geographic area located within the boundaries of the District of Columbia; Montgomery and Prince George's Counties in the State of Maryland; Arlington, Fairfax, Loudon, and Prince William Counties and the City of Alexandria in the Commonwealth of Virginia, and all cities and other units of government within the geographic areas of such district, counties, and cities.

\section{New content}

New websites, webpages, and documents posted to websites, and major updates of websites.

\section{News media representatives}

An individual employed by a civilian radio or television station, newspaper, magazine, periodical, or news agency to gather and report on a newsworthy event.

\section{Nuclear weapon accident}

An unexpected event involving nuclear weapons or nuclear components that results in any of the following: nonnuclear detonation or burning of a nuclear weapon; radioactive contamination; seizure, theft, or loss of a nuclear weapon or nuclear component, including jettisoning; and public hazard, actual or implied.

\section{Official civil ceremonies}

Public events sponsored and conducted by Federal, State, county, and municipal governments. In overseas areas, these include corresponding activities of the host nation. The following are considered official civil ceremonies: inaugurals, dedications of public buildings and projects, ceremonies for officially invited governmental visitors, and convening of legislative bodies. Not considered official civil ceremonies, even though sponsored or attended by civic or governmental dignitaries, are community or civic celebrations such as banquets, dinners, receptions, carnivals, festivals, openings of sports seasons, and anniversaries.

\section{Official statement}

Statement on Army matters by an Army representative acting in an official capacity.

\section{Open house}

An event at which an installation or unit invites the general public to view ceremonies, demonstrations, and equipment; to receive briefings and tours; or to observe operations and training. Such events inform the public of the mission, responsibilities, and capabilities of the Army.

\section{Orientation flights}

Continuous flights in Army aircraft performed within the local flying area that typically begin and return to the point of origin or a point nearby and are not conducted to provide transportation.

\section{Privacy Act of 1974}

The public law that amends Title 5 USC 552 and adds Section 552a. The intent of this law is to safeguard individual privacy from misuse of personal information in federal records. AR 25-22 implements the law.

\section{Propriety}

Consistency with Army and DoD values and commonly held organizational standards of decency and decorum.

\section{Public}

In PA, a segment of the population with common attributes to which a military force can tailor its communication.

\section{Public affairs}

Any communication activity with external and internal audiences.

\section{Public affairs program}

A guide to conducting public information, command information, and community outreach activities directed toward both the external and internal publics with interest in DoD. 


\section{Public events}

An event, to include ceremonies, exhibitions, expositions, athletic contests, fairs, air shows, conventions, meetings, symposia, or similar programs, not connected with the military functioning of DoD and intended primarily for nonmilitary audiences. Exercises, movements, maneuvers, or operations, even though incidentally observed by the general public, are not considered public events. Also, events outside the boundaries of a military installation intended for nonmilitary audiences.

\section{Publisher}

The person responsible for the editorial content of the publication, as applies in this regulation.

\section{Release of information}

Dissemination of information to the public, which may be initiated by the Army or be in response to an external request. Includes written news releases, still photographs, motion picture films, question and answer interviews, speeches, audio or video tape recordings, articles for publication in printed media or for broadcast by radio or television, and oral responses to queries.

\section{Safeguarded information}

Defense information requiring protection under AR 380-5, or information protected or controlled under AR 20-1, or information controlled under DoDD 5230.25.

\section{Scientific and technical material}

Material that has limited interest within a specialized field or to a specific audience because of its subject matter and the technical or scientific language in which the material is presented.

\section{Selective benefit}

Army support to any person, group, or corporation, whether profit or nonprofit; religion, sect, religious or sectarian group, or quasi-religious or ideological movement; fraternal organization; political organization; or commercial venture that the Army would not provide if available under similar conditions to other such entities upon request.

\section{Social media}

Websites and applications that allow people to communicate and share information on the internet using a computer or mobile device.

\section{Speaking engagement}

Any prearranged affair, including official Federal Government, military, and civic functions, or public events where a military or civilian member of any DA component speaks on an Army subject within that member's official knowledge. Impromptu remarks delivered incidentally as part of the person's attendance at an event do not constitute a speaking engagement within the meaning of this regulation.

\section{Special bands}

Military bands with the mission of providing music for proper military ceremonies, recreational activities, and civilian functions as authorized and directed by HQDA. The four special bands are operationally controlled as follows:

a. The United States Army Band (Pershing's Own) is operationally controlled by the Commanding General, MDW. All scheduling and programming is MDW's responsibility.

b. The U.S. Army Field Band is the Army's official touring band and is operationally controlled by the Commanding General, MDW. The U.S. Army Field Band is charged with conducting major concert tours annually.

c. The USMA Band is assigned to, and operationally controlled by, the Superintendent, USMA, West Point, New York.

d. The U.S. Army Fife and Drum Corps is operationally controlled by the Commanding General, MDW.

\section{Spokesperson}

Commander or someone designated by the commander to speak for him or her. Official spokespersons must be Government officials, either military personnel or DoD and Army Civilians.

\section{Travel for community engagement purposes}

Invitational or other authorized PA travel or transportation to support an approved community engagement program, tour, or conference for which the DoD is either a sponsor or a participant. 


\section{Unit public affairs representative}

Command-designated Soldiers, typically an officer from the command staff, who coordinates and functions as a liaison between the unit, the unit commander, and the designated supporting PAO. The UPARs serve closely with battalion commanders as lower level subject matter experts on PA plans and policies on embedding the media, engaging the local media, and conducting media opportunities at the battalion level.

\section{Very important person}

An individual (civilian official, ranking member of a military service, or foreign government head) whose position is of such importance that their travels are of special interest to the news media.

\section{Veterans organizations and associations}

Any organization or association recognized by state or Federal Governments representing a national membership of individuals or chapters oriented toward veterans of military service in general, veterans of specific military services or campaigns, or veterans organized or identified by gender, ethnic group, religion, or region. 
